Prepared in cooperation with the Bureau of Reclamation, U.S. Department of the Interior

\title{
Summary and Trend Analysis of Water-Quality Data for the Oakes Test Area, Southeastern North Dakota, 1984-2004
}

Scientific Investigations Report 2007-5056 
This page intentionally left blank. 


\section{Summary and Trend Analysis of Water-Quality Data for the Oakes Test Area, Southeastern North Dakota, 1984-2004}

By Karen R. Ryberg

Prepared in cooperation with the Bureau of Reclamation, U.S. Department of the Interior

Scientific Investigations Report 2007-5056 


\section{U.S. Department of the Interior DIRK KEMPTHORNE, Secretary}

\section{U.S. Geological Survey \\ Mark D. Myers, Director}

\section{U.S. Geological Survey, Reston, Virginia: 2007}

For product and ordering information:

World Wide Web: http://www.usgs.gov/pubprod

Telephone: 1-888-ASK-USGS

For more information on the USGS--the Federal source for science about the Earth, its natural and living resources, natural hazards, and the environment:

World Wide Web: http://www.usgs.gov

Telephone: 1-888-ASK-USGS

Any use of trade, product, or firm names is for descriptive purposes only and does not imply endorsement by the U.S. Government.

Although this report is in the public domain, permission must be secured from the individual copyright owners to reproduce any copyrighted materials contained within this report.

Suggested citation:

Ryberg, K.R., 2007, Summary and trend analysis of water-quality data for the Oakes Test Area, southeastern North Dakota, 1984-2004: U.S. Geological Survey Scientific Investigations Report 2007-5056, 118 p. 


\section{Contents}

Abstract
Introduction
Purpose and Scope
Description of Oakes Test Area
Methods
Summary Statistics
Results of Trend Analysis
Summary
References Cited
Supplements

\section{Figures}

1. Map showing the Garrison Diversion Conservancy District and Oakes Test Area in

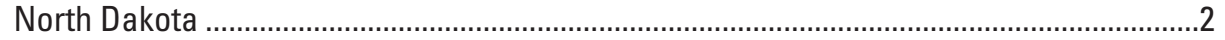

2. Oakes Test Area drain system and water-quality sampling sites, southeastern North Dakota ...

3-5. Graph showing:

3. Sources and amounts of irrigation water used in the Oakes Test Area, southeastern North Dakota, 1988-2004 ................................................................4

4. Drainflow for sites in the Oakes Test Area, southeastern North Dakota ..................5

5. Base-10 logarithm of constituent concentrations at site 3 in the Oakes Test Area, southeastern North Dakota, and associated trend lines.

\section{Tables}

1. Summary of statistics for water-quality physical properties and constituents at sampling sites in the Oakes Test Area, southeastern North Dakota, 1984 through 2004

2. Trends by site for water-quality physical properties and constituents at sampling sites in the Oakes Test Area, southeastern North Dakota, 1988 through 2004, and 1994 through 2004

3. Trends by constituent for water-quality physical properties and constituents at sampling sites in the Oakes Test Area, southeastern North Dakota, 1988 through 2004, and 1994 through 2004. 
Supplements 1-4:

1. Drainflow at sampling sites 3,4 , and 6 in the Oakes Test Area, southeastern North Dakota, 1984 through 2004

2. Physical properties and dissolved solids for sampling sites in the Oakes Test Area, southeastern North Dakota, 1984 through 2004. .46

3. Major ions for sampling sites in the Oakes Test Area, southeastern North Dakota, 1984 through 2004.

4. Nutrients and trace elements for sampling sites in the Oakes Test Area, southeastern North Dakota, 1984 through 2004.

\section{Conversion Factors}

\begin{tabular}{lcl} 
Multiply & \multicolumn{1}{c}{ By } & To obtain \\
\hline & Length & \\
\hline mile $(\mathrm{mi})$ & 1.609 & kilometer $(\mathrm{km})$ \\
\hline & Area & \\
\hline acre & 4,047 & square meter $\left(\mathrm{m}^{2}\right)$ \\
acre & 0.4047 & hectare $($ ha) \\
acre & 0.4047 & square hectometer $\left(\mathrm{hm}^{2}\right)$ \\
acre & 0.004047 & square kilometer $\left(\mathrm{km}^{2}\right)$ \\
square mile $\left(\mathrm{mi}^{2}\right)$ & 259.0 & hectare $($ ha) \\
square mile $\left(\mathrm{mi}^{2}\right)$ & 2.590 & square kilometer $\left(\mathrm{km}^{2}\right)$ \\
\hline & Flow rate & \\
\hline cubic foot per second $\left(\mathrm{ft}^{3} / \mathrm{s}\right)$ & 0.02832 & cubic meter per second $\left(\mathrm{m}^{3} / \mathrm{s}\right)$ \\
\hline
\end{tabular}

Temperature in degrees Celsius $\left({ }^{\circ} \mathrm{C}\right)$ may be converted to degrees Fahrenheit $\left({ }^{\circ} \mathrm{F}\right)$ as follows:

${ }^{\circ} \mathrm{F}=\left(1.8 x^{\circ} \mathrm{C}\right)+32$

Temperature in degrees Fahrenheit $\left({ }^{\circ} \mathrm{F}\right)$ may be converted to degrees Celsius $\left({ }^{\circ} \mathrm{C}\right)$ as follows:

${ }^{\circ} \mathrm{C}=\left({ }^{\circ} \mathrm{F}-32\right) / 1.8$

Specific conductance is given in microsiemens per centimeter at 25 degrees Celsius $(\mu \mathrm{S} / \mathrm{cm}$ at $\left.25^{\circ} \mathrm{C}\right)$.

Concentrations of chemical constituents in water are given either in milligrams per liter (mg/L) or micrograms per liter $(\mu \mathrm{g} / \mathrm{L})$. 


\title{
Summary and Trend Analysis of Water-Quality Data for the Oakes Test Area, Southeastern North Dakota, 1984-2004
}

\author{
By Karen R. Ryberg
}

\begin{abstract}
The Oakes Test Area is operated and maintained by the Garrison Diversion Conservancy District, under a cooperative agreement with the Bureau of Reclamation, to evaluate the effectiveness and environmental consequences of irrigation. As part of the evaluation, the Bureau of Reclamation collected water-quality samples from seven sites on the James River and the Oakes Test Area. The data were summarized and examined for trends in concentration.

A nonparametric statistical test was used to test whether each concentration was increasing or decreasing with time for selected physical properties and constituents, and a trend slope was estimated for each constituent at each site. Trends were examined for two time periods, 1988-2004 and 1994-2004.

Results varied by site and by constituent. All sites and all constituents tested had at least one statistically significant trend in the period 1988-2004. Sulfate, total dissolved solids, nitrate, and orthophosphate have significant positive trends at multiple sites with no significant negative trend at any site. Alkalinity and arsenic have single significant positive trends. Hardness, calcium, magnesium, sodium, sodium-adsorption ratio, potassium, and chloride have both significant positive and negative trends. Ammonia has a single significant negative trend. Fewer significant trends were identified in 1994-2004, and all but one were positive. The contribution to the James River from Oakes Test Area drainage appears to have little effect on water quality in the James River.
\end{abstract}

\section{Introduction}

The Oakes Test Area is a Federal project in southeastern North Dakota developed as part of the Garrison Diversion Unit (GDU) to evaluate the effectiveness and environmental consequences of irrigation in North Dakota. The GDU was created by the U.S. Congress in 1965 with the intent of providing water for agricultural irrigation in North Dakota. Subsequent acts of Congress (the Garrison Diversion Unit Reformulation Act of 1986 and the Dakota Water Resources Act of 2000) have changed the focus of the GDU; however, the Oakes Test Area has continued to operate. The Oakes Test
Area is operated and maintained by the Garrison Diversion Conservancy District (GDCD; fig. 1) under a cooperative agreement with the U.S. Department of the Interior, Bureau of Reclamation (Garrison Diversion Conservancy District, 2004a).

To evaluate the environmental consequences of irrigation, the Bureau of Reclamation collected water-quality samples from seven sites on the James River and the Oakes Test Area drain system (fig. 2). The James River is one of the sources of Oakes Test Area irrigation water and receives return flow from the drain system. A cooperative project with the U.S. Geological Survey (USGS) and the Bureau of Reclamation was conducted to evaluate the data for possible trends in constituent concentrations and to provide information to support decisions regarding the necessity and frequency of continued water-quality sampling.

\section{Purpose and Scope}

Presented in the report are summary statistics for 31 water-quality physical properties and constituents from samples collected by the Bureau of Reclamation at 7 sites on the James River and the Oakes Test Area from January 1984 through November 2004. This report also presents the results of a trend analysis performed on selected physical properties, dissolved solids, major ions, nutrients, and trace elements at the 7 sites. The data used for the statistical summaries and trend analysis are provided in supplements at the end of the report.

\section{Description of Oakes Test Area}

The Oakes Test Area is a 5,000-acre area east of the James River between Oakes and Ludden, North Dakota (fig. 2). The area was established as part of the Garrison Diversion Unit (created by the U.S. Congress on August 5, 1965). The Oakes Test Area was "designed to demonstrate that a well-managed irrigation system could produce high-value, irrigated crops without the potential for damage to nearby water supplies" (Garrison Diversion Conservancy District, 2004b). Irrigation water has been a combination of ground water, surface water from the James 


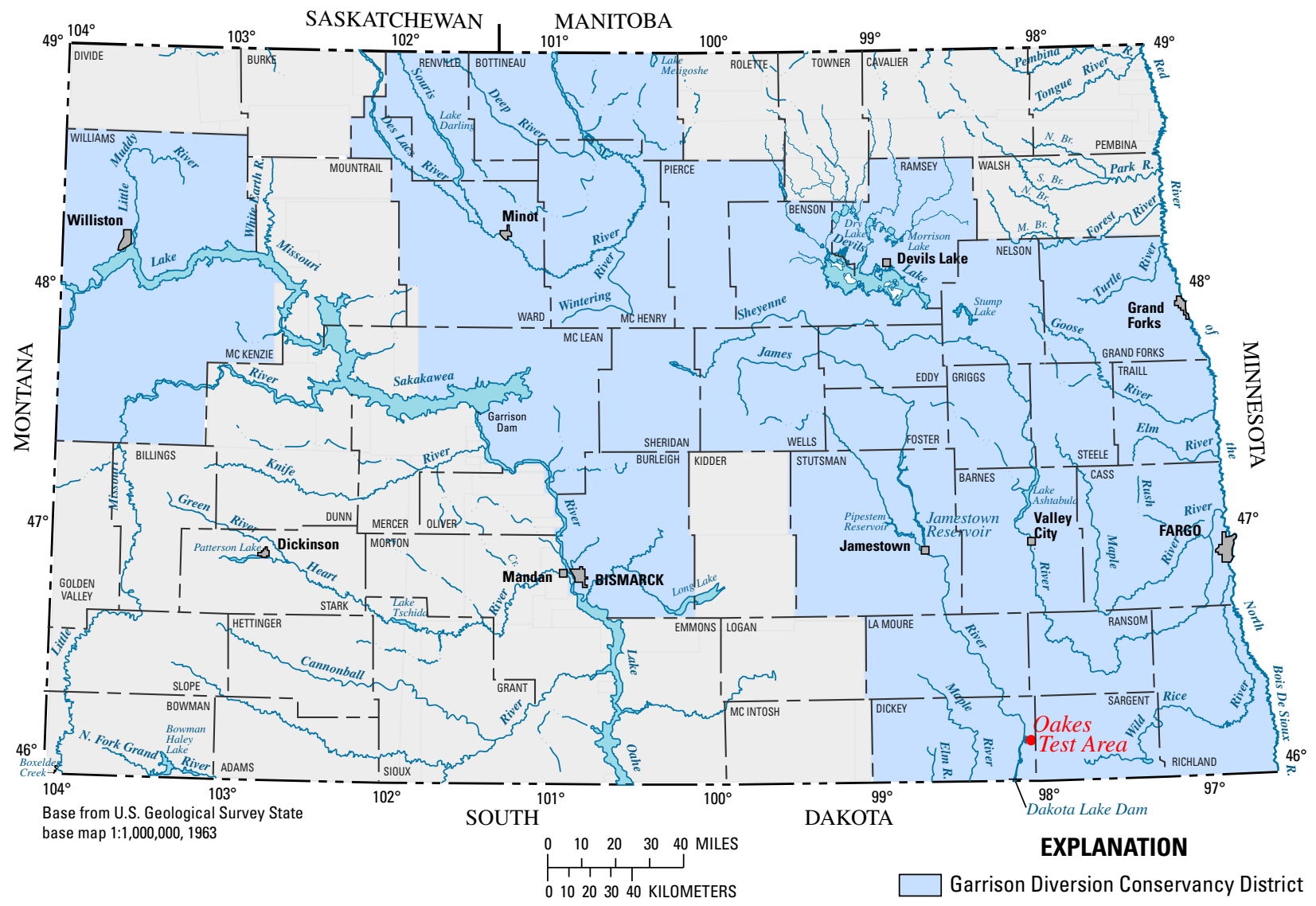

Figure 1. The Garrison Diversion Conservancy District and Oakes Test Area in North Dakota. 


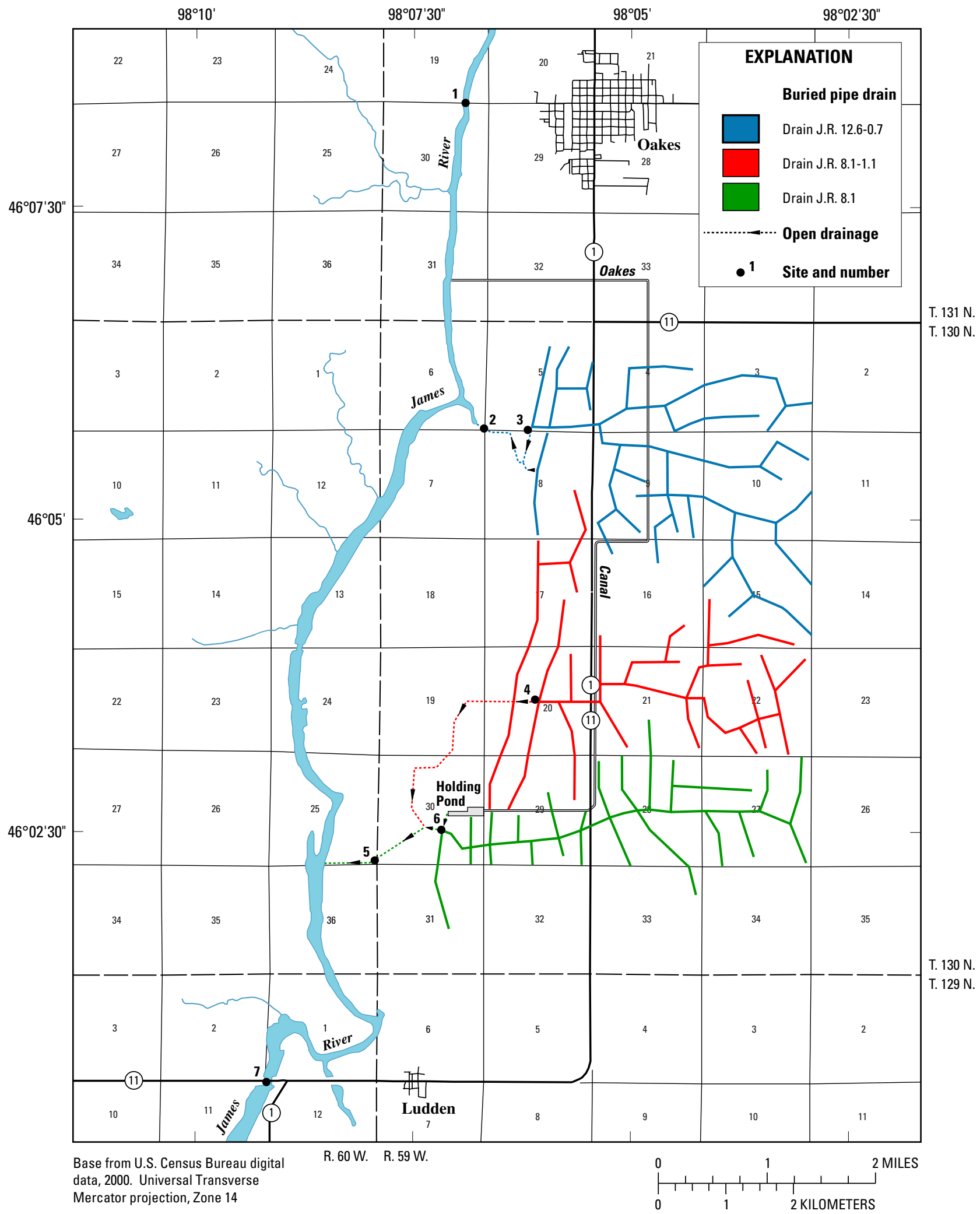

Figure 2. Oakes Test Area drain system and water-quality sampling sites, southeastern North Dakota. 
River, and water recaptured from the drain system by drain pumps (fig. 3).

The James River originates in central North Dakota and flows southeast into South Dakota. At the North DakotaSouth Dakota State line, the drainage area of the James River Basin is 5,480 $\mathrm{mi}^{2}$ (Brigham and Payne, 1999). Natural lakes, low-head dams, and regulated reservoirs are located along the James River. Upstream from the Oakes Test Area is the Jamestown Reservoir (fig. 1), constructed primarily for flood control (Simonds, 1996). The Dakota Lake Dam, $4.5 \mathrm{mi}$ southwest of Ludden, North Dakota, and $0.8 \mathrm{mi}$ upstream from the North Dakota-South Dakota State line, directly affects the James River in the study area (fig. 1). The water-quality sampling sites on the James River (sites 1 and 7, fig. 2) are lake-affected and wind-affected (B.R. Hanson, U.S. Geological Survey, oral commun., 2006).

Approximately 40 miles of subsurface pipe drains were installed in the Oakes Test Area during 1983-85 as a means to control the water table (Goolsby and others, 1989; fig. 2). Irrigation delivery began in 1988, and the number of acres receiving water has varied from 500 to 3,500 acres (Weckerly, 2006). The drains discharge into three open collector drains that discharge water to the James River (Goolsby and others, 1989). The north drain (J.R. 12.6-0.7) discharges to the James
River about 3 mi south of Oakes, North Dakota. The middle drain (J.R. 8.1-1.1) and the south drain (J.R. 8.1) join together and discharge to the James River at the southern end of the Oakes Test Area.

The hydrologic and climatic conditions at the Oakes Test Area were variable over the sampling period of record. From 1986 to the delivery of irrigation water in 1988, water flowed in the drains and water-quality samples were collected and analyzed. Most of the drainflow was due to groundwater infiltration (D. Esser, Garrison Diversion Conservancy District, oral commun., 2007). Under irrigation conditions, the source of water in the drains has varied (fig. 3). Warm, dry conditions during 1988-92 resulted in low runoff and decreased ground-water recharge (Williams-Sether, 1999). A cool, wet period resulting in high runoff began in 1993 (Williams-Sether, 1999). The high runoff resulted in higher drainflow as shown in figure 4 . The drainflow data shown in figure 4 are presented in Supplement 1 at the end of the report.

The Oakes Test Area has many other sources of variability, including the types of crops grown and methods used to clean the drain pipes. "North Dakota State University, operating with Garrison Diversion funding, studies test plots of cabbages, peppers, tomatoes, Chinese vegetables and more" (Garrison Diversion Conservancy District, 2004b). Different

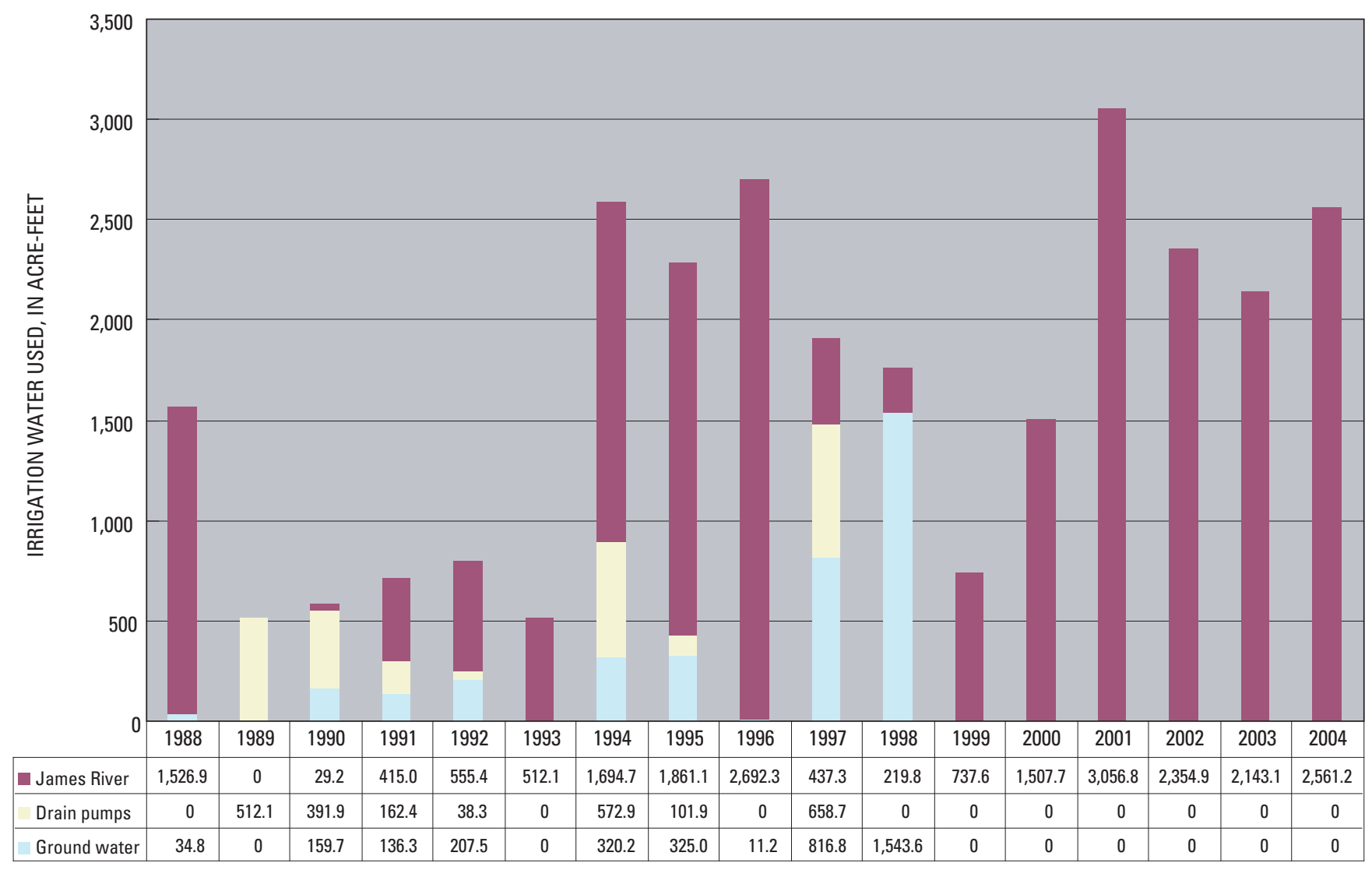

Figure 3. Sources and amounts of irrigation water used in the Oakes Test Area, southeastern North Dakota, 1988-2004. 


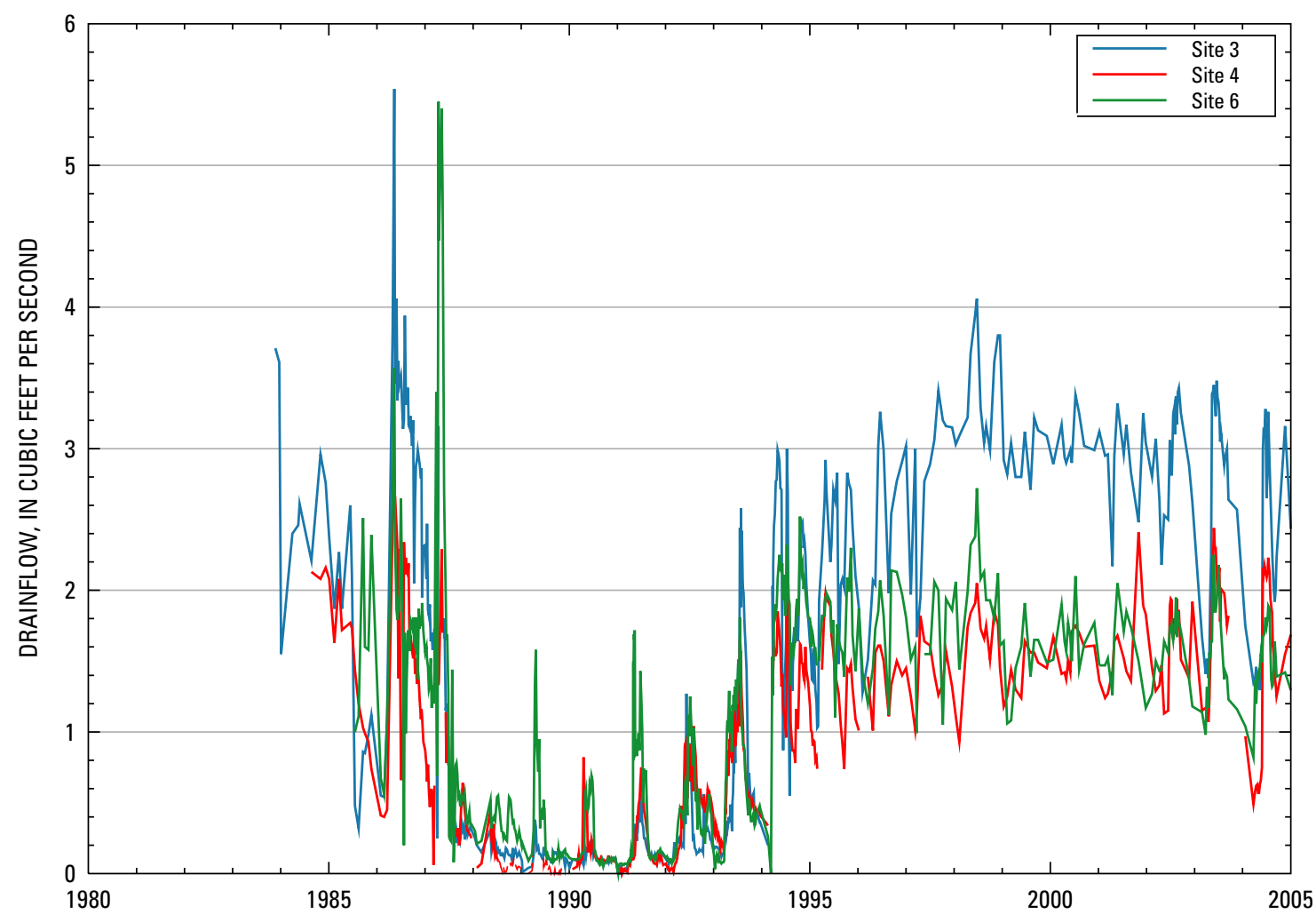

Figure 4. Drainflow for sites in the Oakes Test Area, southeastern North Dakota.

crops have different irrigation requirements and contribute to the variability in irrigation and drainage. The drain pipes need to be cleaned periodically. Depending on location and use, some pipes are cleaned more often than others and the method used may be high pressure water or a brush system (D. Esser, Garrison Diversion Conservancy District, oral commun., 2007).

\section{Methods}

Water-quality data were collected by the Bureau of Reclamation using collection methods that varied with the type of site. Sites on the James River were depth integrated (D. Hartman, Bureau of Reclamation, written commun., 2007). Some sites in the drainage system involved removing a manhole cover to access the buried drain and lowering a weighted bottle to collect a dip sample. Site 2, where the drain flows into the James River, was dip sampled (L.L. Rutschke, U.S. Geological Survey, oral commun., 2007). For quality assurance, periodic duplicate samples were collected from the same location, and periodic split samples were collected and filtered into one bottle and then split into two different bottles prior to preservation and analysis (D. Hartman, Bureau of Reclamation, written commun., 2007).
All water-quality samples were analyzed by the Bureau of Reclamation Dakotas Area Office Water and Soil Laboratory in Bismarck, North Dakota. Laboratory methods used were those of the manufacturer of the analyzing equipment and were based on U.S. Environmental Protection Agency approved methods (D. Hartman, Bureau of Reclamation, written commun., 2007). Quality-control measures included the calibration of equipment and analysis of blank, duplicate, and split samples. The results of these quality-control measures were verified manually and data were accepted according to criteria in an internal quality-control manual (D. Hartman, Bureau of Reclamation, oral commun., 2007). Other quality control measures included the use of check standards, control samples, analytical spikes and duplicates, and cation/anion balance comparison (D. Hartman, Bureau of Reclamation, written commun., 2007). The water-quality concentration data are on file at the Bureau of Reclamation Dakotas Area Office, Bismarck, North Dakota.

Drainflow data were collected by GDCD personnel at Oakes, North Dakota, and are on file in the Oakes office. Drainflow was measured using a portable ultrasonic meter (D. Esser, Garrison Diversion Conservancy District, oral commun., 2007). The amount and source of irrigation water (fig. 3) also were monitored by GDCD personnel at Oakes, and data are on file in that office. 
Summary statistics were calculated for 31 physical properties, dissolved and suspended solids, major ions, nutrients, and trace elements. Some suspended solids, nutrient, and trace element values were censored. Censored values represent concentrations that are known to be less than a certain laboratory reporting level (LRL), but for which the exact value is not known. Summary statistics were estimated for constituents with censored values if less than 80 percent of the values were censored. For constituents with less than 50-percent censoring, the maximum concentration was reported, the minimum concentration was reported as less than the lowest LRL, and the percentiles were estimated by the nonparametric Kaplan-Meier method (Helsel, 2005). For constituents with 50-80 percent of values censored, the maximum concentration was reported, the minimum concentration was reported as less than the lowest LRL for each particular site, and the percentiles were estimated by using regression on order statistics (ROS), a method that calculates summary statistics with a regression equation on a probability plot (Helsel, 2005). ROS estimation requires at least three uncensored observations; therefore, small samples that had less than 80-percent censoring were treated as those with more than 80-percent censoring if there were not three or more uncensored observations. For constituents with more than 80-percent censoring, the maximum concentration was reported, the minimum concentration was reported as less than the lowest LRL, and the 95th percentile was reported if the data had 95-percent censoring or less. Means also were estimated by using the Kaplan-Meier and ROS methods. If a particular site had no censored concentrations for a constituent, the summary statistics reported are actual concentrations, not estimated values.

The trend analysis method used was the nonparametric Mann-Kendall test, which tests whether values tend to increase or decrease with time (monotonic change; Helsel and Hirsch, 1992). In hypothesis terms, the test can be expressed as

$$
\begin{aligned}
& H_{0}: \operatorname{Prob}\left[Y\left(t_{j}\right)>Y\left(t_{i}\right)\right]=0.5 \\
& H_{1}: \operatorname{Prob}\left[Y\left(t_{j}\right)>Y\left(t_{i}\right)\right] \neq 0.5,
\end{aligned}
$$

where

$$
\begin{aligned}
\text { Prob } & \text { denotes probability, } \\
Y(t) & \text { is constituent concentration for time } t
\end{aligned}
$$

and

$$
t_{j}>t_{i} \text {. }
$$

The test statistic is Kendall's S According to Helsel and Hirsch (1992), "Kendall's S is calculated by subtracting the number of 'discordant pairs' $\mathrm{M}$, the number of $(\mathrm{x}, \mathrm{y})$ pairs where $y$ decreases as $x$ increases, from the number of 'concordant pairs' $\mathrm{P}$, the number of (x,y) pairs where $y$ increases with increasing $x$." As used in this study, $y$ is constituent concentration and $x$ is time.

Because Mann-Kendall is a nonparametric test, the assumption of normality is not required and a small percentage of outliers does not substantially affect the results (Helsel and Hirsch, 1992). The Mann-Kendall test was used for both uncensored and censored constituents. The test makes comparisons between all possible pairs of observations. The censored, or "less than," values are considered to be tied with each other when compared. Comparisons are difficult to make when data have multiple LRLs; for example, ammonia at site 2 was censored at $0.02,0.05$, and 0.10 milligrams per liter. In order to perform the Mann-Kendall test, the data were further censored by using the highest LRL, 0.10 , to represent all "less than" values. Not every physical property or constituent was tested at each site, because at some sites sample size was too small or no samples were collected.

The slope of the trend is a Sen slope estimate (also called Theil slope estimate) and is the median of all possible pairwise slopes (U.S. Geological Survey, variously dated). The sign of the Sen slope estimate is accurate for highly censored data; however, the magnitude of the slope may not be accurate (Helsel and Hirsch, 1992). The percentage change from the beginning of any year to the end of that year calculated for statistically significant trends is $\left(10^{b_{1}}-1\right) \times 100$, where $b_{1}$ is the estimated Sen slope as the base-10 logarithm of milligrams per liter or micrograms per liter (Helsel and Hirsch, 1992).

Because of the climatic variability during the sampling period of record and the ground-water drainage prior to irrigation, there are three separate populations of water-quality data, pre-1988 for some sites/constituents, 1988-1993, and post-1993. The number of samples collected before 1988 is small and samples were not collected at all sites; therefore, trends were not calculated for the pre-1988 period. Two trends were calculated for each site/constituent combination: one trend for the sampling period of record under irrigation conditions, 1988-2004, and one for the period 1994-2004.

Other methods of trend analysis were considered for this study. Understanding why these other methods were not used contributes to the understanding of the availability and variability of data related to the Oakes Test Area. Methods considered included regression or LOWESS (Locally Weighted Scatterplot Smoothing; Helsel and Hirsch, 1992) of constituent concentration on time and streamflow or drainflow, and regression or LOWESS of constituent concentration on time and other exogenous variables.

Regression on streamflow, drainflow, or another variable would remove variation in concentration caused by these variables, increasing the ability of a trend test to discern changes in concentration over time. Adjustment for streamflow was an option only for sites 1 and 7 because they are on the James River (fig. 2). The James River sites (sites 1 and 7, fig. 2) are lake-affected because of Dakota Lake Dam (fig. 1) downstream, and are affected by releases from the Jamestown Reservoir (fig. 1) upstream. The lake conditions vary seasonally and with releases from the Jamestown Reservoir (R.J. Renner, U.S. Geological Survey, oral commun., 2007). Because of the lake conditions and the need to have a consistent manner in which to present trends, streamflow was not an appropriate variable for regression. 
Drainflow adjustment was an option for sites 2-6 (fig. 3). For regression analysis, the probability distribution of the exogenous variable is assumed to be unchanged over the period of record (Helsel and Hirsch, 1992). Figure 4 shows that the probability distribution of drainflow has changed over the period of record with low flows in the late 1980s through early 1990s and higher flows in succeeding years. Drainflow is highly variable, being affected by weather conditions and nonrandom conditions including the types of crops grown in the Oakes Test Area and the conditions of the drains, which need to be cleaned periodically.

Other exogenous variables representing natural, random processes that might affect all sites were considered. The North Dakota Agricultural Weather Network (NDAWN, http://ndawn.ndsu.nodak.edu/) collects weather data at Oakes. Variables that might affect irrigation, air temperature and solar radiation, were considered for regression analysis. These variables did not explain a significant amount of the variation in concentration ( $R^{2}$ of approximately 0.10 for some sites), and the period of record for weather data at Oakes did not begin until 1990. Use of the weather data would result in an omission of data early in the period of record, and in many cases this would result in a different trend slope than the slope of a trend identified over the entire period of record.

LOWESS is a robust nonparametric technique that requires the verification of fewer assumptions than does regression. However, LOWESS had the same shortcomings as regression in that possible exogenous variables for LOWESS of concentration were not effective in adjusting concentration. Also, LOWESS is not appropriate for highly censored data.

The data set used to calculate the summary statistics and for trend analysis is presented in Supplements 2-4 at the end of the report.

\section{Summary Statistics}

Summary statistics of the physical properties and constituents are listed in table 1, including summary statistics for censored concentrations. Censored values are indicated by the number of censored values for each site/constituent combination and the LRLs. An LRL of 0.10 indicates that one or more values were censored at 0.10 and recorded as $<0.10$. Multiple LRLs occur for some constituents, such as ammonia at site 1 (table 1), which has LRLs of 0.01, 0.02, 0.05, and 0.10. Multiple LRLs may occur because of changes in laboratory methods or equipment. The summary statistics are for the entire period of record for each constituent at each site.

\section{Results of Trend Analysis}

The procedure to test for trends in water quality resulted in a p-value for the Mann-Kendall test and a Sen slope estimate. A p-value less than 0.01 was considered statistically significant, indicating it was likely that the slope of the observations with time was significantly different from 0 . A negative slope indicates a downward trend, decreasing concentration with time, and a positive slope indicates an upward trend, increasing concentration with time. The slopes and p-values for each site/constituent concentration combination are listed in tables 2 and 3. The leftmost Sen slope and p-value are calculated for the period 1988-2004. The rightmost Sen slope and p-value are calculated for the period 1994-2004. Tables 2 and 3 contain the same data; however, table 2 is grouped by site and table 3 is grouped by constituent to allow for examination of trends by site or by constituent. Significant trends have a + or - following the p-value to indicate significant upward or downward trends. Also listed for significant trends is the percentage change from beginning of any year to the end of that year, based on the Sen slope estimate.

As a visual example of the trends, the base-10 logarithm of constituents tested for site 3 and the associated trend lines are shown in figure 5. The blue trend line represents the trend calculated by using concentrations for 1988-2004. The green trend line represents the trend calculated by using concentrations for 1994-2004. For some constituents, the two trend lines are very similar. Potassium, for example, has a Sen slope of 0.005 for both trend periods. Other constituents appear to have been affected by the change in climatic conditions that began in 1993.

Chloride had relatively low measured concentrations prior to irrigation in 1988. Concentrations were relatively high in 1988, decreased until 1994, and increased afterward. Because of the high concentrations in the beginning of the irrigation period, the long term, 1988-2004, slope is downward, despite the upward trend from 1994 through 2004. Both the overall downward trend and the upward trend for 1994 through 2004 are statistically significant at the 0.01 significance level. Nitrate trends also appear to have been affected by the change in conditions that began in 1993; however, in a manner opposite to that of chloride. Nitrate concentrations were relatively low in 1988, increased until about 1995, and decreased afterward. Because of the low concentrations in the beginning of the irrigation period, the long-term, 1988-2004, slope is upward, despite the downward trend for 1994-2004. Only the overall upward trend for 1988-2004 is statistically significant at the 0.01 significance level.

Alkalinity has statistically significant upward trends for both periods; the slope is steepest for 1994-2004. Sodium and sodium-adsorption ratio have significant upward trends in both periods, with the slopes being less steep for 1994-2004. Ammonia has a downward trend for both periods; however, the trend for 1994-2004 is not statistically significant.

The total dissolved solids graph (fig. 5) and trend test results at site 3 (tables 2 and 3) are examples of the MannKendall test and Sen slope resistance to potential outliers. There was one total dissolved solids concentration that was low in relation to the other observations, but the slope estimates were not unduly affected by the single observation. 


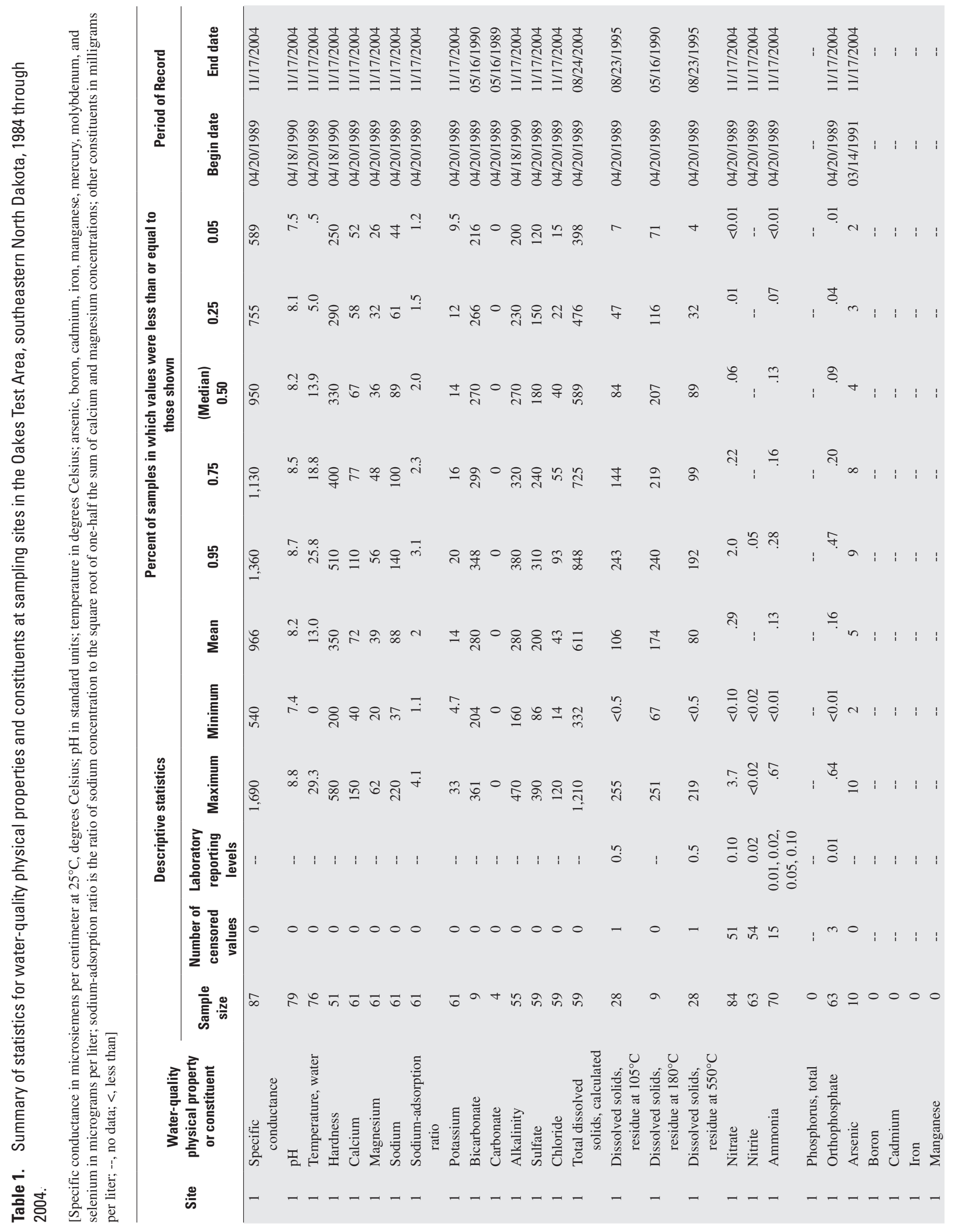




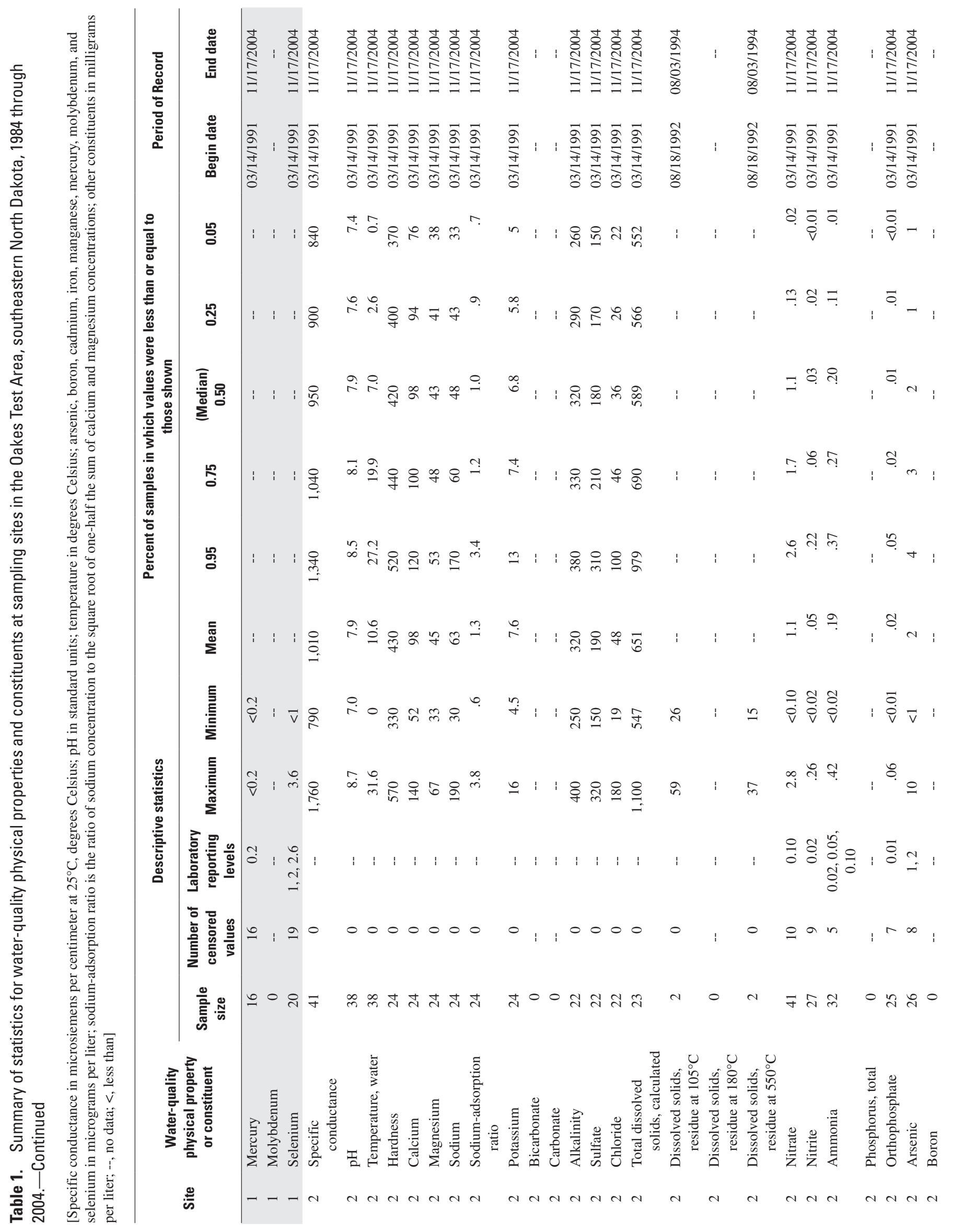




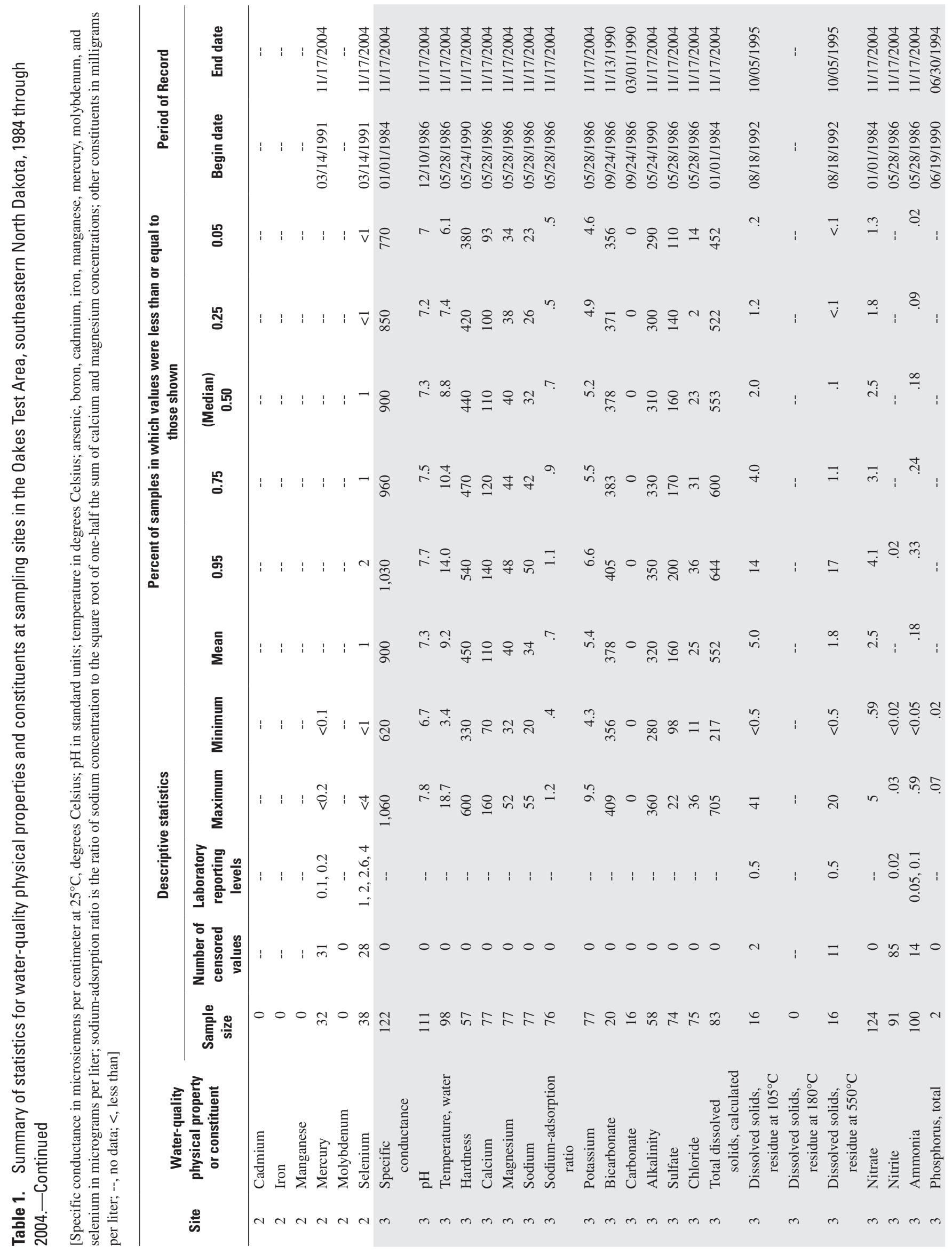




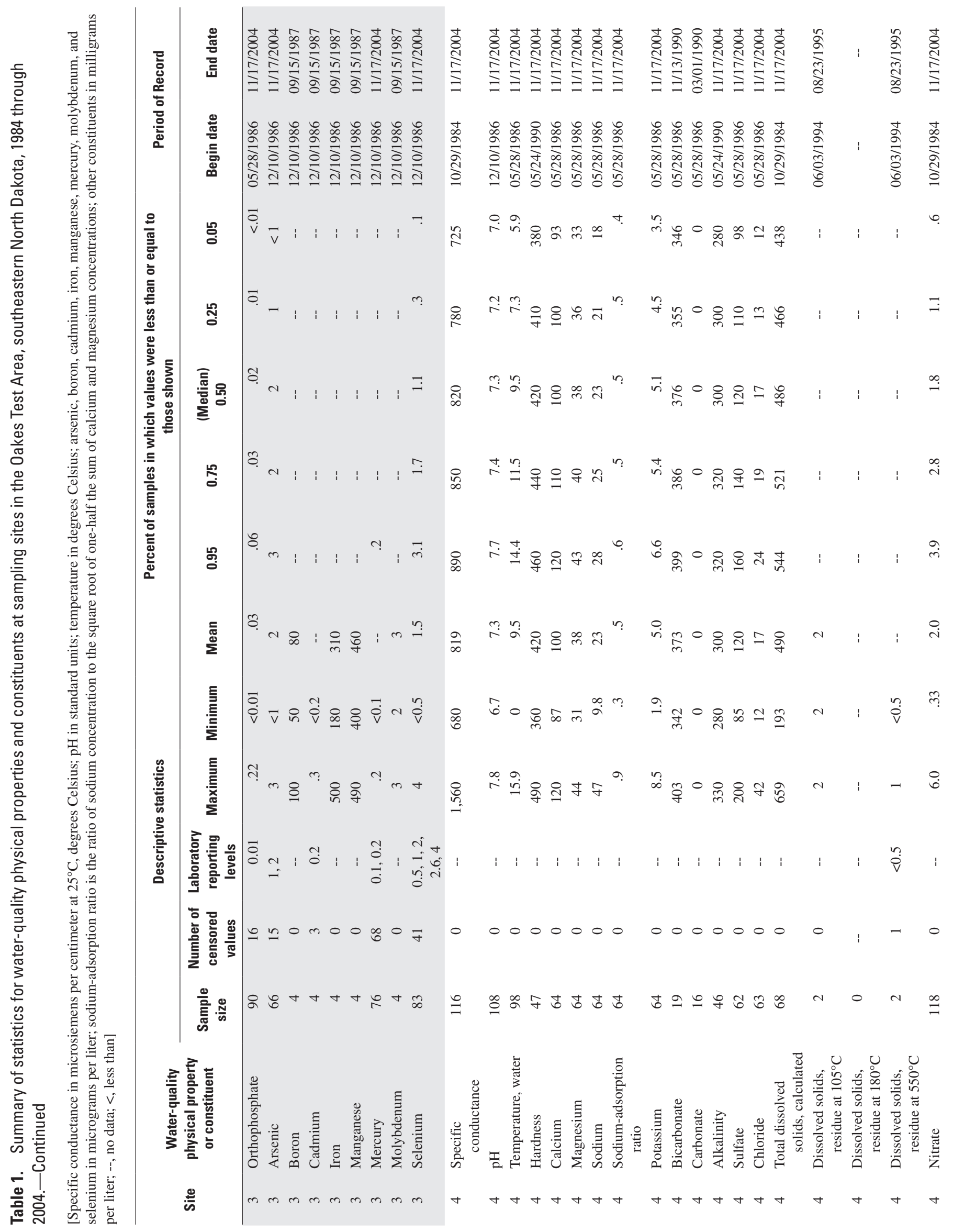




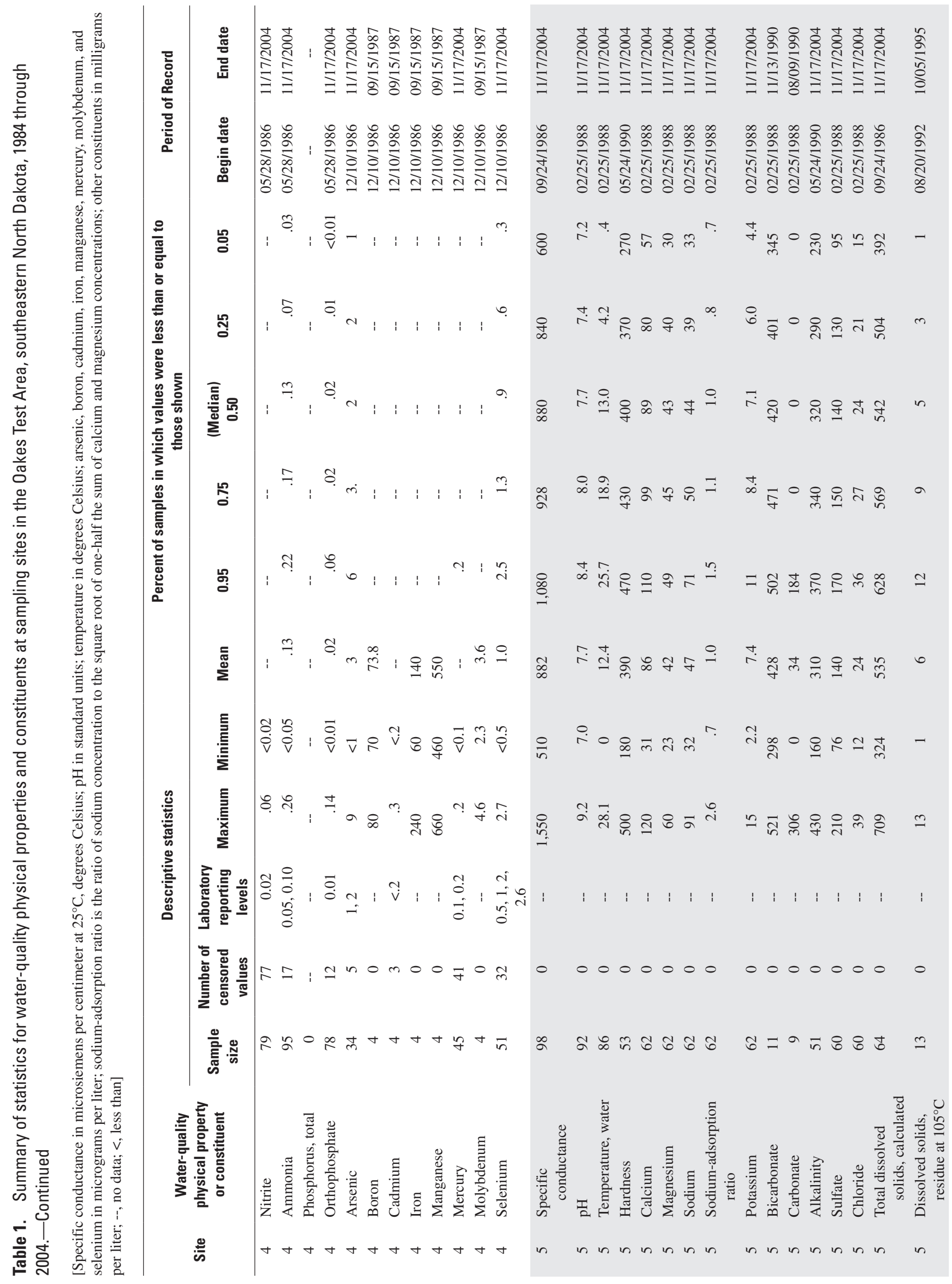




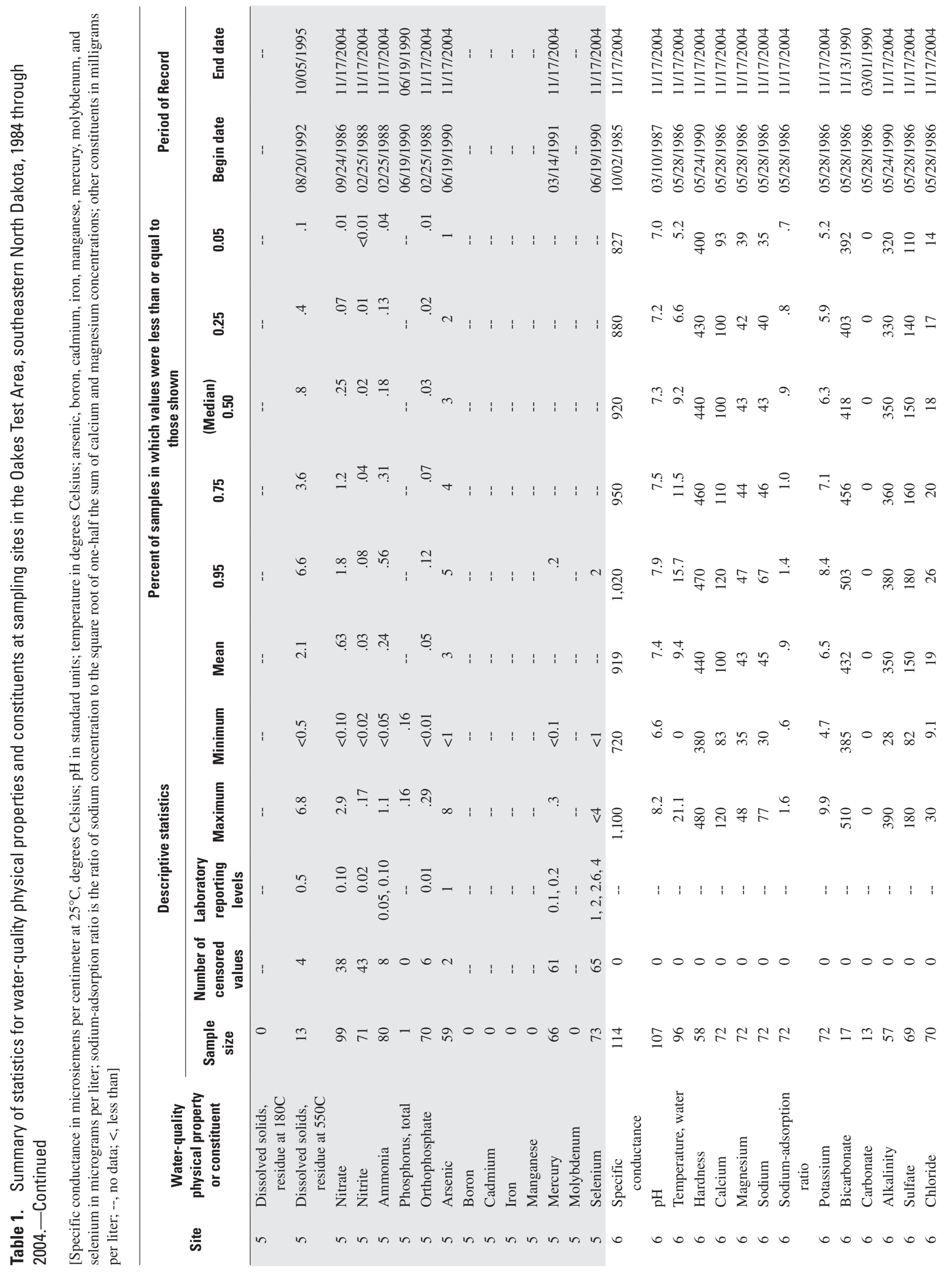




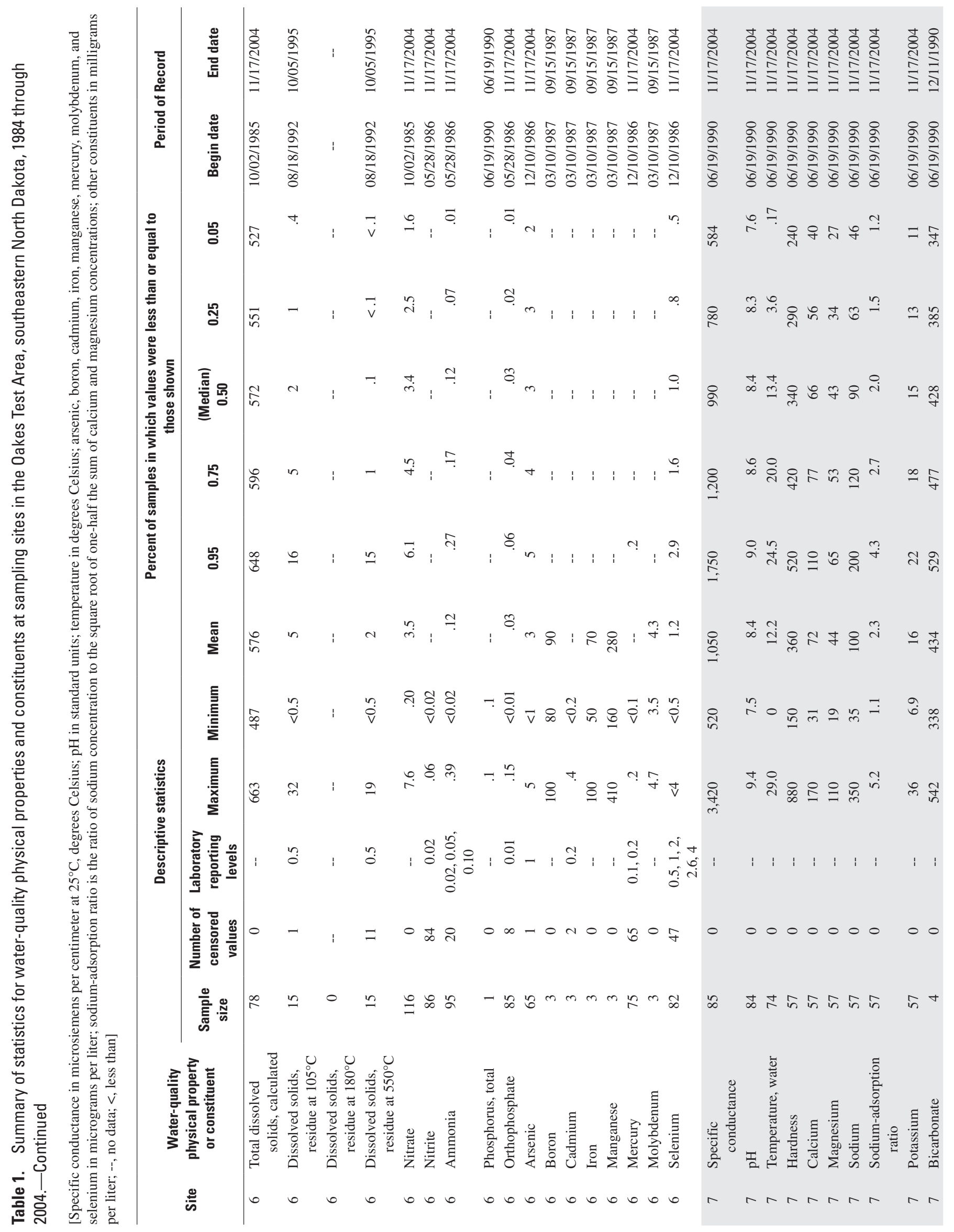




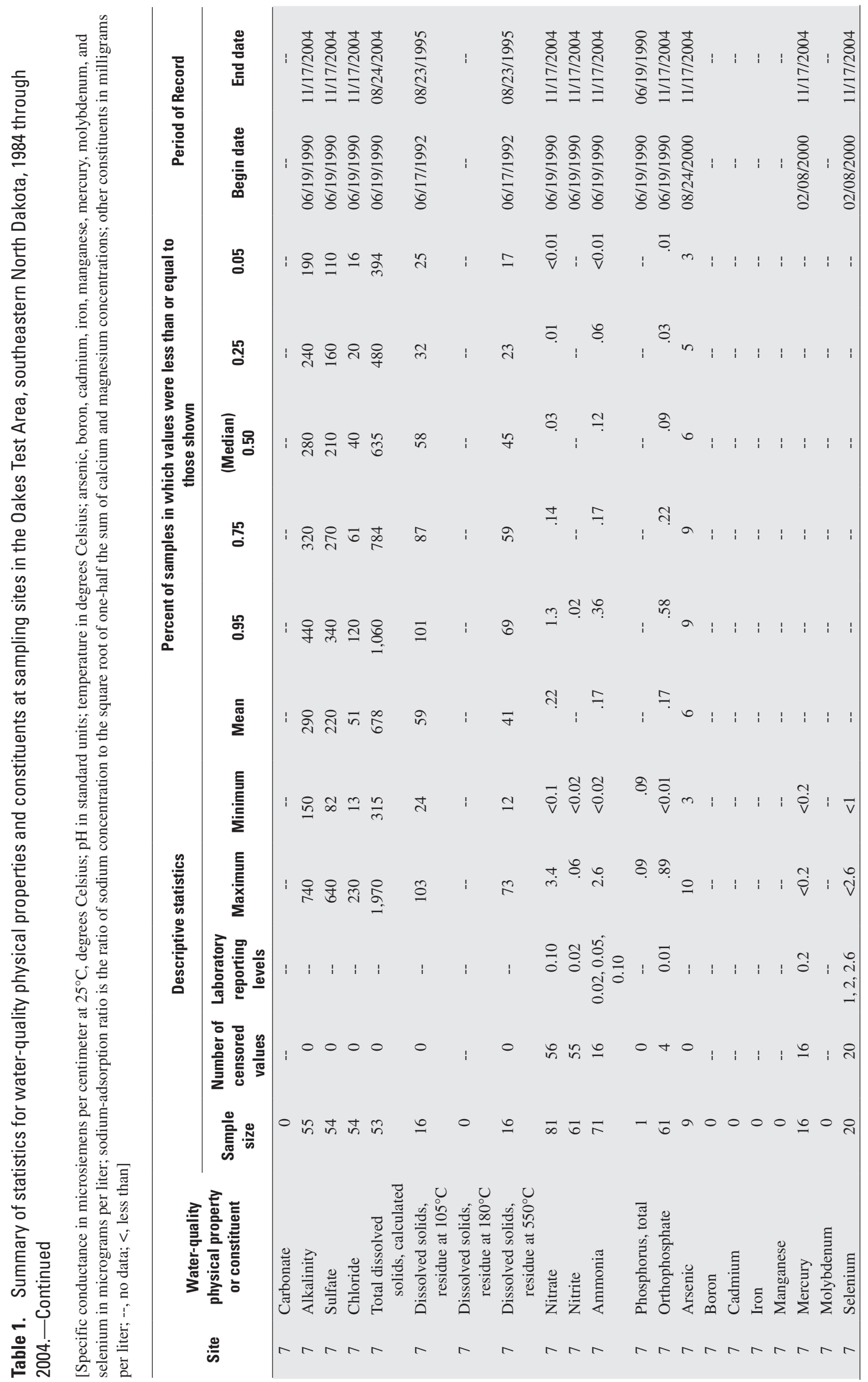




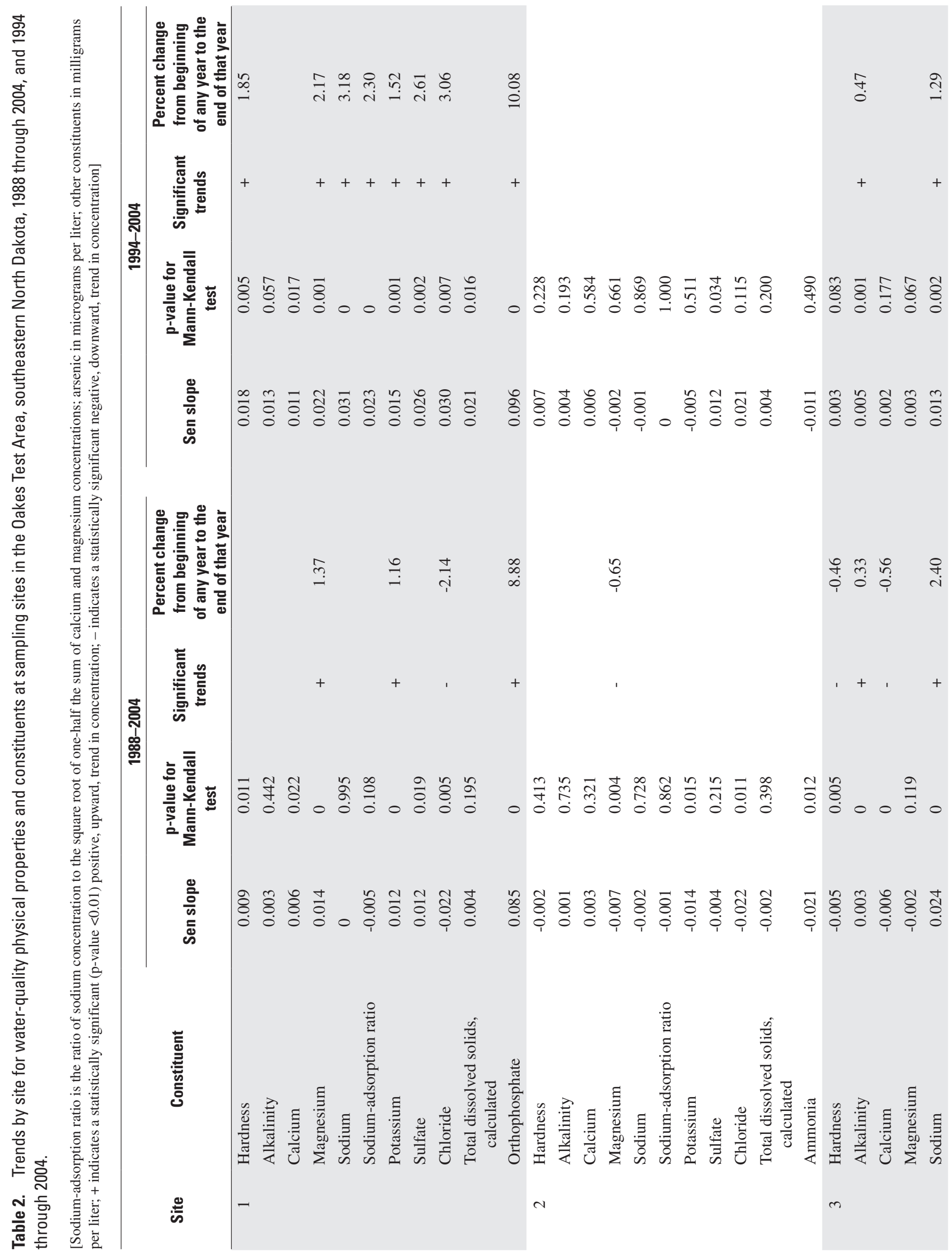



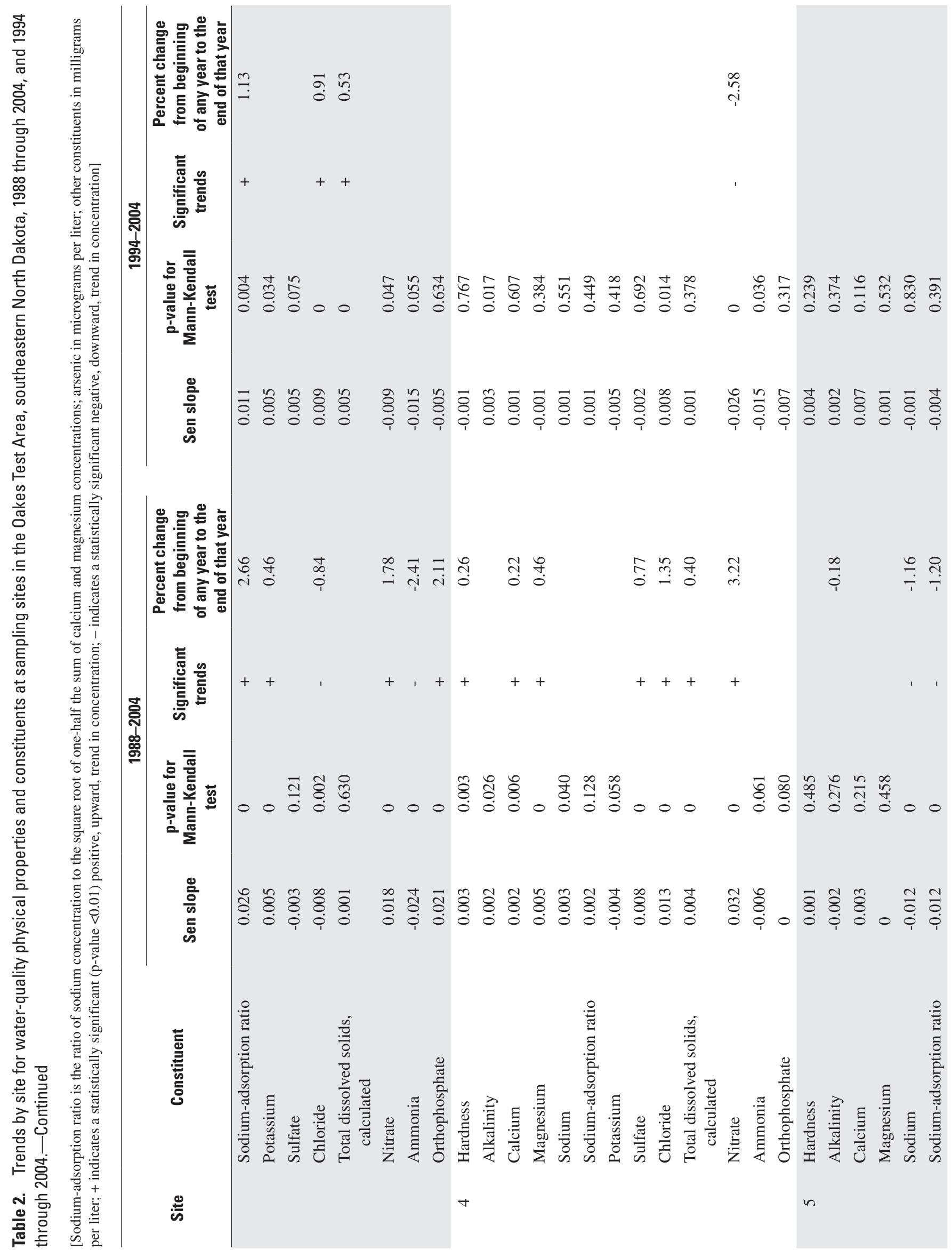


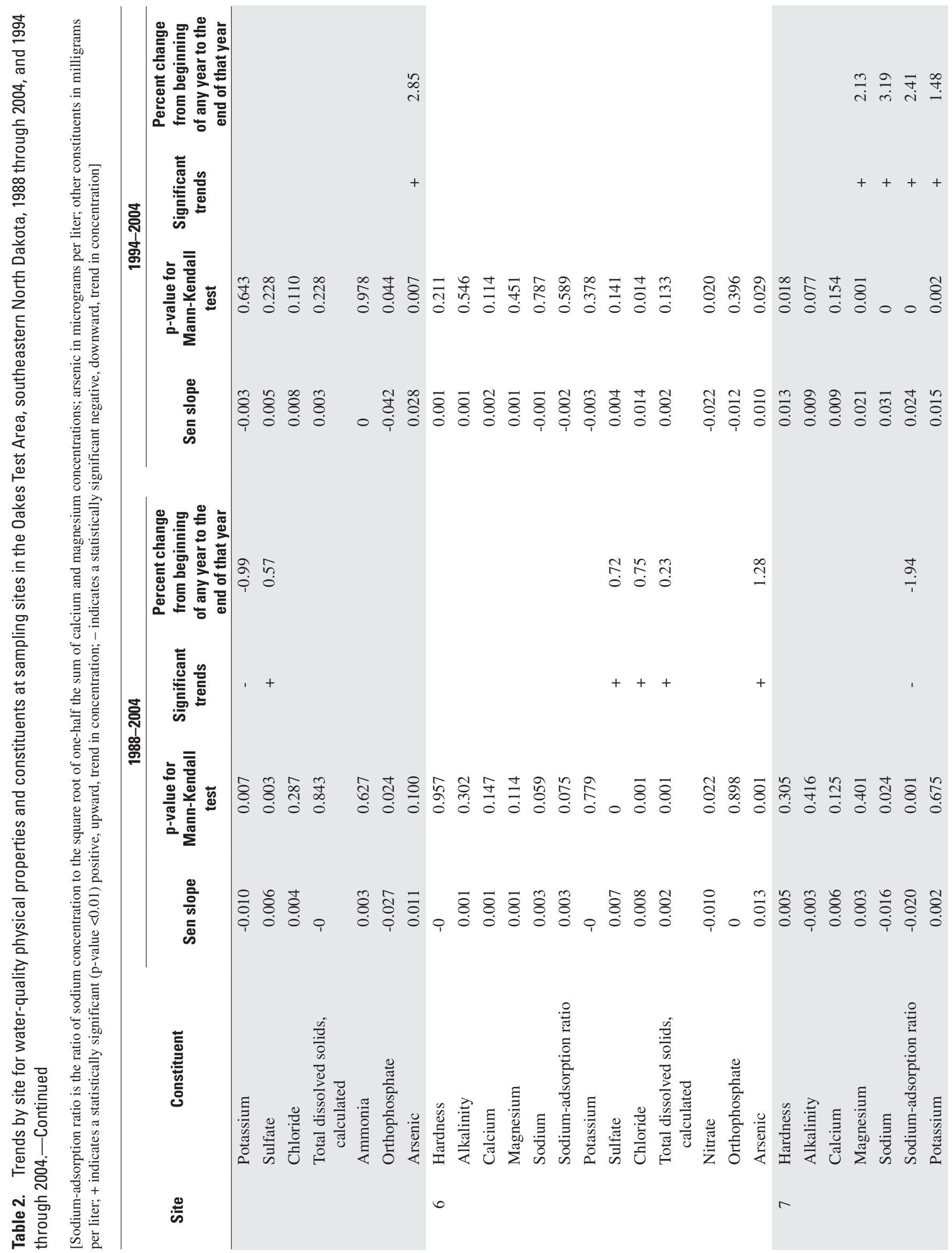




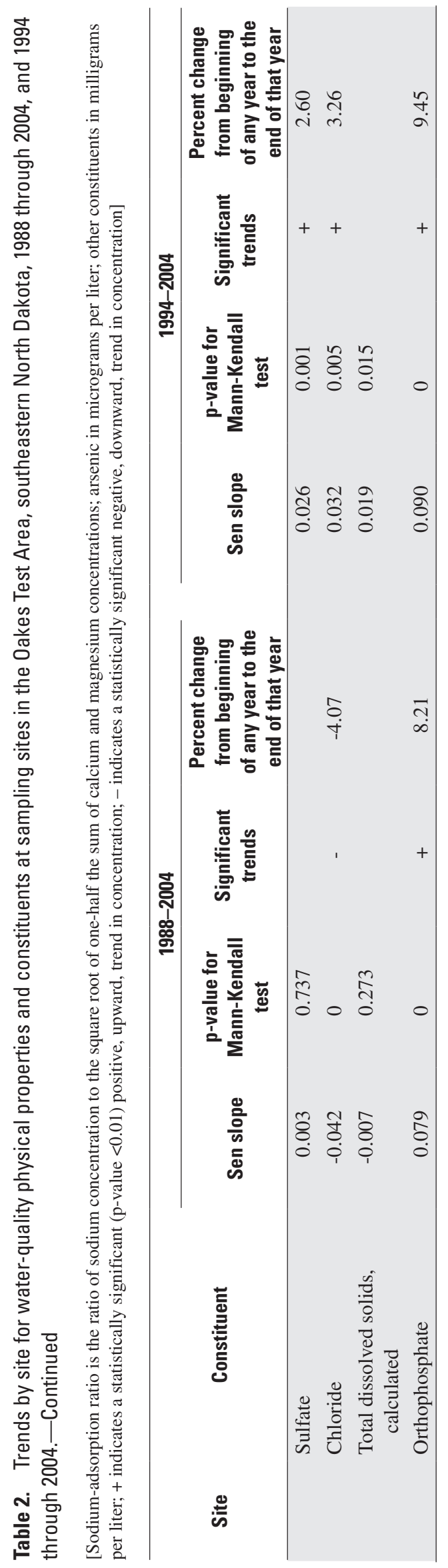




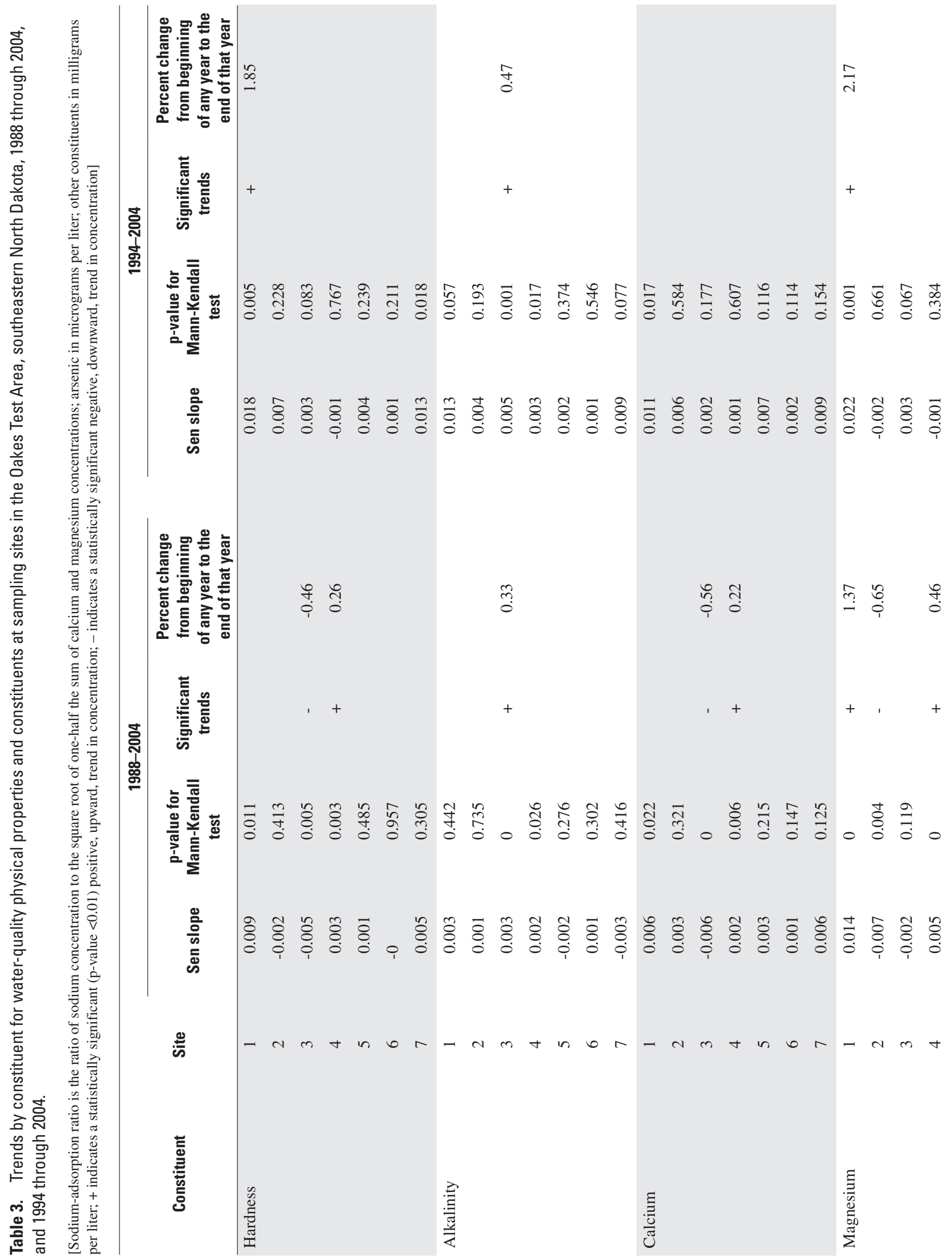




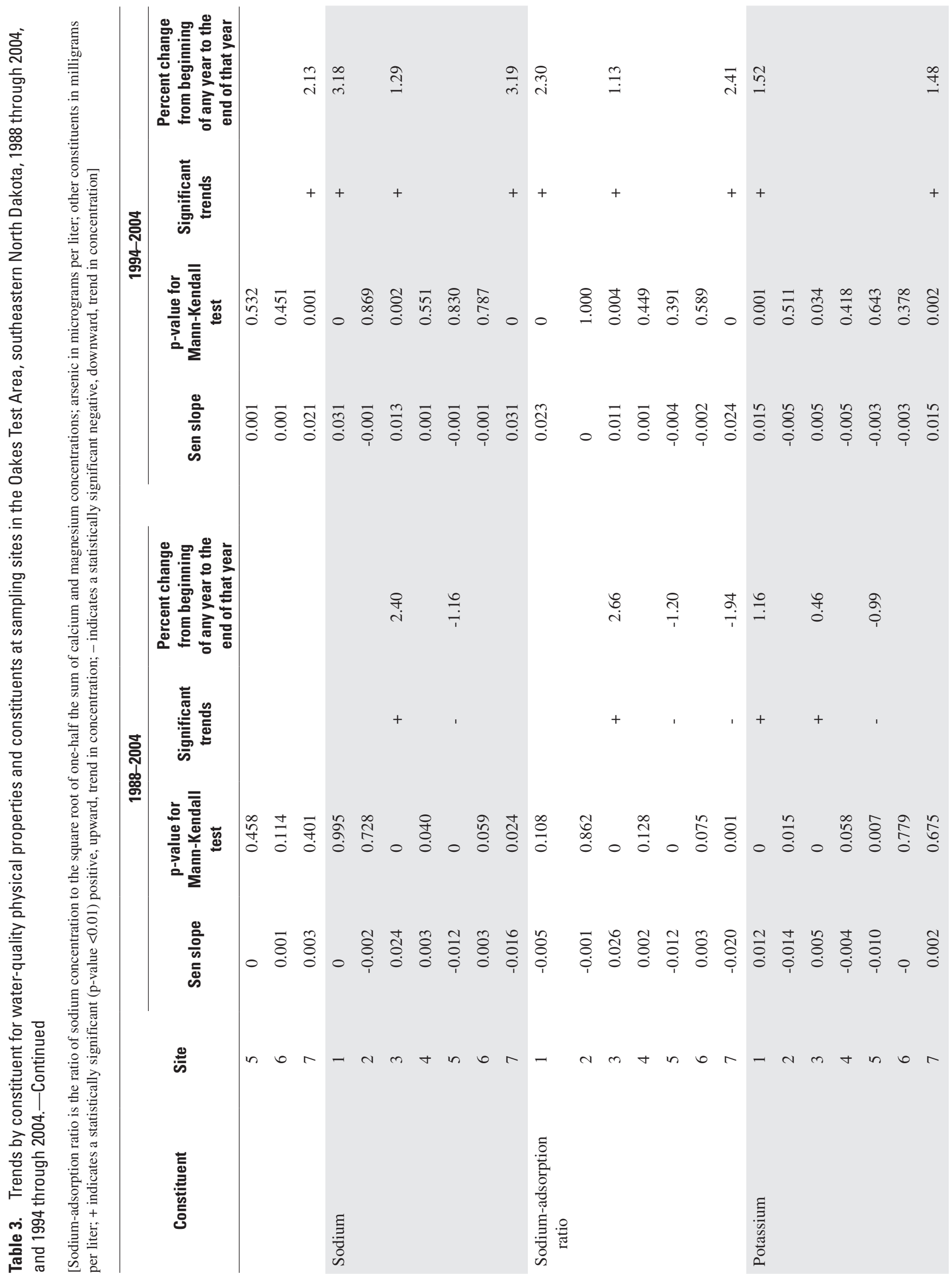



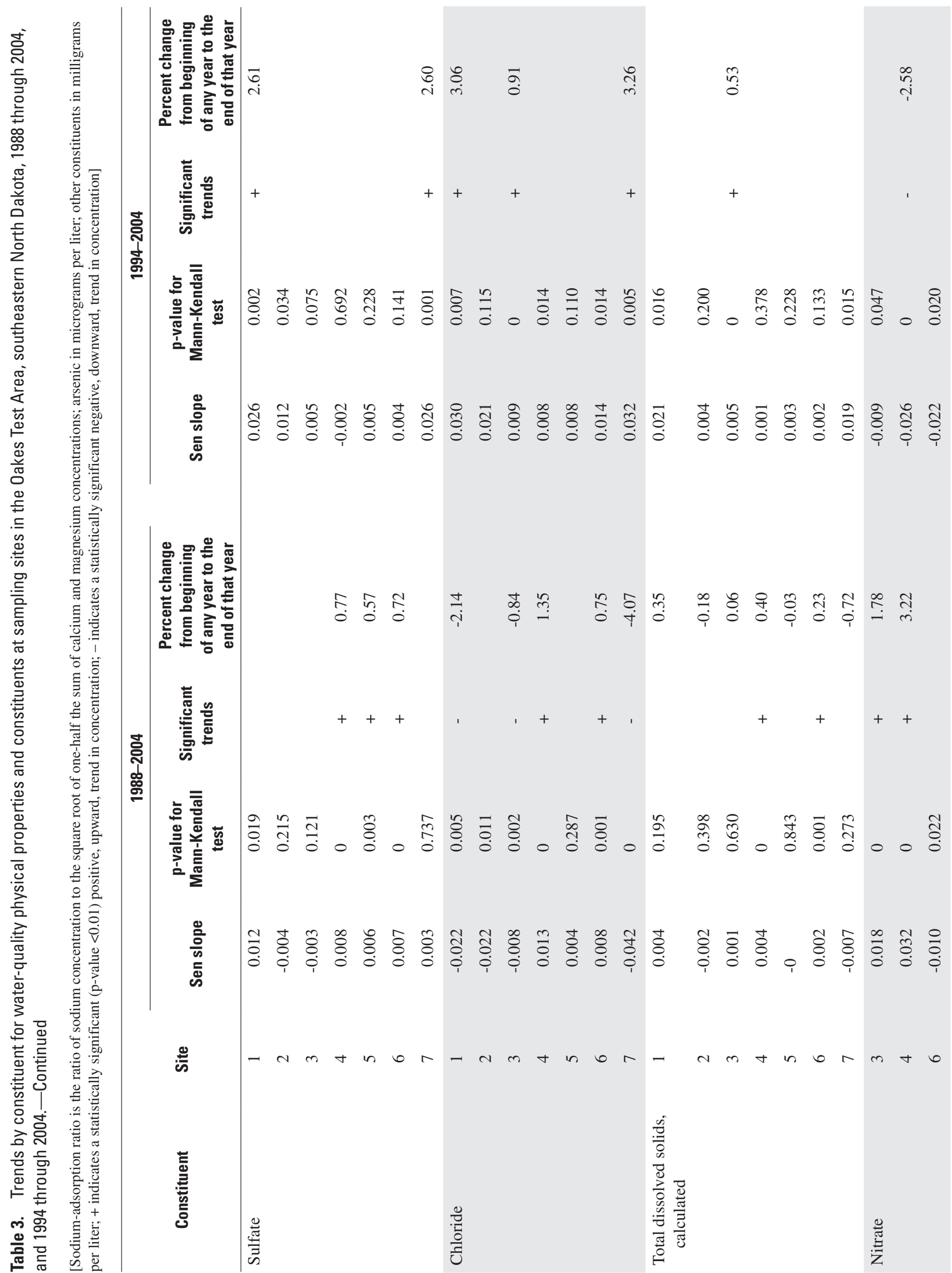


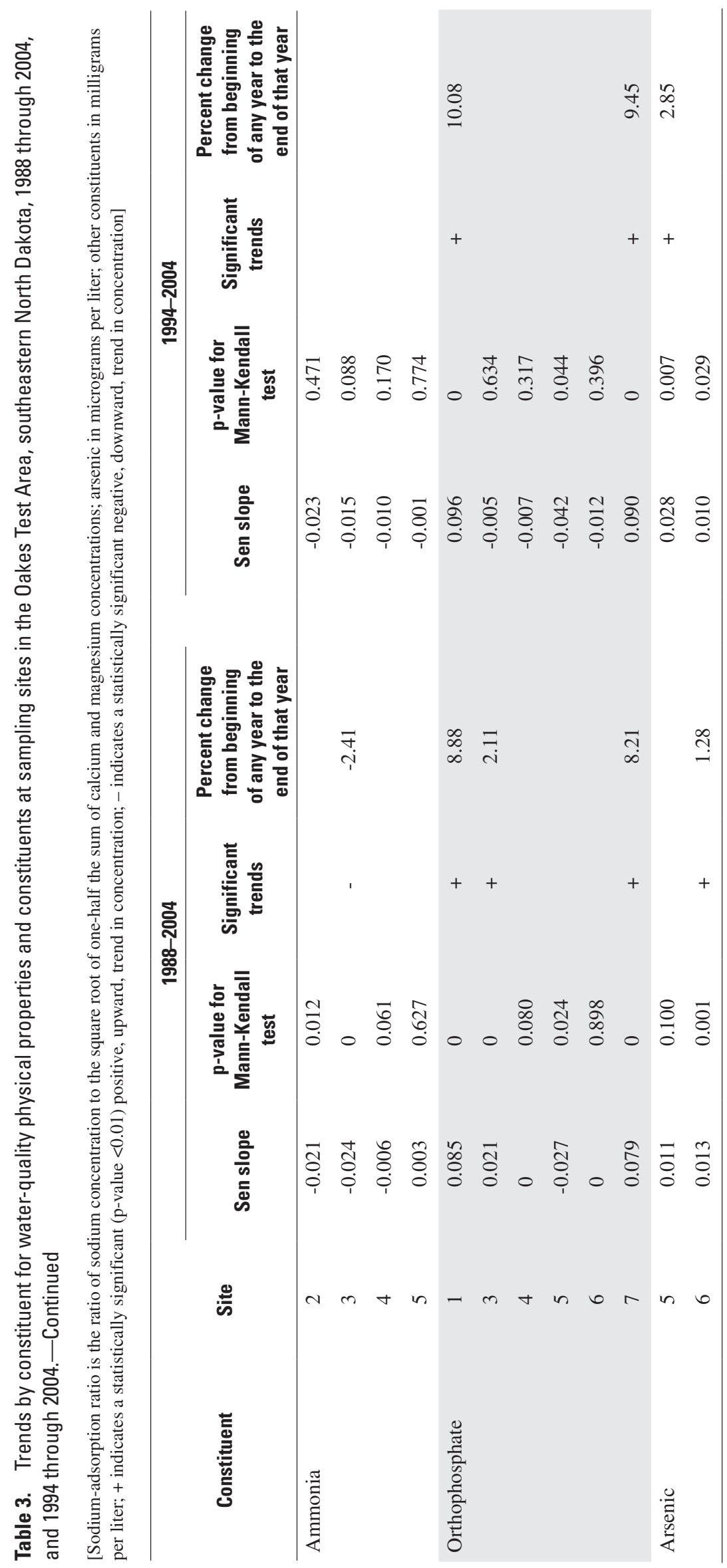



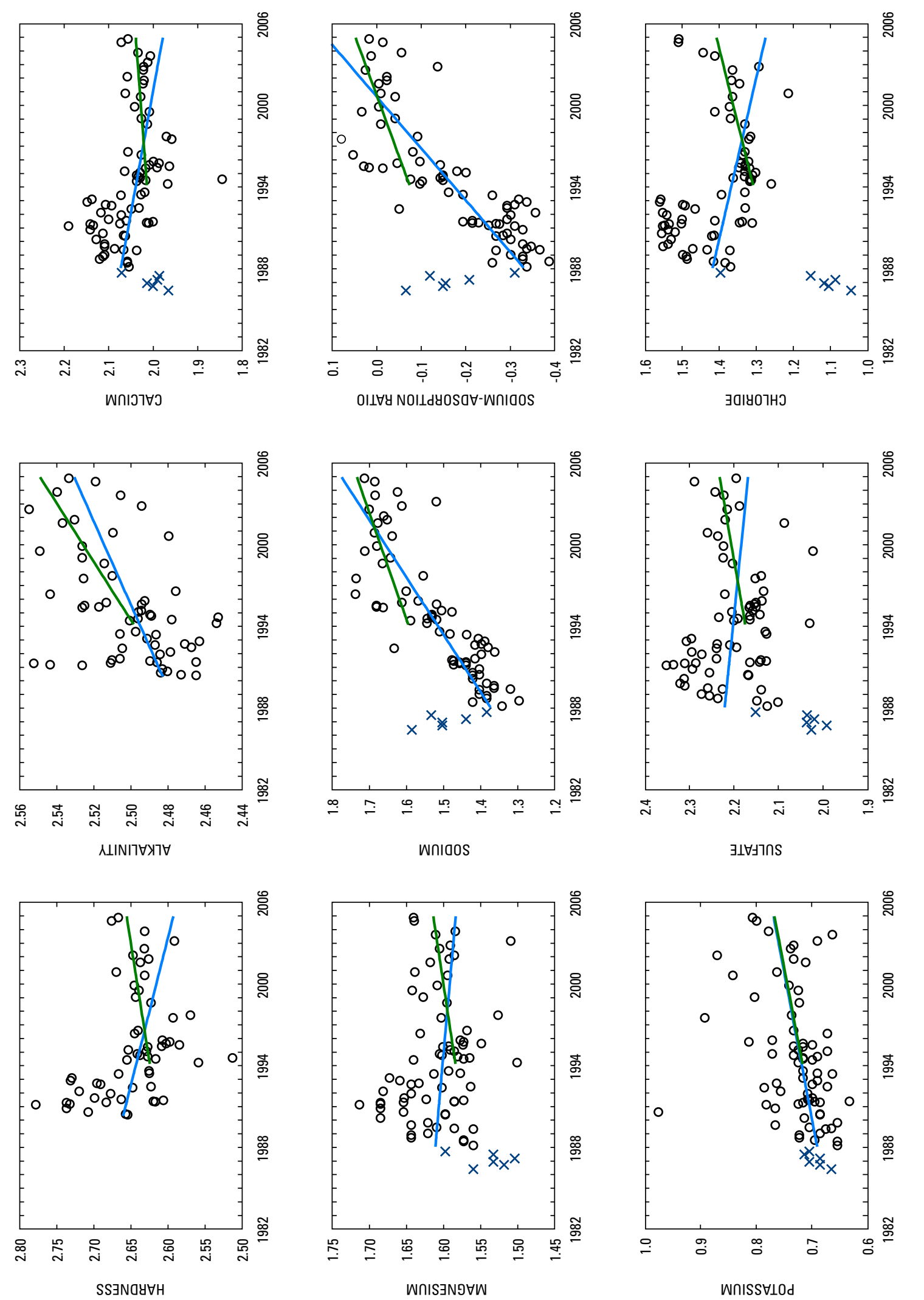

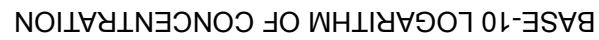



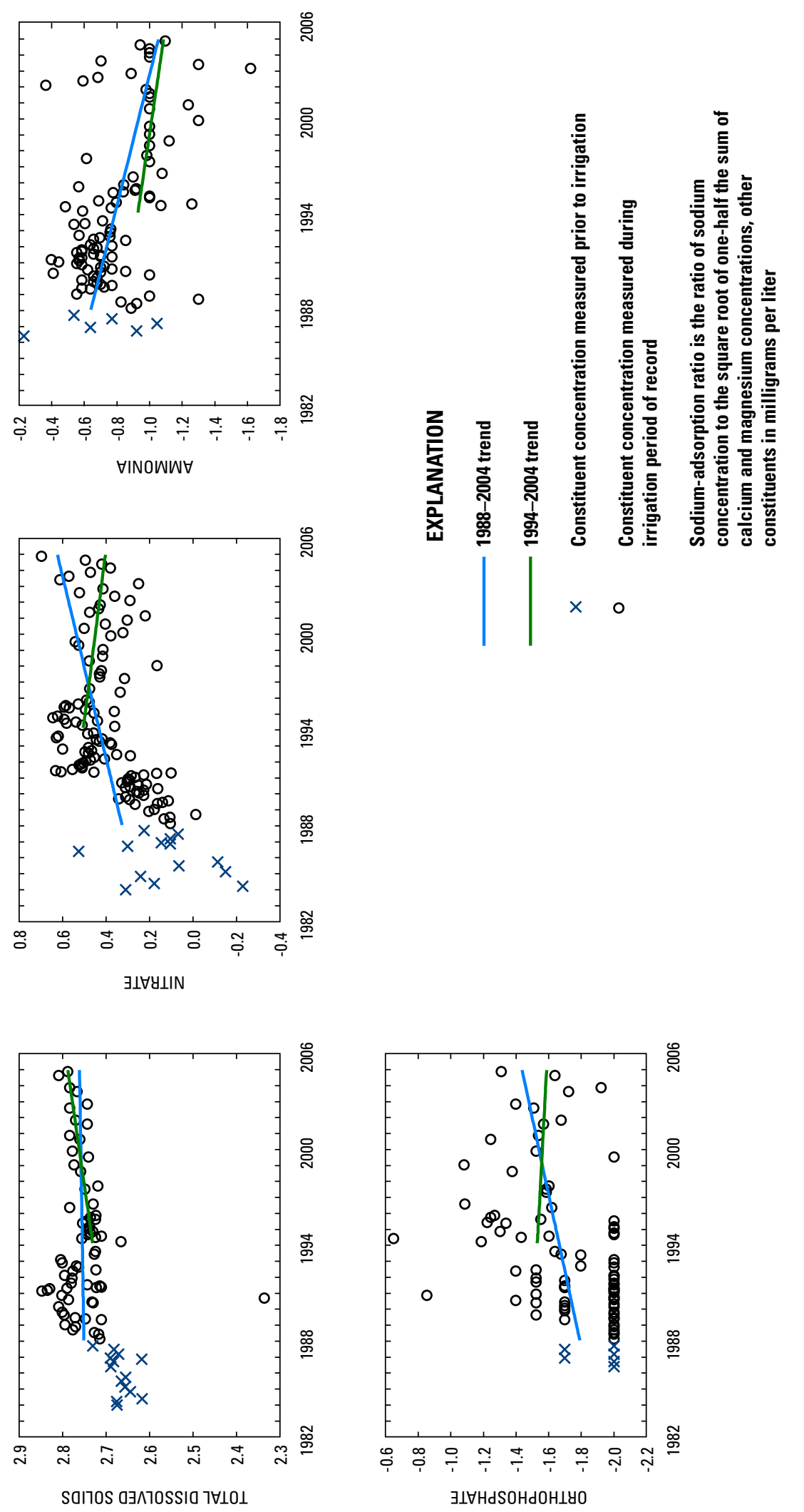

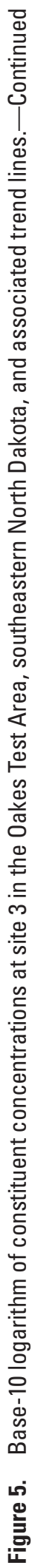

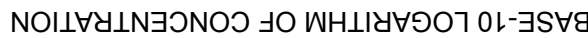


The orthophosphate graph (fig. 5) and trend test results (table 2 and 3) are examples of the Mann-Kendall test and Sen slope calculated for highly censored data. At site 3, orthophosphate was censored at 0.01 (base-10 logarithm -2.0). The positive sign of the slope for 1988-2004 appears to be correct because of the low, highly censored, concentrations early in the period of record. However, the magnitude of the slope is most likely not correct because the censored concentrations were actually lower than the LRL used to calculate the slope. Therefore, the actual slope may be steeper because of the low concentrations early in the period of record.

For 1988-2004, site 2 (fig. 2) has the fewest statistically significant trends (table 2) with 1 negative trend for magnesium, and site 3 has the most trends with 4 negative trends (hardness, calcium, chloride, and ammonia) and 6 positive trends (alkalinity, sodium, sodium-adsorption ratio, potassium, nitrate, and orthophosphate). Sites 4 and 6 have only positive trends, and sites 1 and 5 have both positive and negative trends. Both sites on the James River, sites 1 and 7 , have negative trends in chloride and positive trends in orthophosphate. All constituents have at least 1 significant trend, and no constituent has significant trends at all sampling sites (table 3 ).

For 1994-2004, more statistically significant trends were identified on the James River sites (sites 1 and 7) than for the entire irrigation period (1988-2004). All of the trends are positive, and with the exception of hardness, which is significant only at site 1 , the constituents with statistically significant upward trends are the same for both sites (magnesium, sodium, sodium-adsorption ratio, potassium, sulfate, chloride, and orthophosphate). For 1994-2004, sites 2 and 6 have no significant trends, site 3 has fewer significant trends than for 1988-2004 and all significant trends were positive, site 4 has 1 significant trend (downward for nitrate), and site 5 has 1 significant trend (upward for arsenic). Calcium and ammonia have no significant trends for 1994-2004 (table 3).

Comparison of sites 1 and 7 indicates that the contribution to the James River from Oakes Test Area drainage has little effect on water quality in the James River. For example, sites 4, 5, and 6 had statistically significant upward trends for sulfate for 1988-2004. Upstream from the Oakes Test Area, the James River at site 1 did not have a significant trend in sulfate. Downstream from the Oakes Test Area, the James River at site 7 did not have a significant trend in sulfate despite contribution from Oakes Test Area drainage. For 1994-2004, the Sen slope and p-values for sites 1 and 7 are almost identical in magnitude and all match in sign.

Because of their location (fig. 2), sites 2 and 3 would be expected to have similar trends. However, for 1988-2004 site 2 had only 1 significant trend (table 2 ) and site 3 had 10 significant trends (table 2). This may occur because of the difference in sampling period of record between the two sites (table 1). Site 3 has a longer sampling period of record and low concentrations early in the period that contribute to a positive slope for many of the constituents. Another difference between the two sites is that nitrate and orthophosphate were highly censored ( $>20$ percent) at site 2 and were not tested for trends.

Sites 4, 5, and 6 might be expected to have similar trends because of their locations. All three sites have a positive trend in sulfate for 1988-2004. Sodium and sodium-adsorption ratio have significant downward trends at site 5 for 1988-2004; the corresponding trends are positive at sites 4 and 6 but are not significant at either site. Sites 4 and 6 have significant positive trends in chloride and total dissolved solids for 1988-2004.

\section{Summary}

The Oakes Test Area is operated and maintained by the Garrison Diversion Conservancy District, under a cooperative agreement with the Bureau of Reclamation, to evaluate the effectiveness and environmental consequences of irrigation. As part of the evaluation, the Bureau of Reclamation collected water-quality samples from seven sites on the James River and the Oakes Test Area. The data were summarized and examined for trends in concentration during two periods, 1988-2004 and 1994-2004, by the U.S. Geological Survey in cooperation with the Bureau of Reclamation.

The nonparametric Mann-Kendall test was used to indicate whether concentration was increasing or decreasing with time for the water-quality physical properties and constituents hardness, alkalinity, calcium, magnesium, sodium, sodium-adsorption ratio, potassium, sulfate, chloride, total dissolved solids, nitrate, ammonia, orthophosphate, and arsenic. Not every physical property or constituent was tested at each site because at some sites sample size was too small or no samples were collected. A Sen slope was estimated for each trend. Trend results with a p-value less than 0.01 are considered statistically significant.

Significant trends varied by site, constituent, and time period. For the period 1988-2004 all sites and all constituents tested have at least 1 significant trend. Site 2 (fig. 2) has the fewest trends (table 3 ) with 1 negative trend (magnesium), and site 3 has the most trends, 4 negative trends (hardness, calcium, chloride, and ammonia) and 6 positive trends (alkalinity, sodium, sodium-adsorption ratio, potassium, nitrate, and orthophosphate). Sulfate, total dissolved solids, nitrate, orthophosphate have significant positive trends at multiple sites with no significant negative trend at any site. Ammonia has a single significant trend, downward at site 3 . Alkalinity and arsenic have single significant positive trends at sites 3 and 6, respectively. The remaining constituents have both upward and downward trends at multiple sites.

Fewer trends were identified for 1994-2004 than for 1988-2004. All statistically significant trends are positive, except for a negative trend in nitrate at site 4 . For chloride, the 
positive trend at sites 1,3 , and 7 is in contrast to an overall (1988-2004) negative trend at the same sites. The sign of a nitrate trend (site 4) also changed. The trend is negative for 1994-2004 and positive for 1988-2004.

The contribution to the James River from Oakes Test Area drainage appears to have little effect on water quality in the James River. Sites 4, 5, and 6 have statistically significant upward trends for sulfate for 1988-2004. Upstream from the Oakes Test Area, the James River at site 1 does not have a significant trend in sulfate. Downstream from the Oakes Test Area, the James River at site 7 does not have a significant trend in sulfate despite contribution from Oakes Test Area drainage. For 1994-2004, the Sen slope and p-values for sites 1 and 7 are almost identical in magnitude and all match in sign.

\section{References Cited}

Brigham, M.E., and Payne, G.A., 1999, Stream water-quality characteristics and trends, James River Basin, North Dakota, 1949-95: U.S. Geological Survey Water-Resources Investigations Report 99-4187, 129 p.

Garrison Diversion Conservancy District, 2004a, Operations and maintenance, Garrison Diversion Conservancy District, accessed December 19, 2006, at http://www.garrisondiv. org/pages/programs/om/index.epl

Garrison Diversion Conservancy District, 2004b, The Oakes Irrigation Test Area and agri-processing: Carrington, North Dakota, Garrison Diversion Conservancy District, accessed December 19, 2006, at http://www.garrisondiv.org/pages/ programs/agriculture/index.epl
Goolsby, D.A., Severson, R.C., Wilson, S.A., and Webber, Kurt, 1989, Geochemistry of soils and shallow ground water, with emphasis on arsenic and selenium, in part of the Garrison Diversion Unit, North Dakota, 1985-87: U.S. Geological Survey Water-Resources Investigations Report 89-4104, 132 p., accessed August 3, 2006, at http://pubs.er.usgs.gov/pubs/wri/wri894104

Helsel, D.R., 2005, Nondetects and data analysis-Statistics for censored environmental data: Hoboken, New Jersey, John Wiley \& Sons, Inc., 250 p.

Helsel, D.R., and Hirsch, R.M., 1992, Statistical methods in water resources: U.S. Geological Survey Techniques of Water-Resources Investigations, book 4, chap. A3, 510 p., accessed September 12, 2006, at http://pubs.usgs.gov/twri/ twri4a3/

Simonds, W.J., 1996, Jamestown Dam and Reservoir-A feature of the Garrison Diversion Unit Pick-Sloan Missouri Basin Program: U.S. Department of the Interior, Bureau of Reclamation Research on Historic Reclamation Projects, accessed August 3, 2006, at http://www.usbr.gov/dataweb/ html/jamestownh.html

U.S. Geological Survey [variously dated], USGS Library Reference for Release 3.1 of the U.S. Geological Survey S-PLUS library [variously paged].

Weckerly, Tessa, 2006, Garrison Diversion continues to support Oakes Test Area: North Dakota Water, v. 14, no. 6, p. 25-27.

Williams-Sether, Tara, 1999, From dry to wet, 1988-97, North Dakota: U.S. Geological Survey Fact Sheet FS-075-99, 4 p., accessed February 26, 2007, at http://pubs.er.usgs. gov/pubs/fs/fs07599 
This page intentionally left blank. 
Supplements 
Supplement 1. Drainflow at sampling sites 3,4 , and 6 in the Oakes Test Area, southeastern North Dakota, 1984 through 2004.

[Drainflow in cubic feet per second; --, no data]

\begin{tabular}{|c|c|c|c|}
\hline Date & Site 3 & Site 4 & Site 6 \\
\hline 01/04/1984 & 1.55 & -- & -- \\
\hline 03/29/1984 & 2.40 & -- & -- \\
\hline 05/14/1984 & 2.46 & -- & -- \\
\hline 05/23/1984 & 2.61 & -- & -- \\
\hline 08/22/1984 & 2.21 & 2.13 & -- \\
\hline 10/29/1984 & 2.96 & 2.08 & -- \\
\hline $12 / 07 / 1984$ & 2.76 & 2.16 & -- \\
\hline 01/03/1985 & 2.37 & 2.08 & -- \\
\hline $02 / 12 / 1985$ & 1.87 & 1.63 & -- \\
\hline 03/18/1985 & 2.27 & 2.08 & -- \\
\hline 04/10/1985 & 1.87 & 1.72 & -- \\
\hline 06/13/1985 & 2.60 & 1.77 & -- \\
\hline 06/25/1985 & 2.10 & 1.73 & -- \\
\hline 07/18/1985 & 0.48 & 1.44 & 1.00 \\
\hline 08/14/1985 & 0.32 & 1.20 & 1.11 \\
\hline 09/18/1985 & 0.86 & 1.03 & 2.51 \\
\hline $10 / 02 / 1985$ & 0.85 & 0.99 & 1.60 \\
\hline $10 / 28 / 1985$ & 0.98 & 0.93 & 1.58 \\
\hline $11 / 20 / 1985$ & 1.12 & 0.74 & 2.39 \\
\hline 01/30/1986 & 0.55 & 0.41 & 0.67 \\
\hline 02/24/1986 & 0.54 & 0.40 & 0.56 \\
\hline 03/19/1986 & 1.11 & 0.45 & 1.08 \\
\hline 04/30/1986 & 3.84 & 2.46 & 2.74 \\
\hline 05/13/1986 & 5.54 & 2.68 & 3.57 \\
\hline 05/19/1986 & 3.46 & 2.66 & 2.35 \\
\hline 05/30/1986 & 4.06 & 2.45 & 1.86 \\
\hline 06/06/1986 & 3.34 & 2.28 & 1.79 \\
\hline 06/13/1986 & 3.62 & 1.38 & 1.89 \\
\hline 06/20/1986 & 3.45 & 2.29 & 1.85 \\
\hline 07/03/1986 & 3.51 & 0.66 & 2.65 \\
\hline 07/18/1986 & 3.14 & 0.85 & 1.50 \\
\hline 07/25/1986 & 3.20 & 2.34 & 0.20 \\
\hline 08/01/1986 & 3.94 & 2.11 & 1.70 \\
\hline 08/08/1986 & 3.43 & 2.23 & 0.99 \\
\hline 08/15/1986 & 3.31 & 2.15 & 1.36 \\
\hline 08/25/1986 & 3.43 & 2.11 & 1.71 \\
\hline 08/29/1986 & 3.17 & 2.19 & 1.71 \\
\hline 09/05/1986 & 3.15 & 1.63 & 1.57 \\
\hline 09/12/1986 & 3.23 & 1.68 & 1.79 \\
\hline
\end{tabular}


Supplement 1. Drainflow at sampling sites 3, 4, and 6 in the Oakes Test Area, southeastern North Dakota, 1984 through 2004.-Continued

[Drainflow in cubic feet per second; --, no data]

\begin{tabular}{|c|c|c|c|}
\hline Date & Site 3 & Site 4 & Site 6 \\
\hline 09/24/1986 & 3.02 & 1.57 & 1.74 \\
\hline 10/03/1986 & 3.20 & 1.52 & 1.81 \\
\hline 10/10/1986 & 2.05 & 1.66 & 1.64 \\
\hline 10/17/1986 & 2.62 & 1.41 & 1.61 \\
\hline $10 / 24 / 1986$ & 2.88 & 1.52 & 1.81 \\
\hline 10/31/1986 & 2.92 & 1.34 & 1.67 \\
\hline 11/07/1986 & 2.99 & 1.45 & 1.37 \\
\hline 11/14/1986 & 2.94 & 1.36 & 1.87 \\
\hline $11 / 21 / 1986$ & 2.89 & 1.23 & 1.73 \\
\hline 12/01/1986 & 2.79 & 1.09 & 1.82 \\
\hline 12/05/1986 & 2.86 & 1.16 & 1.75 \\
\hline $12 / 10 / 1986$ & 1.95 & 1.11 & 1.91 \\
\hline 12/19/1986 & 2.31 & 0.93 & 1.71 \\
\hline 01/02/1987 & 2.32 & 0.87 & 1.56 \\
\hline 01/12/1987 & 2.08 & 0.76 & 1.60 \\
\hline 01/16/1987 & 2.47 & 0.65 & 1.51 \\
\hline 01/23/1987 & 1.86 & 0.77 & 1.46 \\
\hline 01/30/1987 & 1.82 & 0.58 & 1.30 \\
\hline 02/06/1987 & 1.90 & 0.47 & 1.33 \\
\hline 02/13/1987 & 1.64 & 0.59 & 1.52 \\
\hline 02/20/1987 & 1.70 & 0.59 & 1.17 \\
\hline 02/27/1987 & 1.58 & 0.56 & 1.33 \\
\hline 03/06/1987 & 1.64 & 0.06 & 1.20 \\
\hline 03/13/1987 & 1.73 & 0.62 & 1.42 \\
\hline 03/27/1987 & -- & 1.35 & -- \\
\hline 04/03/1987 & 0.25 & -- & 0.69 \\
\hline 04/13/1987 & -- & 3.16 & 1.33 \\
\hline 04/17/1987 & -- & -- & 1.36 \\
\hline 05/01/1987 & -- & -- & 1.96 \\
\hline 05/08/1987 & -- & -- & 2.29 \\
\hline 05/15/1987 & -- & -- & 1.70 \\
\hline 05/26/1987 & 1.66 & -- & 2.71 \\
\hline 05/29/1987 & 1.80 & -- & 2.51 \\
\hline 06/08/1987 & 1.15 & 1.14 & 1.96 \\
\hline 06/12/1987 & 1.20 & 0.78 & 1.65 \\
\hline 06/19/1987 & 0.89 & 0.88 & 1.69 \\
\hline 06/27/1987 & 0.77 & 0.97 & 1.29 \\
\hline 07/02/1987 & 0.75 & 0.69 & 0.26 \\
\hline 07/10/1987 & 0.67 & 0.62 & 0.24 \\
\hline
\end{tabular}


Supplement 1. Drainflow at sampling sites 3,4 , and 6 in the Oakes Test Area, southeastern North Dakota, 1984 through 2004.-Continued

[Drainflow in cubic feet per second; --, no data]

\begin{tabular}{|c|c|c|c|}
\hline Date & Site 3 & Site 4 & Site 6 \\
\hline 07/17/1987 & 0.49 & 0.57 & 0.23 \\
\hline 07/27/1987 & 0.46 & 0.41 & 1.44 \\
\hline 08/07/1987 & 0.38 & 0.34 & 0.08 \\
\hline 08/14/1987 & 0.31 & 0.25 & 0.31 \\
\hline 08/21/1987 & 0.22 & 0.30 & 0.76 \\
\hline 08/28/1987 & 0.30 & 0.28 & 0.78 \\
\hline 09/04/1987 & 0.25 & 0.27 & 0.70 \\
\hline 09/10/1987 & 0.29 & 0.32 & 0.54 \\
\hline 09/18/1987 & 0.28 & 0.20 & 0.56 \\
\hline 09/25/1987 & 0.24 & 0.31 & 0.48 \\
\hline 10/02/1987 & 0.30 & 0.46 & 0.48 \\
\hline 10/07/1987 & 0.35 & 0.50 & 0.55 \\
\hline $10 / 15 / 1987$ & 0.31 & 0.64 & 0.52 \\
\hline 10/23/1987 & 0.34 & 0.51 & 0.52 \\
\hline $10 / 30 / 1987$ & 0.24 & 0.44 & 0.56 \\
\hline 11/06/1987 & 0.31 & 0.38 & 0.46 \\
\hline 11/13/1987 & 0.35 & 0.34 & 0.37 \\
\hline $11 / 20 / 1987$ & 0.27 & 0.30 & 0.35 \\
\hline $12 / 04 / 1987$ & 0.31 & 0.28 & 0.44 \\
\hline 12/11/1987 & 0.33 & 0.27 & 0.35 \\
\hline $12 / 18 / 1987$ & 0.31 & 0.25 & 0.35 \\
\hline 01/15/1988 & 0.25 & -- & 0.30 \\
\hline 01/29/1988 & 0.20 & 0.04 & 0.21 \\
\hline 03/04/1988 & 0.15 & 0.07 & 0.23 \\
\hline 05/12/1988 & 0.31 & 0.45 & 0.52 \\
\hline 05/20/1988 & 0.16 & 0.24 & 0.32 \\
\hline 05/27/1988 & 0.20 & 0.20 & 0.38 \\
\hline 06/06/1988 & 0.22 & 0.35 & 0.40 \\
\hline 06/10/1988 & 0.18 & 0.20 & 0.38 \\
\hline 06/17/1988 & 0.24 & 0.12 & 0.37 \\
\hline 06/24/1988 & 0.22 & 0.14 & 0.46 \\
\hline 07/01/1988 & 0.15 & 0.11 & 0.54 \\
\hline 07/09/1988 & 0.17 & 0.09 & 0.55 \\
\hline 07/13/1988 & 0.15 & 0.09 & 0.50 \\
\hline $07 / 22 / 1988$ & 0.16 & 0.08 & 0.44 \\
\hline 07/29/1988 & 0.13 & 0.05 & 0.36 \\
\hline 08/05/1988 & 0.13 & 0.03 & 0.30 \\
\hline 08/12/1988 & 0.14 & 0.01 & 0.30 \\
\hline 08/19/1988 & 0.13 & 0.05 & 0.25 \\
\hline
\end{tabular}


Supplement 1. Drainflow at sampling sites 3,4 , and 6 in the Oakes Test Area, southeastern North Dakota, 1984 through 2004.-Continued

[Drainflow in cubic feet per second; --, no data]

\begin{tabular}{|c|c|c|c|}
\hline Date & Site 3 & Site 4 & Site 6 \\
\hline 08/26/1988 & 0.11 & 0.01 & 0.27 \\
\hline 09/06/1988 & 0.18 & 0.01 & 0.24 \\
\hline 09/14/1988 & 0.17 & 0.03 & 0.23 \\
\hline 09/23/1988 & 0.14 & 0.08 & 0.42 \\
\hline 09/30/1988 & 0.13 & 0.07 & 0.54 \\
\hline 10/11/1988 & 0.13 & 0.07 & 0.52 \\
\hline 10/14/1988 & 0.13 & 0.06 & 0.50 \\
\hline 10/21/1988 & 0.10 & 0.07 & 0.42 \\
\hline 10/28/1988 & 0.18 & 0.06 & 0.36 \\
\hline 11/04/1988 & 0.12 & 0.10 & 0.37 \\
\hline 11/09/1988 & 0.15 & 0.06 & 0.32 \\
\hline 11/18/1988 & 0.17 & 0.06 & 0.30 \\
\hline 11/30/1988 & 0.12 & 0.03 & 0.23 \\
\hline 12/09/1988 & 0.13 & 0.05 & 0.26 \\
\hline $12 / 16 / 1988$ & 0.15 & 0.05 & 0.30 \\
\hline 01/06/1989 & 0.09 & 0.03 & 0.19 \\
\hline 01/11/1989 & 0.01 & -- & 0.21 \\
\hline 02/24/1989 & 0.04 & 0.00 & 0.09 \\
\hline 03/24/1989 & 0.05 & 0.02 & 0.14 \\
\hline 04/05/1989 & 0.13 & 0.24 & 0.31 \\
\hline 04/14/1989 & 0.38 & -- & 1.34 \\
\hline 04/21/1989 & 0.33 & -- & 1.58 \\
\hline 04/28/1989 & 0.17 & -- & 0.91 \\
\hline 05/10/1989 & 0.19 & -- & 0.72 \\
\hline 05/17/1989 & 0.14 & -- & 0.95 \\
\hline 05/24/1989 & 0.14 & -- & 0.32 \\
\hline 05/31/1989 & 0.13 & -- & 0.44 \\
\hline 06/07/1989 & 0.11 & -- & 0.45 \\
\hline 06/14/1989 & 0.10 & -- & 0.38 \\
\hline 06/19/1989 & 0.18 & 0.11 & 0.48 \\
\hline 06/20/1989 & 0.18 & 0.05 & 0.52 \\
\hline 06/22/1989 & 0.18 & 0.06 & 0.47 \\
\hline 06/27/1989 & 0.18 & 0.03 & 0.46 \\
\hline 07/05/1989 & 0.13 & 0.08 & 0.16 \\
\hline 07/12/1989 & 0.12 & 0.10 & 0.12 \\
\hline 07/19/1989 & 0.11 & 0.02 & 0.14 \\
\hline 07/25/1989 & 0.12 & 0.03 & 0.12 \\
\hline 08/02/1989 & 0.10 & 0.05 & 0.11 \\
\hline 08/09/1989 & 0.10 & 0.03 & 0.10 \\
\hline
\end{tabular}


Supplement 1. Drainflow at sampling sites 3,4 , and 6 in the Oakes Test Area, southeastern North Dakota, 1984 through 2004.-Continued

[Drainflow in cubic feet per second; --, no data]

\begin{tabular}{|c|c|c|c|}
\hline Date & Site 3 & Site 4 & Site 6 \\
\hline 08/15/1989 & 0.08 & 0.00 & 0.09 \\
\hline 08/23/1989 & 0.08 & 0.02 & 0.08 \\
\hline 08/29/1989 & 0.16 & 0.03 & 0.13 \\
\hline 09/08/1989 & 0.14 & 0.00 & 0.09 \\
\hline 09/13/1989 & 0.15 & 0.03 & 0.10 \\
\hline 09/19/1989 & 0.15 & 0.00 & 0.10 \\
\hline 09/26/1989 & 0.14 & 0.00 & 0.10 \\
\hline 10/03/1989 & 0.13 & 0.03 & 0.12 \\
\hline 10/10/1989 & 0.14 & 0.00 & 0.18 \\
\hline 10/18/1989 & 0.15 & 0.02 & 0.11 \\
\hline 10/24/1989 & 0.15 & 0.00 & 0.14 \\
\hline 11/01/1989 & 0.12 & 0.03 & 0.12 \\
\hline 11/08/1989 & 0.14 & 0.02 & 0.12 \\
\hline 11/15/1989 & 0.12 & 0.04 & 0.14 \\
\hline $11 / 21 / 1989$ & 0.10 & -- & 0.16 \\
\hline 11/29/1989 & 0.05 & 0.12 & 0.17 \\
\hline $12 / 05 / 1989$ & 0.11 & 0.12 & 0.14 \\
\hline $12 / 12 / 1989$ & 0.10 & 0.12 & 0.14 \\
\hline 01/02/1990 & 0.04 & -- & 0.11 \\
\hline 01/24/1990 & 0.10 & 0.03 & 0.10 \\
\hline 03/01/1990 & 0.09 & 0.05 & 0.10 \\
\hline 03/13/1990 & 0.10 & 0.14 & 0.10 \\
\hline 03/21/1990 & 0.10 & 0.07 & 0.11 \\
\hline 03/29/1990 & 0.08 & 0.11 & 0.12 \\
\hline 04/03/1990 & 0.09 & 0.10 & 0.14 \\
\hline 04/09/1990 & 0.09 & 0.10 & 0.14 \\
\hline 04/19/1990 & 0.06 & 0.82 & 0.16 \\
\hline 04/24/1990 & 0.12 & 0.62 & 0.18 \\
\hline 04/30/1990 & 0.17 & 0.58 & 0.55 \\
\hline 05/07/1990 & 0.12 & 0.53 & 0.59 \\
\hline 05/14/1990 & 0.18 & 0.49 & 0.47 \\
\hline 05/21/1990 & 0.18 & 0.15 & 0.45 \\
\hline 05/29/1990 & 0.21 & 0.20 & 0.48 \\
\hline 06/05/1990 & 0.22 & 0.19 & 0.63 \\
\hline 06/11/1990 & 0.18 & 0.15 & 0.60 \\
\hline 06/18/1990 & 0.16 & 0.24 & 0.69 \\
\hline 06/25/1990 & 0.18 & 0.21 & 0.66 \\
\hline 07/02/1990 & 0.12 & 0.20 & 0.52 \\
\hline 07/09/1990 & 0.14 & 0.13 & 0.17 \\
\hline
\end{tabular}


Supplement 1. Drainflow at sampling sites 3,4 , and 6 in the Oakes Test Area, southeastern North Dakota, 1984 through 2004.-Continued

[Drainflow in cubic feet per second; --, no data]

\begin{tabular}{|c|c|c|c|}
\hline Date & Site 3 & Site 4 & Site 6 \\
\hline 07/16/1990 & 0.14 & 0.12 & 0.16 \\
\hline 07/23/1990 & 0.13 & 0.10 & 0.11 \\
\hline 07/30/1990 & 0.11 & 0.11 & 0.09 \\
\hline 08/06/1990 & 0.10 & 0.10 & 0.09 \\
\hline 08/13/1990 & 0.10 & 0.10 & 0.07 \\
\hline 08/20/1990 & 0.08 & 0.09 & 0.06 \\
\hline 08/27/1990 & 0.07 & 0.11 & 0.07 \\
\hline 09/05/1990 & 0.11 & 0.09 & 0.10 \\
\hline 09/11/1990 & 0.10 & 0.09 & 0.08 \\
\hline 09/17/1990 & 0.08 & 0.07 & 0.05 \\
\hline 09/24/1990 & 0.09 & 0.09 & 0.07 \\
\hline 10/01/1990 & 0.08 & 0.08 & 0.08 \\
\hline 10/09/1990 & 0.09 & 0.08 & 0.08 \\
\hline 10/15/1990 & 0.08 & 0.09 & 0.08 \\
\hline $10 / 23 / 1990$ & 0.10 & 0.12 & 0.11 \\
\hline 10/29/1990 & 0.08 & 0.12 & 0.10 \\
\hline 11/05/1990 & 0.10 & 0.10 & 0.09 \\
\hline 11/14/1990 & 0.11 & 0.10 & 0.08 \\
\hline 11/19/1990 & 0.11 & 0.10 & 0.11 \\
\hline $11 / 26 / 1990$ & 0.11 & 0.10 & 0.10 \\
\hline 12/03/1990 & 0.10 & 0.09 & 0.11 \\
\hline $12 / 10 / 1990$ & 0.11 & 0.10 & 0.10 \\
\hline 12/17/1990 & 0.11 & 0.10 & 0.11 \\
\hline 01/07/1991 & 0.00 & 0.02 & 0.00 \\
\hline 01/14/1991 & 0.00 & 0.01 & 0.07 \\
\hline 01/22/1991 & 0.00 & 0.03 & 0.07 \\
\hline 01/28/1991 & 0.06 & 0.02 & 0.07 \\
\hline 02/04/1991 & 0.00 & 0.00 & 0.07 \\
\hline 02/11/1991 & 0.02 & 0.03 & 0.06 \\
\hline 02/19/1991 & 0.02 & 0.02 & 0.06 \\
\hline 02/25/1991 & 0.02 & 0.03 & 0.07 \\
\hline 03/04/1991 & 0.02 & 0.02 & 0.07 \\
\hline 03/11/1991 & 0.04 & 0.02 & 0.07 \\
\hline 03/18/1991 & 0.05 & 0.01 & 0.06 \\
\hline 03/25/1991 & 0.07 & 0.06 & 0.09 \\
\hline 04/01/1991 & 0.07 & 0.07 & 0.10 \\
\hline 04/08/1991 & 0.08 & 0.06 & 0.09 \\
\hline 04/15/1991 & 0.10 & 0.13 & 0.17 \\
\hline 04/22/1991 & 0.10 & 0.10 & 0.12 \\
\hline
\end{tabular}


Supplement 1. Drainflow at sampling sites 3,4 , and 6 in the Oakes Test Area, southeastern North Dakota, 1984 through 2004.-Continued

[Drainflow in cubic feet per second; --, no data]

\begin{tabular}{|c|c|c|c|}
\hline Date & Site 3 & Site 4 & Site 6 \\
\hline 04/29/1991 & 0.11 & 0.10 & 0.13 \\
\hline 05/01/1991 & 0.15 & 0.10 & 1.45 \\
\hline 05/02/1991 & 0.19 & 0.11 & 1.50 \\
\hline 05/03/1991 & 0.19 & 0.11 & 1.41 \\
\hline 05/06/1991 & 0.26 & 0.11 & 1.69 \\
\hline 05/08/1991 & 0.27 & 0.12 & 1.68 \\
\hline 05/09/1991 & 0.27 & 0.13 & 1.65 \\
\hline 05/10/1991 & 0.27 & 0.13 & 1.71 \\
\hline 05/13/1991 & 0.26 & 0.13 & 1.71 \\
\hline 05/16/1991 & 0.35 & 0.18 & 0.84 \\
\hline 05/20/1991 & 0.32 & 0.31 & 0.85 \\
\hline 05/23/1991 & 0.31 & 0.32 & 0.95 \\
\hline 05/28/1991 & 0.23 & 0.32 & 0.83 \\
\hline 05/30/1991 & 0.29 & 0.41 & 0.89 \\
\hline 06/03/1991 & 0.29 & 0.38 & 0.90 \\
\hline 06/10/1991 & 0.43 & 0.48 & 0.99 \\
\hline 06/18/1991 & 0.36 & 0.53 & 0.87 \\
\hline 06/24/1991 & 0.48 & 0.64 & 1.43 \\
\hline 07/01/1991 & 0.59 & 0.75 & 1.25 \\
\hline 07/08/1991 & 0.36 & 0.60 & 1.02 \\
\hline 07/15/1991 & 0.33 & 0.61 & 0.50 \\
\hline $07 / 22 / 1991$ & 0.25 & 0.44 & 0.74 \\
\hline 07/29/1991 & 0.25 & 0.41 & 0.66 \\
\hline 08/05/1991 & 0.21 & 0.36 & 0.73 \\
\hline 08/12/1991 & 0.18 & 0.30 & 0.49 \\
\hline 08/19/1991 & 0.16 & 0.26 & 0.26 \\
\hline 08/26/1991 & 0.17 & 0.13 & 0.19 \\
\hline 09/03/1991 & 0.13 & 0.13 & 0.11 \\
\hline 09/09/1991 & 0.12 & 0.12 & 0.10 \\
\hline 09/16/1991 & 0.14 & 0.12 & 0.12 \\
\hline 09/23/1991 & 0.11 & 0.11 & 0.12 \\
\hline 09/30/1991 & 0.12 & 0.08 & 0.12 \\
\hline 10/07/1991 & 0.10 & 0.07 & 0.10 \\
\hline 10/15/1991 & 0.14 & 0.07 & 0.12 \\
\hline 10/21/1991 & 0.13 & 0.07 & 0.11 \\
\hline 10/28/1991 & 0.09 & 0.06 & 0.14 \\
\hline 11/04/1991 & 0.14 & 0.10 & 0.15 \\
\hline $11 / 12 / 1991$ & 0.12 & 0.11 & 0.16 \\
\hline 11/18/1991 & 0.10 & 0.14 & 0.15 \\
\hline
\end{tabular}


Supplement 1. Drainflow at sampling sites 3, 4, and 6 in the Oakes Test Area, southeastern North Dakota, 1984 through 2004.-Continued

[Drainflow in cubic feet per second; --, no data]

\begin{tabular}{|c|c|c|c|}
\hline Date & Site 3 & Site 4 & Site 6 \\
\hline $11 / 25 / 1991$ & 0.14 & 0.10 & 0.17 \\
\hline $12 / 02 / 1991$ & 0.13 & 0.11 & 0.15 \\
\hline 12/09/1991 & 0.13 & 0.08 & 0.15 \\
\hline $12 / 16 / 1991$ & 0.13 & 0.06 & 0.14 \\
\hline 01/06/1992 & 0.10 & 0.07 & 0.11 \\
\hline 01/13/1992 & 0.09 & 0.05 & 0.12 \\
\hline 01/21/1992 & 0.10 & 0.03 & 0.10 \\
\hline 01/27/1992 & 0.07 & 0.04 & 0.09 \\
\hline 02/03/1992 & 0.09 & 0.02 & 0.10 \\
\hline 02/10/1992 & 0.08 & 0.03 & 0.10 \\
\hline 02/18/1992 & 0.08 & 0.04 & 0.07 \\
\hline 02/24/1992 & 0.08 & 0.03 & 0.09 \\
\hline 03/02/1992 & 0.13 & 0.01 & 0.09 \\
\hline 03/09/1992 & 0.22 & 0.05 & 0.15 \\
\hline 03/16/1992 & 0.15 & 0.07 & 0.13 \\
\hline 03/23/1992 & 0.18 & 0.08 & 0.17 \\
\hline 03/30/1992 & 0.22 & 0.11 & 0.28 \\
\hline 04/06/1992 & 0.22 & 0.16 & 0.36 \\
\hline 04/13/1992 & 0.25 & 0.18 & 0.41 \\
\hline 04/20/1992 & 0.26 & 0.20 & 0.46 \\
\hline 04/27/1992 & 0.23 & 0.23 & 0.44 \\
\hline 05/04/1992 & 0.19 & 0.48 & 0.44 \\
\hline 05/11/1992 & 0.20 & 0.32 & 0.42 \\
\hline 05/18/1992 & 0.19 & 0.46 & 0.38 \\
\hline 05/26/1992 & 0.63 & 0.90 & 0.59 \\
\hline 06/01/1992 & 0.35 & 0.92 & 0.65 \\
\hline 06/08/1992 & 1.27 & 0.63 & 0.61 \\
\hline 06/15/1992 & 0.71 & 0.53 & 0.41 \\
\hline 06/22/1992 & 0.91 & 0.72 & 1.12 \\
\hline 06/29/1992 & 0.70 & 0.65 & 0.97 \\
\hline 07/06/1992 & 0.92 & 0.80 & 1.25 \\
\hline 07/13/1992 & 0.71 & 0.91 & 1.09 \\
\hline 07/20/1992 & 0.50 & 0.70 & 0.95 \\
\hline 07/27/1992 & 0.25 & 0.58 & 0.76 \\
\hline 08/03/1992 & 0.26 & 1.04 & 1.03 \\
\hline 08/10/1992 & 0.18 & 0.91 & 0.77 \\
\hline 08/17/1992 & 0.17 & 0.83 & 0.51 \\
\hline 08/24/1992 & 0.14 & 0.63 & 0.57 \\
\hline 08/31/1992 & 0.15 & 0.56 & 0.31 \\
\hline
\end{tabular}


Supplement 1. Drainflow at sampling sites 3,4 , and 6 in the Oakes Test Area, southeastern North Dakota, 1984 through 2004.-Continued

[Drainflow in cubic feet per second; --, no data]

\begin{tabular}{|c|c|c|c|}
\hline Date & Site 3 & Site 4 & Site 6 \\
\hline 09/08/1992 & 0.15 & 0.57 & 0.60 \\
\hline 09/14/1992 & 0.17 & 0.54 & 0.47 \\
\hline 09/21/1992 & 0.16 & 0.60 & 0.34 \\
\hline 09/28/1992 & 0.16 & 0.52 & 0.28 \\
\hline 10/06/1992 & 0.17 & 0.49 & 0.27 \\
\hline 10/13/1992 & 0.15 & 0.52 & 0.31 \\
\hline 10/19/1992 & 0.56 & 0.53 & 0.31 \\
\hline 10/26/1992 & 0.35 & 0.43 & 0.21 \\
\hline 11/02/1992 & 0.30 & 0.49 & 0.33 \\
\hline 11/09/1992 & 0.30 & 0.49 & 0.38 \\
\hline 11/16/1992 & 0.32 & 0.60 & 0.48 \\
\hline $11 / 23 / 1992$ & 0.30 & 0.58 & 0.51 \\
\hline 11/30/1992 & 0.29 & 0.58 & 0.56 \\
\hline 12/07/1992 & 0.24 & 0.48 & 0.44 \\
\hline 12/14/1992 & 0.24 & 0.51 & 0.43 \\
\hline $12 / 21 / 1992$ & 0.20 & 0.47 & 0.30 \\
\hline 12/29/1992 & 0.17 & 0.41 & 0.17 \\
\hline 01/04/1993 & 0.19 & 0.29 & 0.13 \\
\hline 01/11/1993 & 0.18 & 0.27 & 0.03 \\
\hline 01/18/1993 & 0.19 & 0.35 & 0.09 \\
\hline 01/25/1993 & 0.19 & 0.32 & 0.13 \\
\hline 02/01/1993 & 0.18 & 0.25 & 0.10 \\
\hline 02/08/1993 & 0.18 & 0.27 & 0.13 \\
\hline 02/16/1993 & 0.15 & 0.21 & 0.08 \\
\hline 02/22/1993 & 0.15 & 0.18 & 0.08 \\
\hline 03/01/1993 & 0.12 & 0.23 & 0.07 \\
\hline 03/08/1993 & 0.14 & 0.21 & 0.08 \\
\hline 03/16/1993 & 0.14 & 0.18 & 0.08 \\
\hline 03/22/1993 & 0.16 & 0.14 & 0.09 \\
\hline 03/29/1993 & 0.31 & 0.32 & 0.47 \\
\hline 03/31/1993 & 0.25 & 0.46 & 0.56 \\
\hline 04/02/1993 & 0.27 & 0.42 & 0.64 \\
\hline 04/05/1993 & 0.29 & 0.51 & 0.68 \\
\hline 04/08/1993 & 0.27 & 0.57 & 0.81 \\
\hline 04/12/1993 & 0.31 & 0.76 & 1.02 \\
\hline 04/14/1993 & 0.35 & 0.79 & 1.07 \\
\hline 04/16/1993 & 0.37 & 0.85 & 1.08 \\
\hline 04/19/1993 & 0.34 & 0.87 & 1.00 \\
\hline 04/21/1993 & 0.36 & 0.69 & 1.10 \\
\hline
\end{tabular}


Supplement 1. Drainflow at sampling sites 3,4 , and 6 in the Oakes Test Area, southeastern North Dakota, 1984 through 2004.-Continued

[Drainflow in cubic feet per second; --, no data]

\begin{tabular}{|c|c|c|c|}
\hline Date & Site 3 & Site 4 & Site 6 \\
\hline 04/23/1993 & 0.36 & 0.76 & 1.13 \\
\hline 04/26/1993 & 0.40 & 0.85 & 1.17 \\
\hline 04/28/1993 & 0.38 & 0.86 & 1.29 \\
\hline 04/30/1993 & 0.38 & 0.95 & 1.09 \\
\hline 05/03/1993 & 0.37 & 0.89 & 1.06 \\
\hline 05/05/1993 & 0.37 & 0.93 & 0.99 \\
\hline 05/07/1993 & 0.48 & 1.04 & 1.13 \\
\hline 05/10/1993 & 0.48 & 0.95 & 1.12 \\
\hline 05/14/1993 & 0.40 & 0.83 & 1.07 \\
\hline 05/17/1993 & 0.38 & 0.83 & 1.12 \\
\hline 05/19/1993 & 0.33 & 0.80 & 0.86 \\
\hline 05/21/1993 & 0.30 & 0.78 & 1.00 \\
\hline 05/24/1993 & 0.51 & 0.88 & 1.19 \\
\hline 05/28/1993 & 0.57 & 0.86 & 1.13 \\
\hline 06/01/1993 & 0.78 & 0.93 & 1.26 \\
\hline 06/04/1993 & 0.71 & 0.90 & 1.17 \\
\hline 06/07/1993 & 0.83 & 0.95 & 1.20 \\
\hline 06/10/1993 & 0.89 & 1.20 & 1.32 \\
\hline 06/14/1993 & 0.78 & 0.90 & 1.15 \\
\hline 06/17/1993 & 0.97 & 0.94 & 1.19 \\
\hline 06/21/1993 & 1.24 & 0.98 & 1.37 \\
\hline 06/24/1993 & 1.19 & 1.06 & 1.24 \\
\hline 06/29/1993 & 1.07 & 1.00 & 1.29 \\
\hline 07/06/1993 & 1.51 & 1.19 & 1.48 \\
\hline 07/12/1993 & 1.28 & 1.04 & 1.39 \\
\hline 07/15/1993 & 1.32 & 1.08 & 1.38 \\
\hline 07/19/1993 & 2.44 & 1.66 & 1.81 \\
\hline $07 / 22 / 1993$ & 2.04 & 1.64 & 1.55 \\
\hline 07/26/1993 & 1.88 & 1.56 & 1.57 \\
\hline 07/28/1993 & 2.58 & 1.50 & 1.23 \\
\hline 07/30/1993 & 2.26 & 1.34 & 1.13 \\
\hline 08/02/1993 & 2.42 & 1.25 & 1.04 \\
\hline 08/05/1993 & 2.32 & 1.20 & 1.01 \\
\hline 08/09/1993 & 2.07 & 1.11 & 0.97 \\
\hline 08/12/1993 & 2.01 & 1.04 & 0.91 \\
\hline 08/16/1993 & 1.98 & 0.88 & 0.91 \\
\hline 08/23/1993 & 1.76 & 0.85 & 0.88 \\
\hline 08/30/1993 & 1.62 & 0.68 & 0.69 \\
\hline 09/08/1993 & 1.44 & 0.63 & 0.57 \\
\hline
\end{tabular}


Supplement 1. Drainflow at sampling sites 3,4 , and 6 in the Oakes Test Area, southeastern North Dakota, 1984 through 2004.-Continued

[Drainflow in cubic feet per second; --, no data]

\begin{tabular}{|c|c|c|c|}
\hline Date & Site 3 & Site 4 & Site 6 \\
\hline 09/14/1993 & 1.13 & 0.58 & 0.50 \\
\hline 09/20/1993 & 0.57 & 0.53 & 0.41 \\
\hline 09/27/1993 & 0.71 & 0.55 & 0.53 \\
\hline 10/04/1993 & 0.58 & 0.48 & 0.44 \\
\hline $10 / 12 / 1993$ & 0.53 & 0.51 & 0.37 \\
\hline 10/18/1993 & 0.52 & 0.48 & 0.37 \\
\hline $10 / 25 / 1993$ & 0.55 & 0.51 & 0.40 \\
\hline 11/01/1993 & 0.57 & 0.48 & 0.43 \\
\hline 11/08/1993 & 0.34 & 0.45 & 0.34 \\
\hline 11/15/1993 & 0.45 & 0.46 & 0.36 \\
\hline $11 / 23 / 1993$ & 0.45 & 0.43 & 0.42 \\
\hline $12 / 16 / 1993$ & 0.36 & 0.44 & 0.48 \\
\hline $12 / 20 / 1993$ & 0.36 & 0.41 & 0.46 \\
\hline 02/17/1994 & 0.20 & 0.34 & 0.26 \\
\hline 03/22/1994 & 2.03 & 1.29 & 1.53 \\
\hline 03/28/1994 & 1.45 & 1.45 & 1.26 \\
\hline 03/29/1994 & 2.17 & 1.45 & 1.51 \\
\hline 04/01/1994 & 2.32 & 1.59 & 1.51 \\
\hline 04/04/1994 & 2.45 & 1.61 & 1.79 \\
\hline 04/11/1994 & 2.54 & 1.54 & 1.90 \\
\hline 04/18/1994 & 2.77 & 1.54 & 1.84 \\
\hline 04/25/1994 & 2.78 & 1.56 & 1.89 \\
\hline 05/02/1994 & 2.99 & 1.85 & 2.08 \\
\hline 05/09/1994 & 2.96 & 1.78 & 2.17 \\
\hline 05/16/1994 & 2.91 & 1.69 & 2.25 \\
\hline 05/23/1994 & 2.72 & 1.59 & 2.15 \\
\hline 05/31/1994 & 2.71 & 1.32 & 2.13 \\
\hline 06/06/1994 & 1.50 & 1.41 & 2.19 \\
\hline 06/13/1994 & 0.87 & 1.19 & 1.93 \\
\hline 06/20/1994 & 1.37 & 1.12 & 2.11 \\
\hline 06/27/1994 & 1.40 & 1.07 & 1.82 \\
\hline 07/05/1994 & 1.66 & 0.96 & 1.88 \\
\hline 07/11/1994 & 3.00 & 2.00 & 2.32 \\
\hline 07/18/1994 & 2.68 & 1.69 & 2.15 \\
\hline 07/25/1994 & 1.17 & 1.67 & 1.94 \\
\hline 08/01/1994 & 0.55 & 1.36 & 1.90 \\
\hline 08/08/1994 & 1.35 & 1.06 & 1.33 \\
\hline 08/15/1994 & 1.49 & 0.97 & 1.63 \\
\hline 08/22/1994 & 1.29 & 0.87 & 1.56 \\
\hline
\end{tabular}


Supplement 1. Drainflow at sampling sites 3, 4, and 6 in the Oakes Test Area, southeastern North Dakota, 1984 through 2004.-Continued

[Drainflow in cubic feet per second; --, no data]

\begin{tabular}{|c|c|c|c|}
\hline Date & Site 3 & Site 4 & Site 6 \\
\hline 08/29/1994 & 1.65 & 0.87 & 1.54 \\
\hline 09/06/1994 & 1.74 & 0.85 & 1.62 \\
\hline 09/12/1994 & 1.63 & 0.78 & 1.67 \\
\hline 09/19/1994 & 1.75 & 1.16 & 1.87 \\
\hline 09/26/1994 & 1.90 & 1.10 & 1.94 \\
\hline $10 / 03 / 1994$ & 1.64 & 1.02 & 1.82 \\
\hline 10/11/1994 & 1.90 & 1.27 & 1.97 \\
\hline 10/19/1994 & 2.38 & 1.62 & 2.52 \\
\hline $10 / 24 / 1994$ & 2.51 & 1.61 & 2.26 \\
\hline 10/31/1994 & 2.45 & 1.49 & 2.14 \\
\hline 11/07/1994 & 2.47 & 1.48 & 2.18 \\
\hline 11/14/1994 & 2.30 & 1.39 & 2.01 \\
\hline $11 / 21 / 1994$ & 2.34 & 1.36 & 2.06 \\
\hline $11 / 28 / 1994$ & 2.26 & 1.60 & 2.00 \\
\hline $12 / 05 / 1994$ & 2.05 & 1.44 & 1.91 \\
\hline $12 / 19 / 1994$ & 1.81 & 1.35 & 1.81 \\
\hline 01/03/1995 & 1.62 & 1.18 & 1.80 \\
\hline 01/09/1995 & 1.55 & 1.01 & 1.60 \\
\hline 01/17/1995 & 1.37 & 1.00 & 1.72 \\
\hline 01/23/1995 & 1.36 & 0.90 & 1.69 \\
\hline 01/30/1995 & 1.59 & 0.94 & 1.64 \\
\hline 02/06/1995 & 1.49 & 0.93 & 1.59 \\
\hline 02/13/1995 & 1.30 & 0.80 & 1.59 \\
\hline 02/21/1995 & 1.21 & 0.82 & 1.48 \\
\hline 02/27/1995 & 1.03 & 0.74 & 1.47 \\
\hline 03/06/1995 & 1.04 & -- & -- \\
\hline 03/13/1995 & 1.93 & -- & 1.50 \\
\hline 04/04/1995 & 2.26 & 1.44 & 1.82 \\
\hline 04/24/1995 & 2.64 & 1.91 & 1.82 \\
\hline 05/01/1995 & 2.92 & 1.98 & 1.95 \\
\hline 05/08/1995 & 2.70 & 1.94 & 1.98 \\
\hline 06/06/1995 & 2.20 & 1.89 & 1.92 \\
\hline 06/15/1995 & 2.32 & 1.68 & 1.70 \\
\hline 06/28/1995 & 2.71 & 1.57 & 1.79 \\
\hline 07/12/1995 & 2.64 & 1.41 & 1.10 \\
\hline 07/28/1995 & 2.83 & 1.33 & 1.76 \\
\hline 08/09/1995 & 1.48 & 1.27 & 1.65 \\
\hline 08/24/1995 & 2.04 & 1.05 & 1.59 \\
\hline 09/06/1995 & 2.08 & 0.92 & 1.56 \\
\hline
\end{tabular}


Supplement 1. Drainflow at sampling sites 3,4 , and 6 in the Oakes Test Area, southeastern North Dakota, 1984 through 2004.-Continued

[Drainflow in cubic feet per second; --, no data]

\begin{tabular}{|c|c|c|c|}
\hline Date & Site 3 & Site 4 & Site 6 \\
\hline 09/20/1995 & 2.02 & 0.74 & 1.39 \\
\hline $10 / 12 / 1995$ & 2.83 & 1.45 & 2.09 \\
\hline $10 / 26 / 1995$ & 2.75 & 1.43 & 1.99 \\
\hline 11/09/1995 & 2.71 & 1.48 & 2.30 \\
\hline $11 / 22 / 1995$ & 2.45 & 1.31 & 1.68 \\
\hline $12 / 14 / 1995$ & 2.10 & 1.09 & 1.43 \\
\hline 01/08/1996 & 1.88 & 1.01 & 1.87 \\
\hline 02/06/1996 & 1.28 & -- & 1.42 \\
\hline 03/18/1996 & 1.51 & 1.39 & 1.20 \\
\hline 04/24/1996 & 2.07 & 1.01 & 1.45 \\
\hline 05/13/1996 & 2.04 & 1.56 & 1.73 \\
\hline 06/04/1996 & 3.02 & 1.61 & 1.85 \\
\hline 06/18/1996 & 3.26 & 1.61 & 2.07 \\
\hline 07/15/1996 & 2.99 & 1.50 & 1.82 \\
\hline 08/23/1996 & 1.98 & 1.11 & 1.12 \\
\hline 09/10/1996 & 2.54 & 1.33 & 2.14 \\
\hline 10/23/1996 & 2.77 & 1.50 & 2.13 \\
\hline $12 / 02 / 1996$ & 2.91 & 1.40 & 1.97 \\
\hline 01/01/1997 & 3.02 & 1.45 & 1.81 \\
\hline 02/06/1997 & 1.97 & 1.25 & 1.51 \\
\hline 03/12/1997 & 3.00 & 1.01 & 1.60 \\
\hline 03/25/1997 & 1.67 & 1.15 & 0.99 \\
\hline 04/21/1997 & 1.95 & 1.82 & -- \\
\hline 05/20/1997 & 2.77 & 1.64 & 1.55 \\
\hline 07/02/1997 & 2.89 & 1.61 & 1.55 \\
\hline 08/04/1997 & 3.06 & 1.41 & 2.06 \\
\hline 09/04/1997 & 3.41 & 1.26 & 2.00 \\
\hline 10/07/1997 & 3.20 & 1.34 & 1.05 \\
\hline 10/31/1997 & 3.16 & 1.57 & 1.94 \\
\hline 12/16/1997 & 3.15 & 1.32 & 1.86 \\
\hline 01/14/1998 & 3.03 & 1.11 & 2.06 \\
\hline 02/09/1998 & 3.09 & 0.93 & 1.44 \\
\hline 04/14/1998 & 3.22 & 1.74 & 1.99 \\
\hline 05/06/1998 & 3.67 & 1.84 & 2.32 \\
\hline 06/10/1998 & 3.95 & 1.91 & 2.38 \\
\hline 06/23/1998 & 4.06 & 2.05 & 2.72 \\
\hline 07/21/1998 & 3.29 & 1.73 & 2.08 \\
\hline 08/17/1998 & 3.04 & 1.66 & 2.13 \\
\hline 09/01/1998 & 3.16 & 1.75 & 1.93 \\
\hline
\end{tabular}


Supplement 1. Drainflow at sampling sites 3,4 , and 6 in the Oakes Test Area, southeastern North Dakota, 1984 through 2004.-Continued

[Drainflow in cubic feet per second; --, no data]

\begin{tabular}{|c|c|c|c|}
\hline Date & Site 3 & Site 4 & Site 6 \\
\hline 09/30/1998 & 2.99 & 1.51 & 1.93 \\
\hline 11/02/1998 & 3.61 & 1.85 & 1.80 \\
\hline 11/30/1998 & 3.80 & 1.76 & 2.12 \\
\hline 12/15/1998 & 3.80 & 1.45 & 1.61 \\
\hline 01/13/1999 & 2.92 & 1.18 & 1.64 \\
\hline 02/08/1999 & 2.82 & 1.25 & 1.06 \\
\hline 03/10/1999 & 3.04 & 1.44 & 1.08 \\
\hline 04/12/1999 & 2.80 & 1.30 & 1.45 \\
\hline 05/26/1999 & 2.80 & 1.24 & 1.60 \\
\hline 06/22/1999 & 3.12 & 1.64 & 1.91 \\
\hline 08/04/1999 & 2.71 & 1.56 & 1.39 \\
\hline 09/02/1999 & 3.22 & 1.56 & 1.65 \\
\hline 10/01/1999 & 3.13 & 1.49 & 1.65 \\
\hline 12/06/1999 & 3.09 & 1.45 & 1.49 \\
\hline $01 / 24 / 2000$ & 2.89 & 1.67 & 1.51 \\
\hline 03/27/2000 & 3.17 & 1.41 & 1.90 \\
\hline 04/19/2000 & 2.94 & 1.42 & 1.64 \\
\hline 05/02/2000 & 2.90 & 1.37 & 1.57 \\
\hline 05/15/2000 & 2.94 & 1.50 & 1.77 \\
\hline 06/01/2000 & 2.99 & 1.42 & 1.67 \\
\hline 06/13/2000 & 2.90 & 1.71 & 1.50 \\
\hline 07/10/2000 & 3.38 & 1.75 & 2.10 \\
\hline 08/08/2000 & 3.25 & 1.70 & 1.44 \\
\hline 09/14/2000 & 3.02 & 1.60 & 1.62 \\
\hline $12 / 01 / 2000$ & 2.99 & 1.61 & 1.77 \\
\hline 01/08/2001 & 3.12 & 1.36 & 1.47 \\
\hline 02/20/2001 & 2.95 & 1.24 & 1.47 \\
\hline 03/14/2001 & 2.96 & 1.27 & 1.52 \\
\hline 04/18/2001 & 2.17 & 1.43 & 1.26 \\
\hline 05/02/2001 & 2.95 & 1.64 & 1.70 \\
\hline 05/25/2001 & 3.32 & 1.68 & 2.05 \\
\hline $07 / 12 / 2001$ & 2.96 & 1.52 & 1.71 \\
\hline 08/01/2001 & 3.17 & 1.43 & 1.85 \\
\hline 09/05/2001 & 2.83 & 1.36 & 1.74 \\
\hline $11 / 02 / 2001$ & 2.48 & 2.41 & 1.50 \\
\hline $12 / 07 / 2001$ & 3.25 & 1.89 & 1.29 \\
\hline $12 / 27 / 2001$ & 3.04 & 1.83 & 1.17 \\
\hline $02 / 13 / 2002$ & 2.80 & 1.45 & 1.27 \\
\hline 03/13/2002 & 3.07 & 1.29 & 1.50 \\
\hline
\end{tabular}


Supplement 1. Drainflow at sampling sites 3,4 , and 6 in the Oakes Test Area, southeastern North Dakota, 1984 through 2004.-Continued

[Drainflow in cubic feet per second; --, no data]

\begin{tabular}{|c|c|c|c|}
\hline Date & Site 3 & Site 4 & Site 6 \\
\hline 04/09/2002 & 2.63 & 1.33 & 1.43 \\
\hline $04 / 25 / 2002$ & 2.18 & 1.47 & 1.44 \\
\hline $05 / 15 / 2002$ & 2.53 & 1.13 & 1.64 \\
\hline 06/14/2002 & 2.50 & 1.15 & 1.56 \\
\hline 06/27/2002 & 3.06 & 1.89 & 1.73 \\
\hline 07/04/2002 & 2.87 & 1.94 & 1.72 \\
\hline 07/11/2002 & 2.81 & 1.93 & 1.76 \\
\hline 07/16/2002 & 2.93 & 1.73 & 1.70 \\
\hline 07/23/2002 & 3.24 & 1.66 & 1.65 \\
\hline 07/30/2002 & 3.28 & 1.80 & 1.74 \\
\hline 08/06/2002 & 3.10 & 1.71 & 1.73 \\
\hline 08/13/2002 & 3.37 & 1.73 & 1.95 \\
\hline 08/20/2002 & 3.17 & 1.94 & 1.67 \\
\hline 08/27/2002 & 3.40 & 1.77 & 1.85 \\
\hline 09/04/2002 & 3.43 & 1.86 & 1.78 \\
\hline 09/20/2002 & 3.25 & 1.51 & 1.71 \\
\hline $11 / 20 / 2002$ & 2.88 & 1.38 & 1.37 \\
\hline $12 / 16 / 2002$ & 2.62 & 1.92 & 1.18 \\
\hline $02 / 26 / 2003$ & 1.67 & 1.15 & 1.14 \\
\hline 03/27/2003 & 1.41 & 1.17 & 0.98 \\
\hline 04/04/2003 & 1.51 & 1.14 & 1.31 \\
\hline $04 / 11 / 2003$ & 1.51 & 1.11 & 1.31 \\
\hline $04 / 17 / 2003$ & 1.38 & 1.07 & 1.17 \\
\hline $04 / 24 / 2003$ & 1.57 & 1.23 & 1.56 \\
\hline $04 / 30 / 2003$ & 1.95 & 1.46 & 1.52 \\
\hline 05/06/2003 & 2.23 & 1.69 & 1.64 \\
\hline 05/13/2003 & 3.39 & 1.88 & 1.64 \\
\hline $05 / 20 / 2003$ & 3.40 & 2.19 & 2.17 \\
\hline $05 / 28 / 2003$ & 3.45 & 2.44 & 2.25 \\
\hline 06/03/2003 & 3.33 & 2.31 & 1.85 \\
\hline 06/10/2003 & 3.23 & 2.30 & 1.85 \\
\hline $06 / 17 / 2003$ & 3.48 & 2.12 & 1.92 \\
\hline $06 / 24 / 2003$ & 3.36 & 1.98 & 2.02 \\
\hline 07/01/2003 & 3.33 & 2.10 & 2.18 \\
\hline 07/08/2003 & 3.23 & 2.16 & 2.03 \\
\hline
\end{tabular}


Supplement 1. Drainflow at sampling sites 3,4 , and 6 in the Oakes Test Area, southeastern North Dakota, 1984 through 2004.-Continued

[Drainflow in cubic feet per second; --, no data]

\begin{tabular}{|c|c|c|c|}
\hline Date & Site 3 & Site 4 & Site 6 \\
\hline $07 / 15 / 2003$ & 3.05 & 1.78 & 1.84 \\
\hline $07 / 22 / 2003$ & 3.11 & 2.01 & 1.72 \\
\hline $08 / 14 / 2003$ & 2.88 & 1.98 & 1.37 \\
\hline $08 / 20 / 2003$ & 2.93 & 1.93 & 1.43 \\
\hline 09/04/2003 & 3.00 & 1.75 & 1.39 \\
\hline $09 / 15 / 2003$ & 2.64 & 1.82 & 1.23 \\
\hline $11 / 19 / 2003$ & 2.57 & -- & 1.16 \\
\hline $01 / 22 / 2004$ & 1.75 & 0.97 & 1.04 \\
\hline $03 / 23 / 2004$ & 1.35 & 0.49 & 0.82 \\
\hline $04 / 05 / 2004$ & 1.38 & 0.58 & 1.36 \\
\hline $04 / 13 / 2004$ & 1.46 & 0.62 & 1.20 \\
\hline $04 / 22 / 2004$ & 1.37 & 0.63 & 1.39 \\
\hline $04 / 27 / 2004$ & 1.34 & 0.57 & 1.41 \\
\hline $05 / 04 / 2004$ & 1.37 & 0.57 & 1.36 \\
\hline $05 / 12 / 2004$ & 1.30 & 0.63 & 1.47 \\
\hline 05/18/2004 & 1.42 & 0.66 & 1.55 \\
\hline $05 / 27 / 2004$ & 1.36 & 0.75 & 1.49 \\
\hline $06 / 03 / 2004$ & 2.99 & 2.16 & 1.67 \\
\hline 06/09/2004 & 3.13 & 2.12 & 1.68 \\
\hline $06 / 16 / 2004$ & 3.12 & 2.17 & 1.70 \\
\hline $06 / 23 / 2004$ & 3.28 & 2.12 & 1.81 \\
\hline $07 / 01 / 2004$ & 2.65 & 2.09 & 1.75 \\
\hline 07/09/2004 & 2.86 & 2.14 & 1.81 \\
\hline 07/13/2004 & 3.26 & 2.23 & 1.89 \\
\hline $07 / 23 / 2004$ & 2.91 & 2.12 & 1.87 \\
\hline $07 / 30 / 2004$ & 2.69 & 1.94 & 1.58 \\
\hline 08/05/2004 & 2.48 & 1.89 & 1.37 \\
\hline $08 / 12 / 2004$ & 2.30 & 1.84 & 1.32 \\
\hline 08/18/2004 & 2.16 & 1.61 & 1.33 \\
\hline $08 / 25 / 2004$ & 2.00 & 1.54 & 1.45 \\
\hline 09/01/2004 & 1.92 & 1.39 & 1.64 \\
\hline 09/08/2004 & 2.00 & 1.34 & 1.53 \\
\hline 09/15/2004 & 2.23 & 1.25 & 1.39 \\
\hline $11 / 18 / 2004$ & 3.16 & 1.55 & 1.42 \\
\hline
\end{tabular}




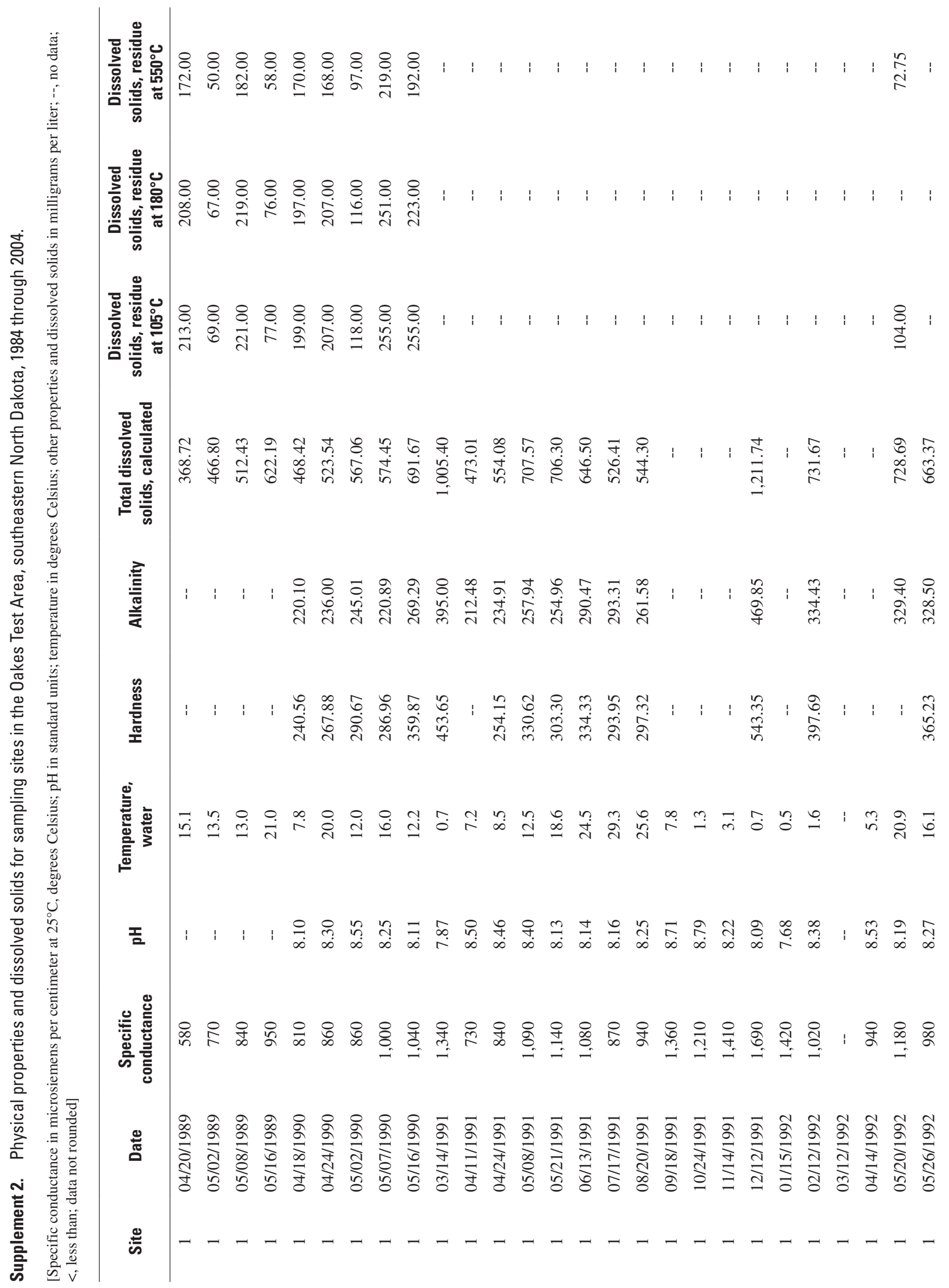




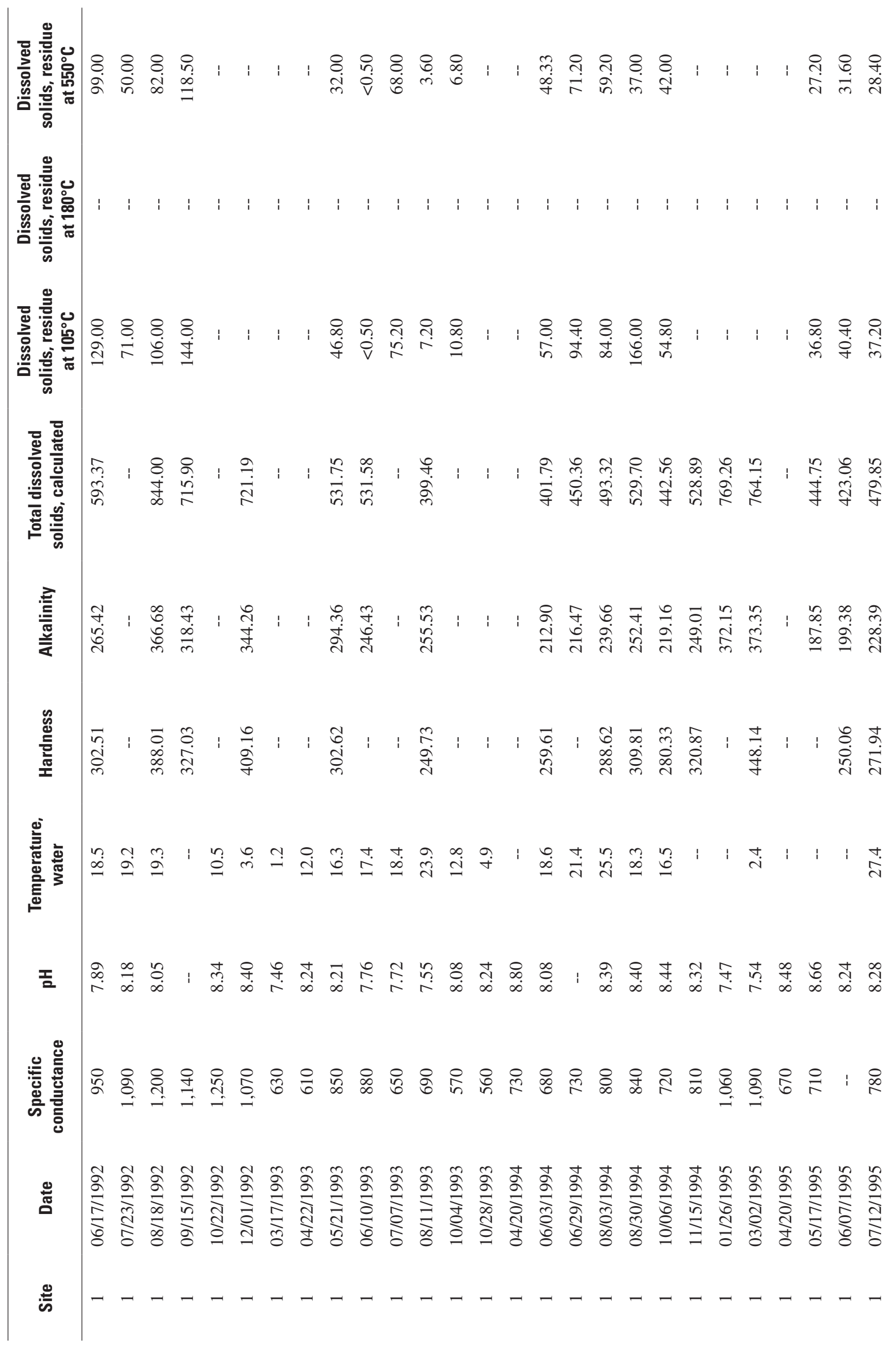




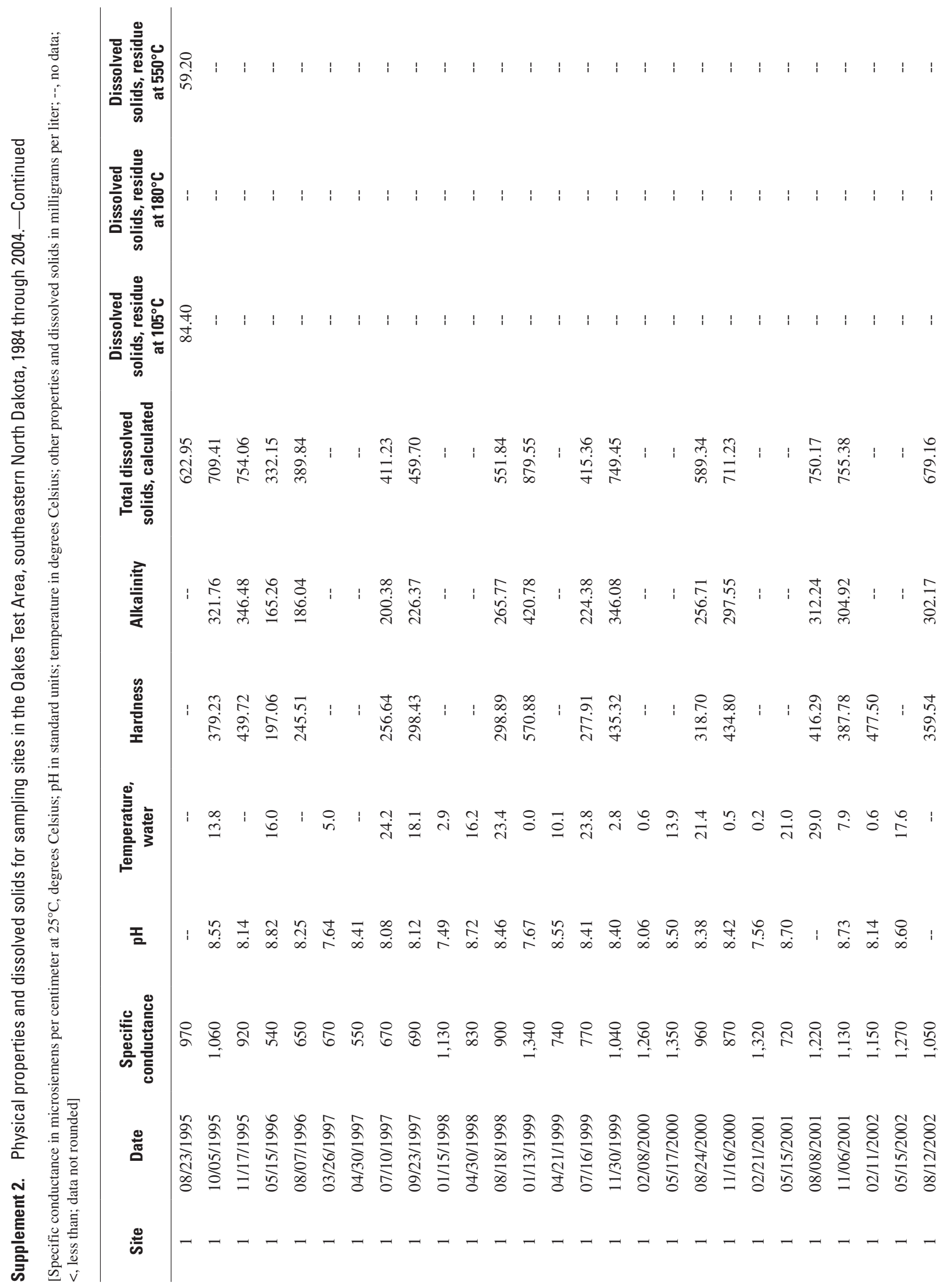




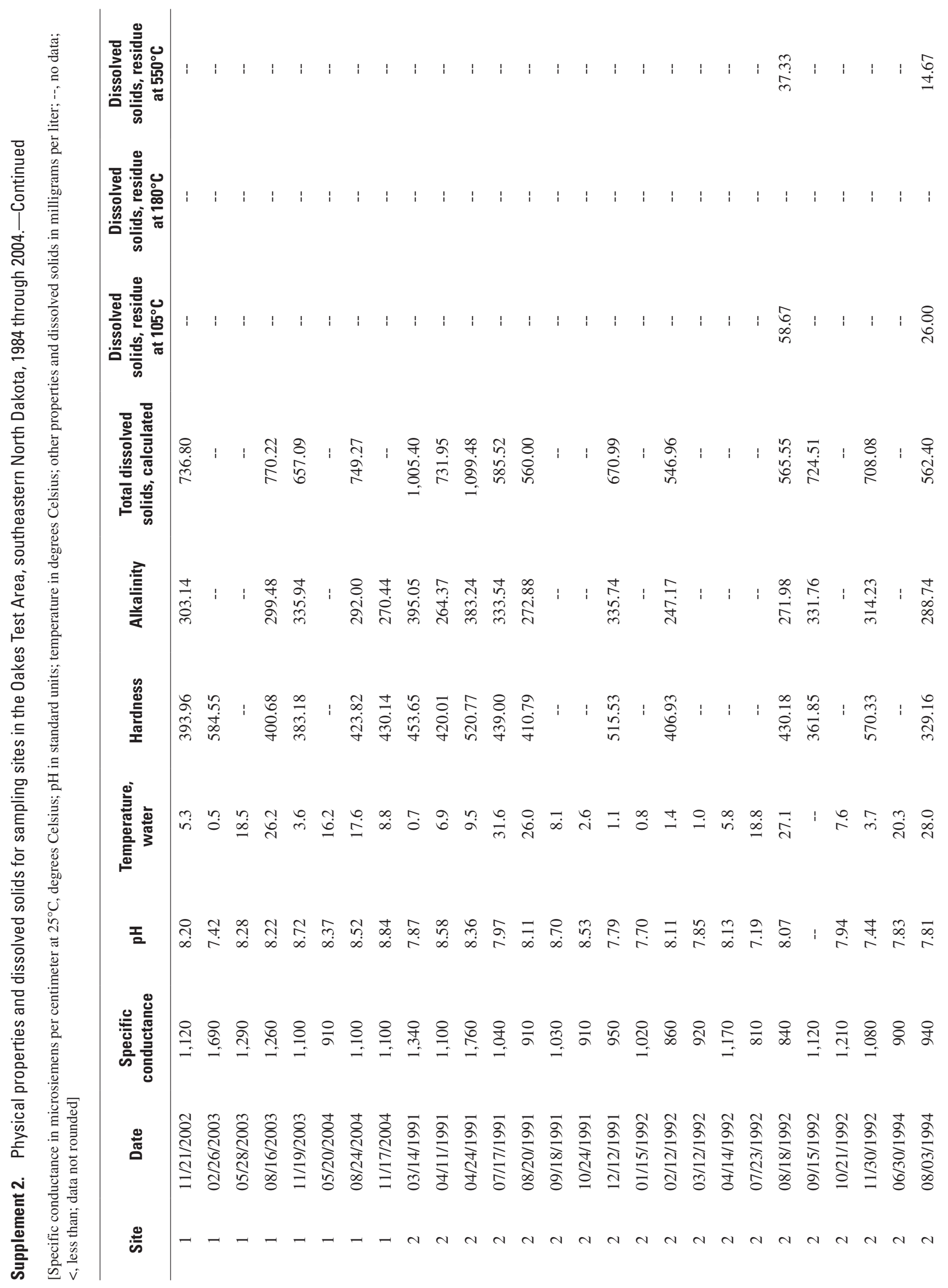




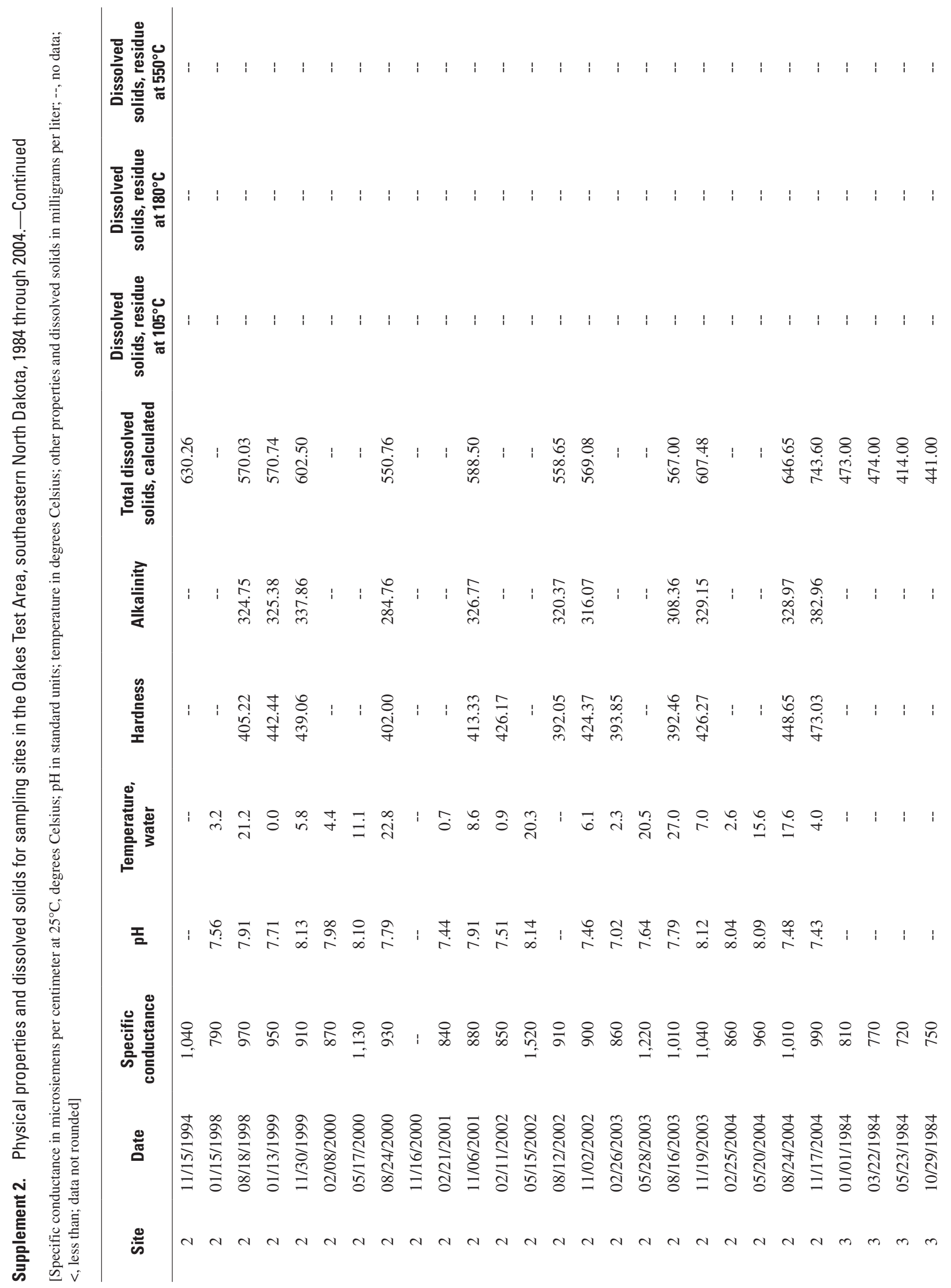




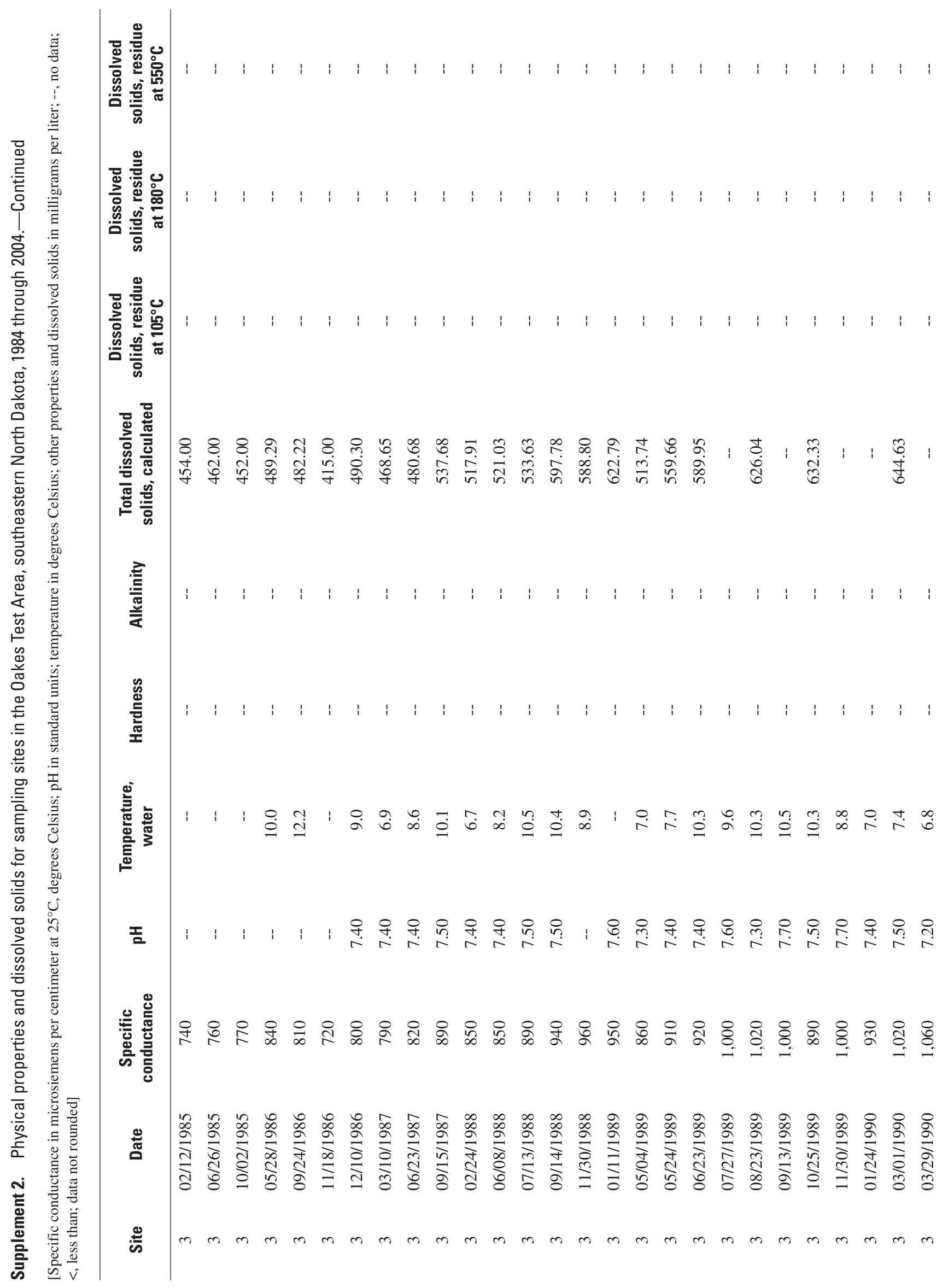




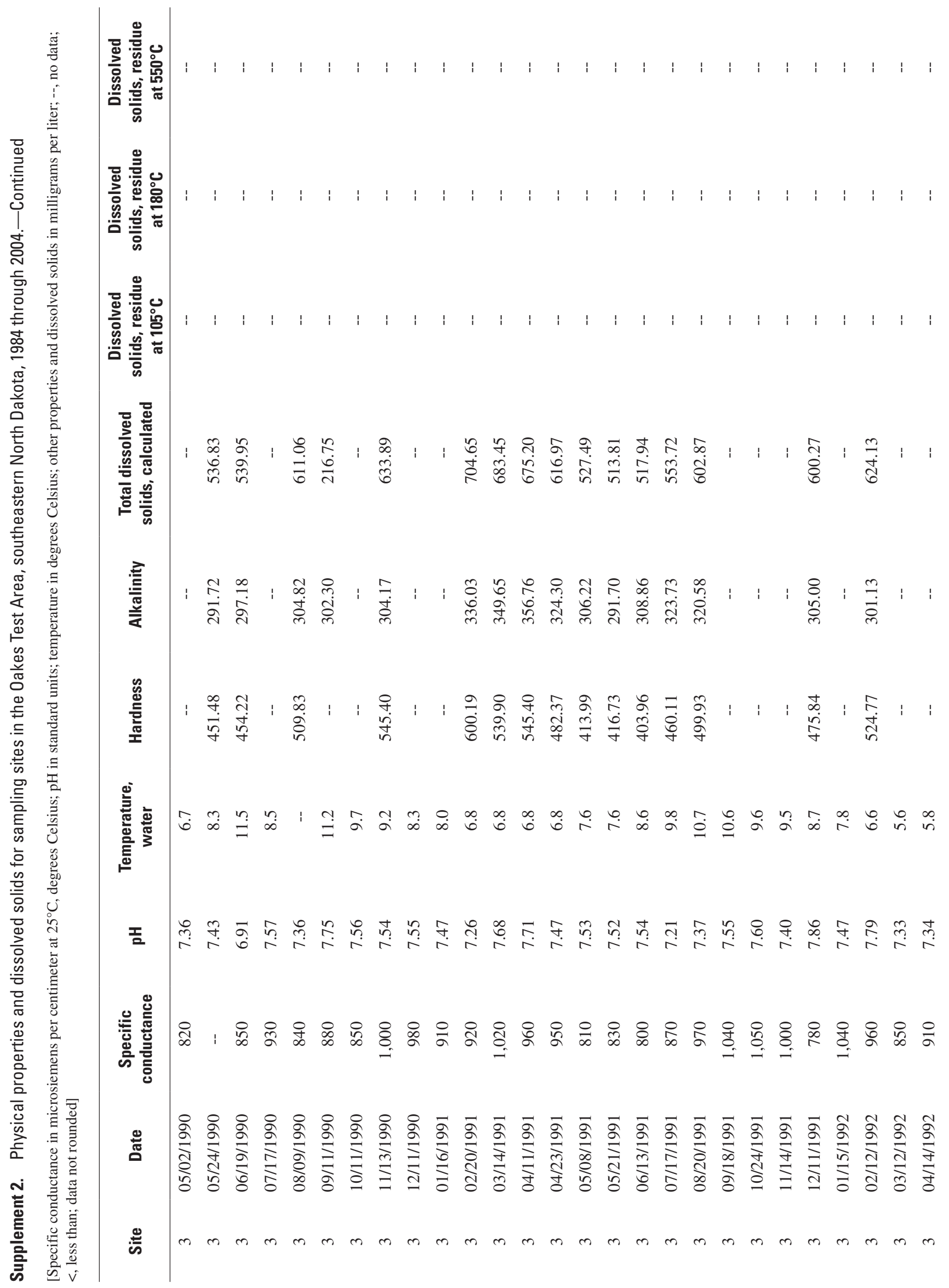




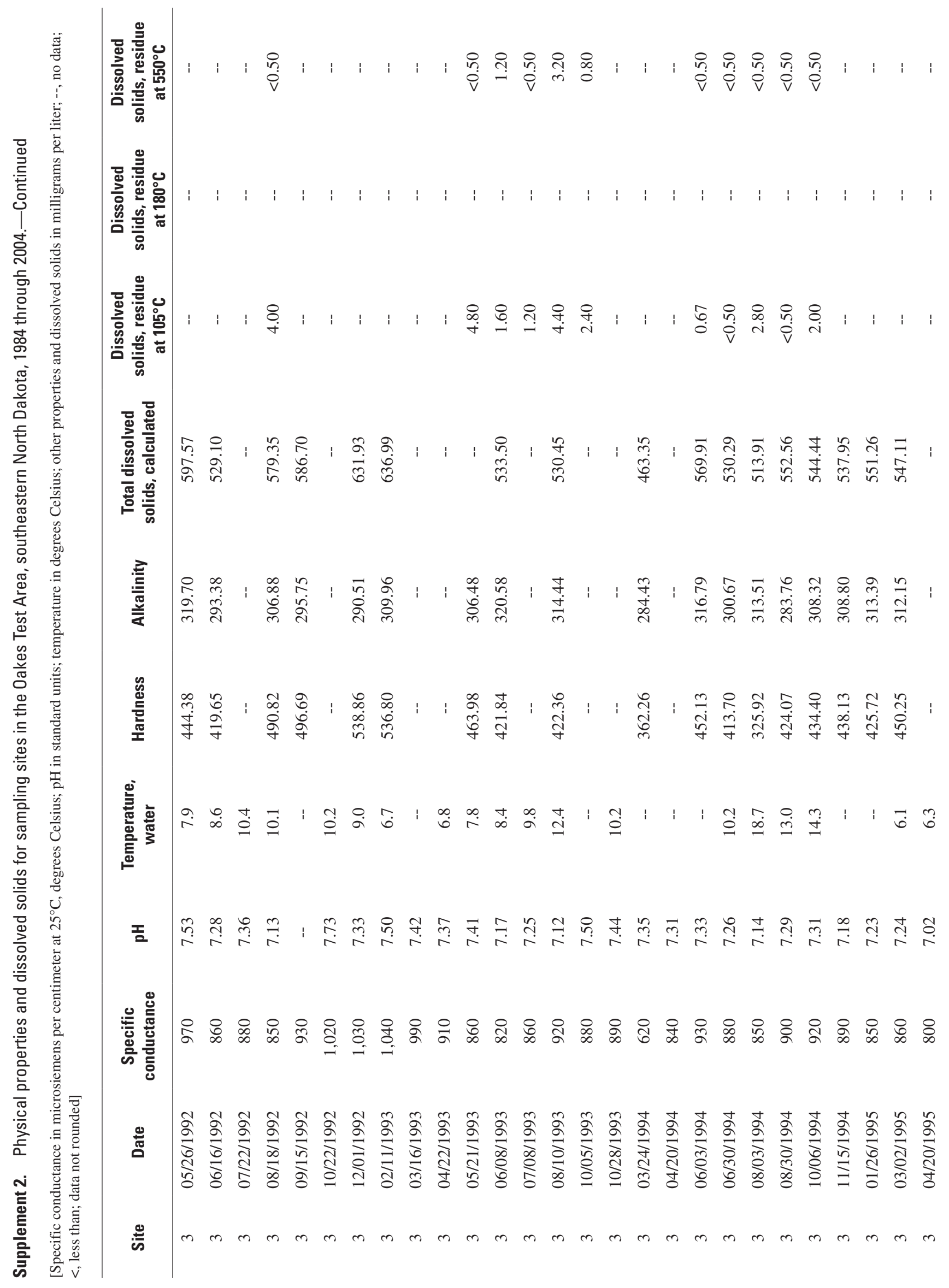




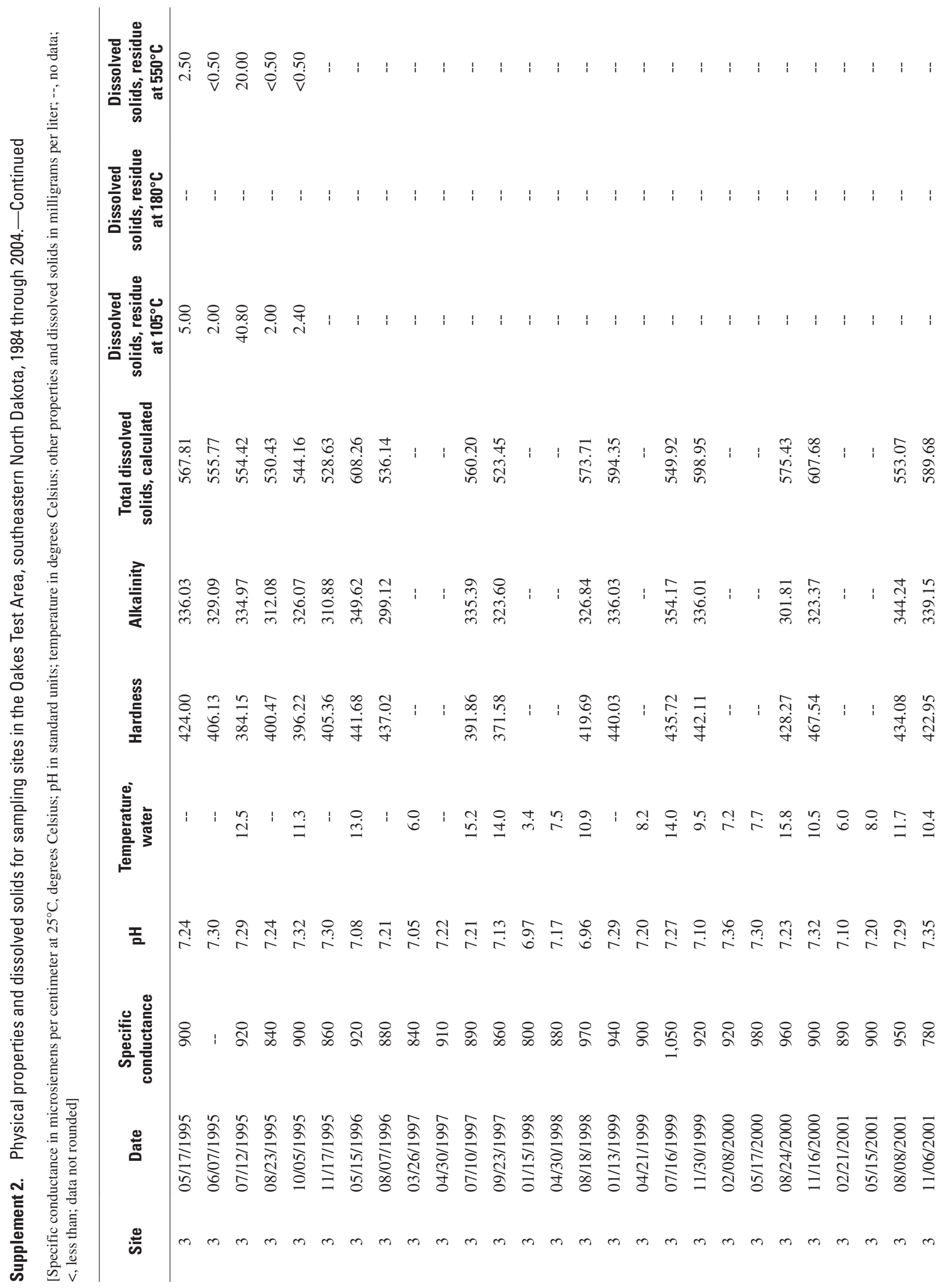




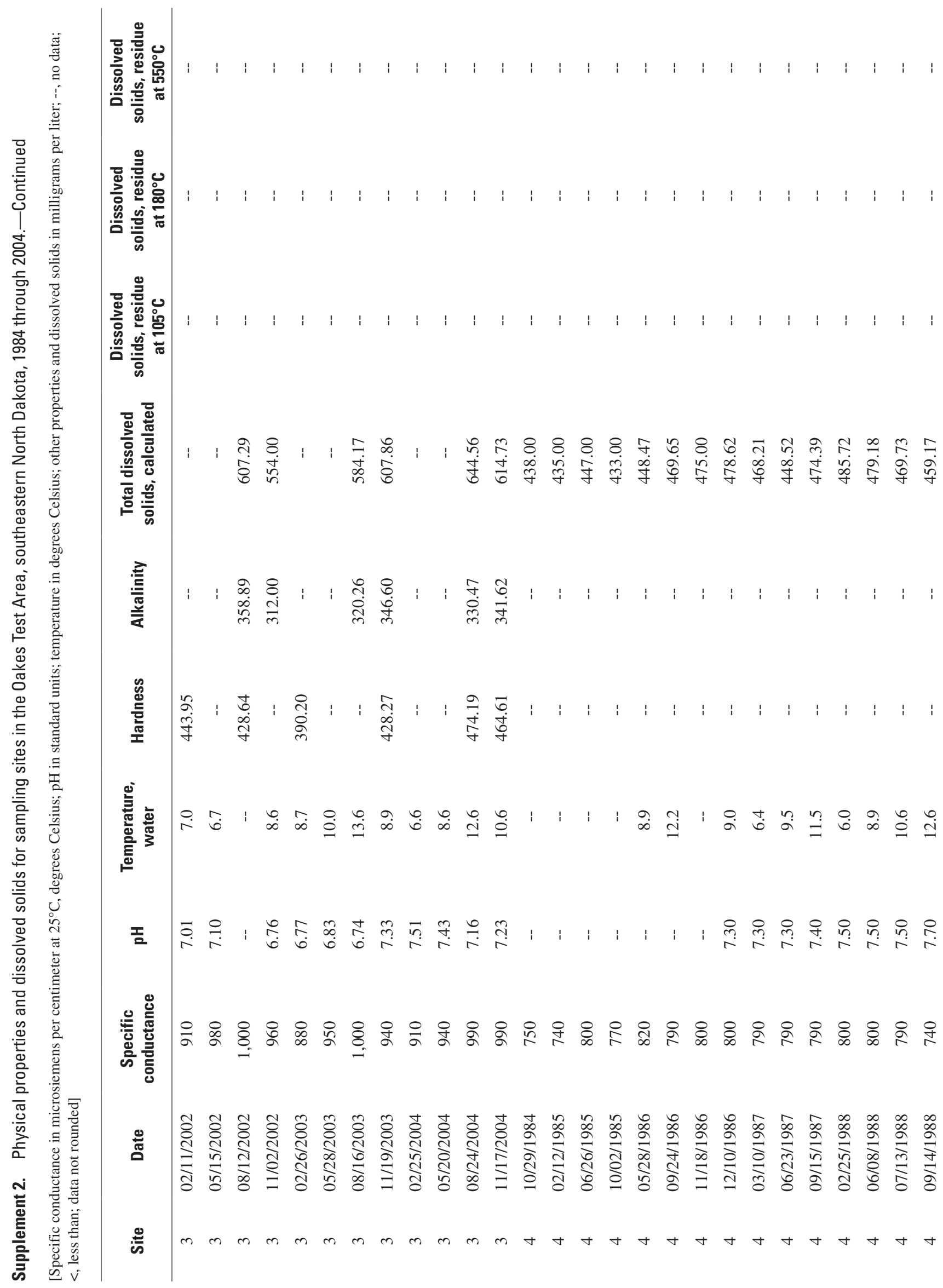




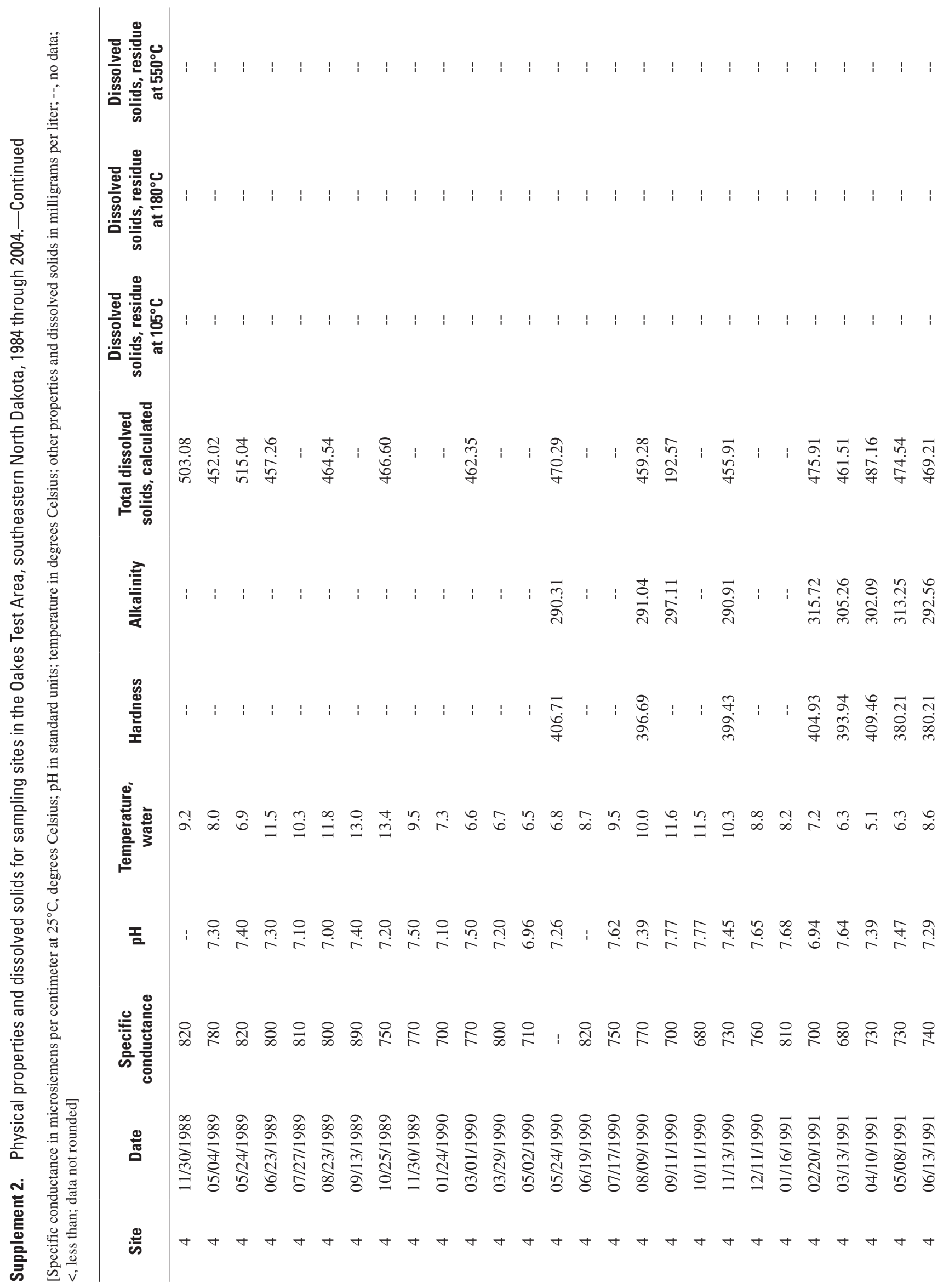




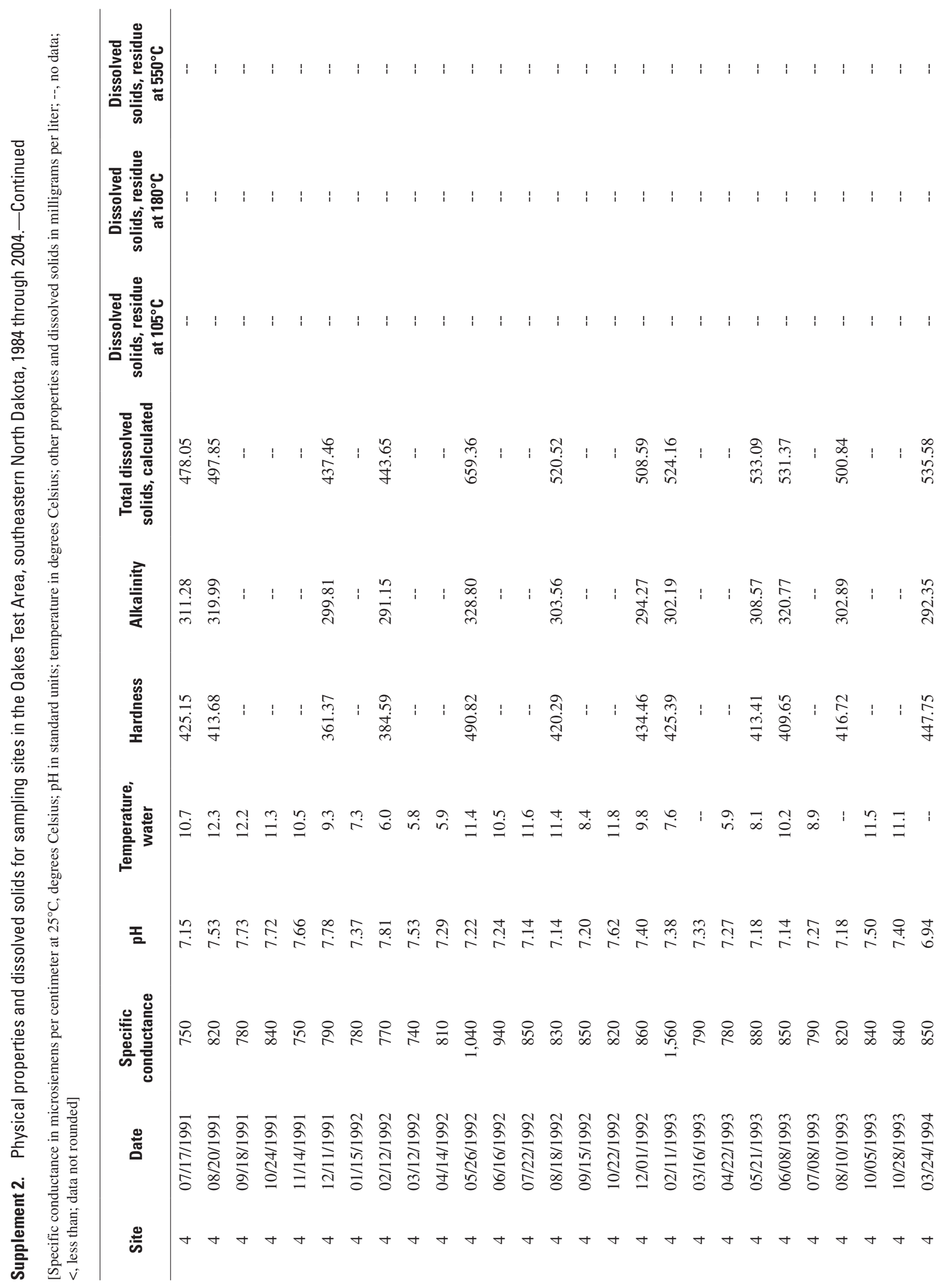




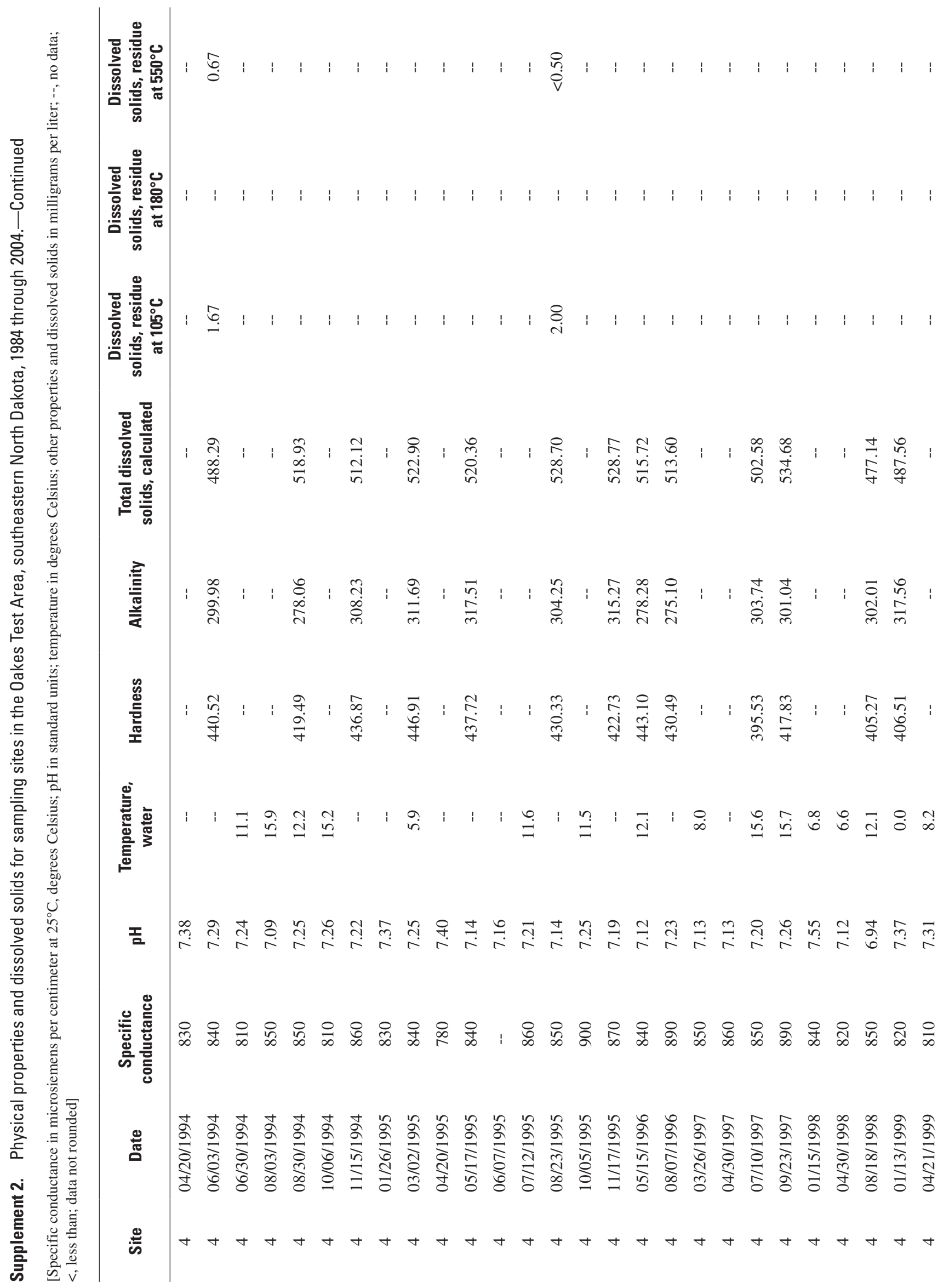




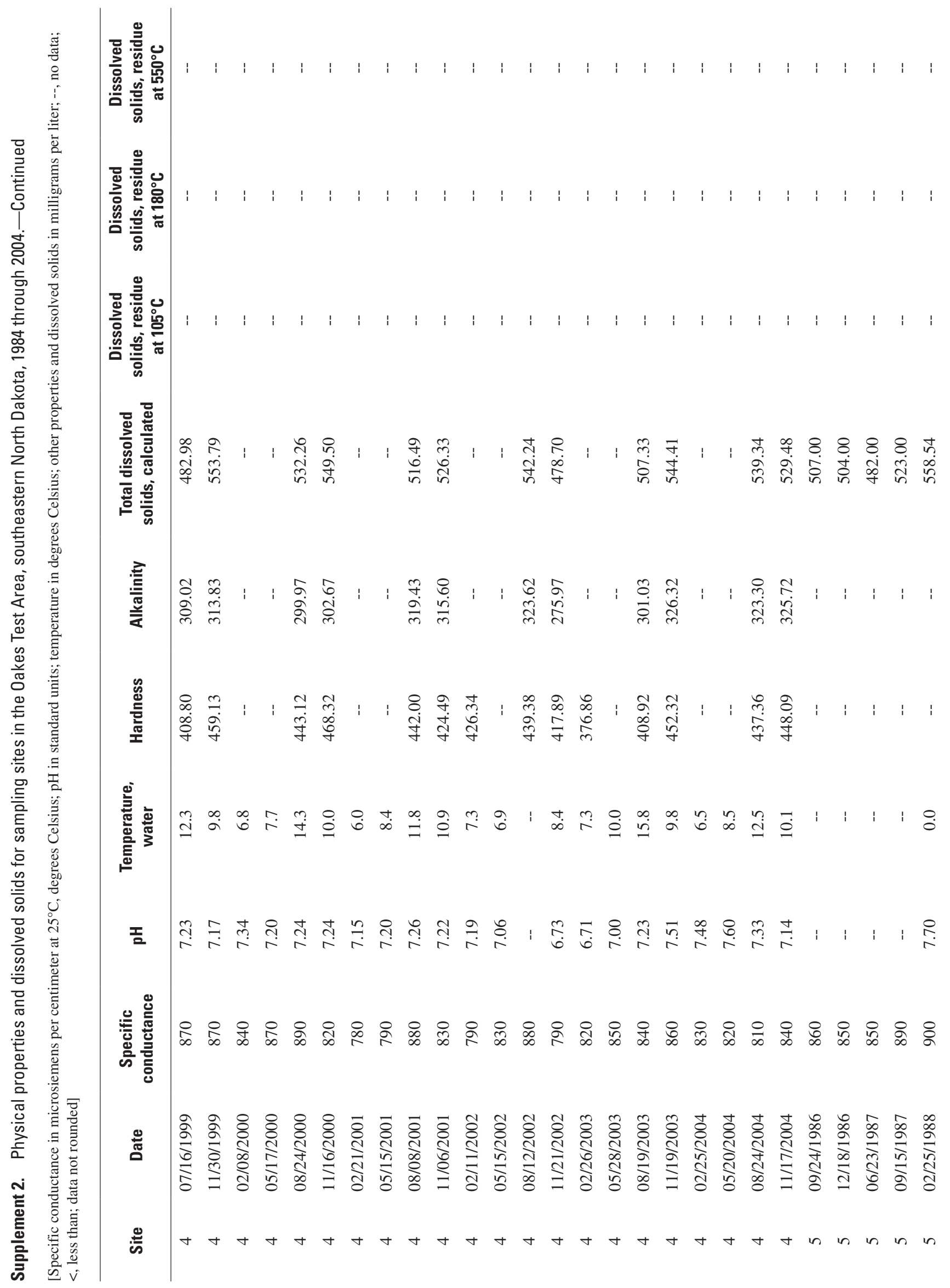




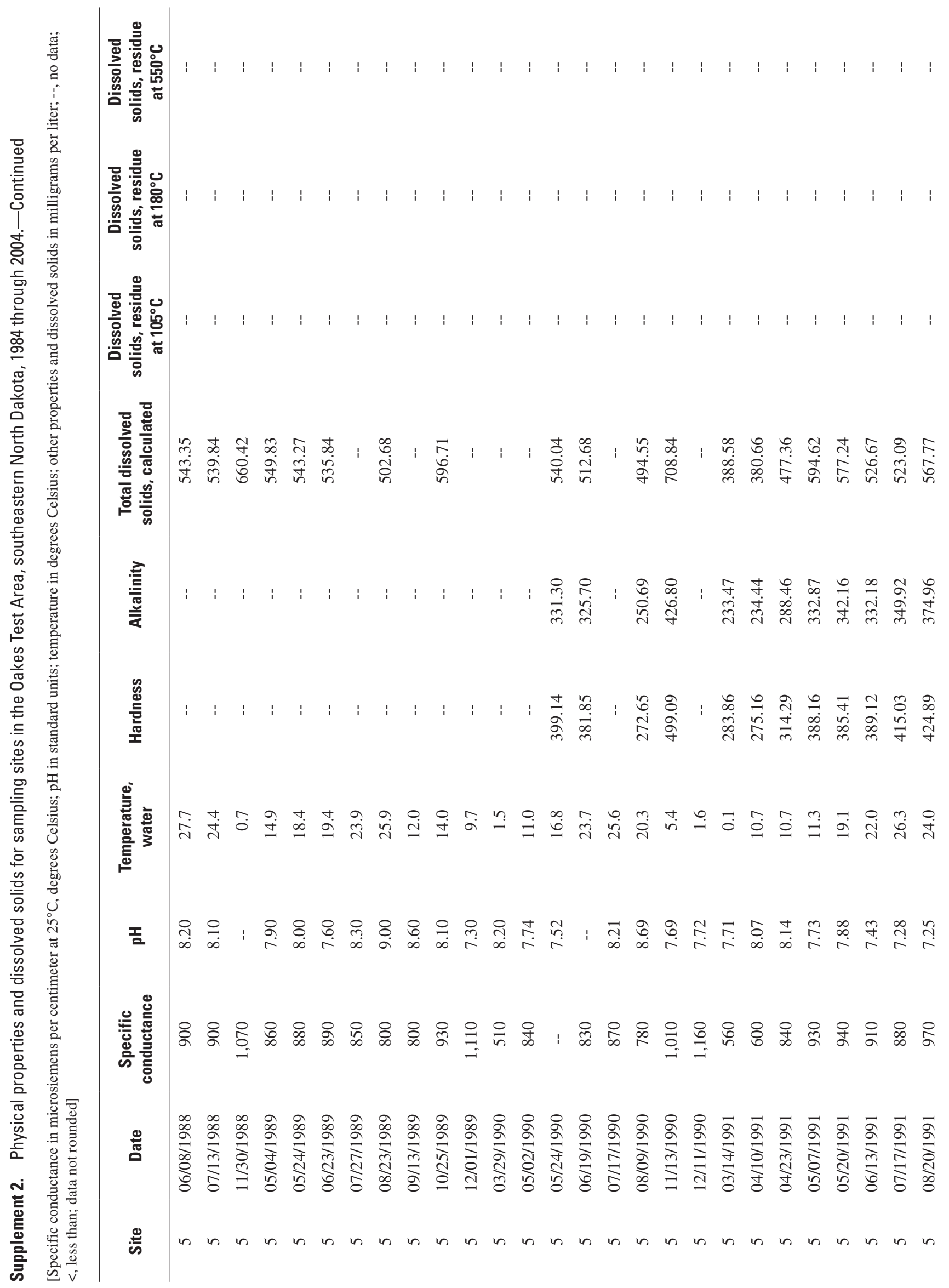




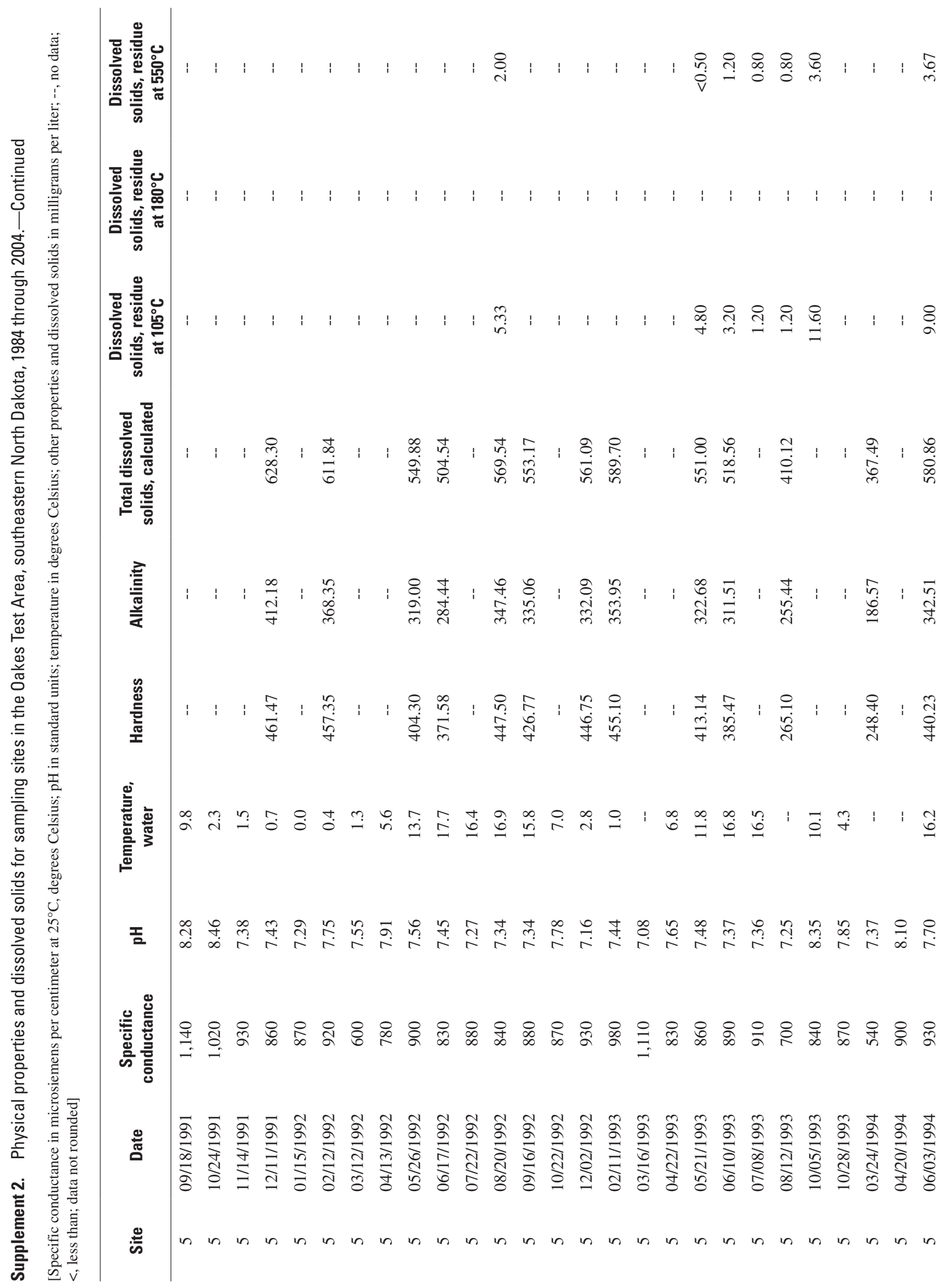




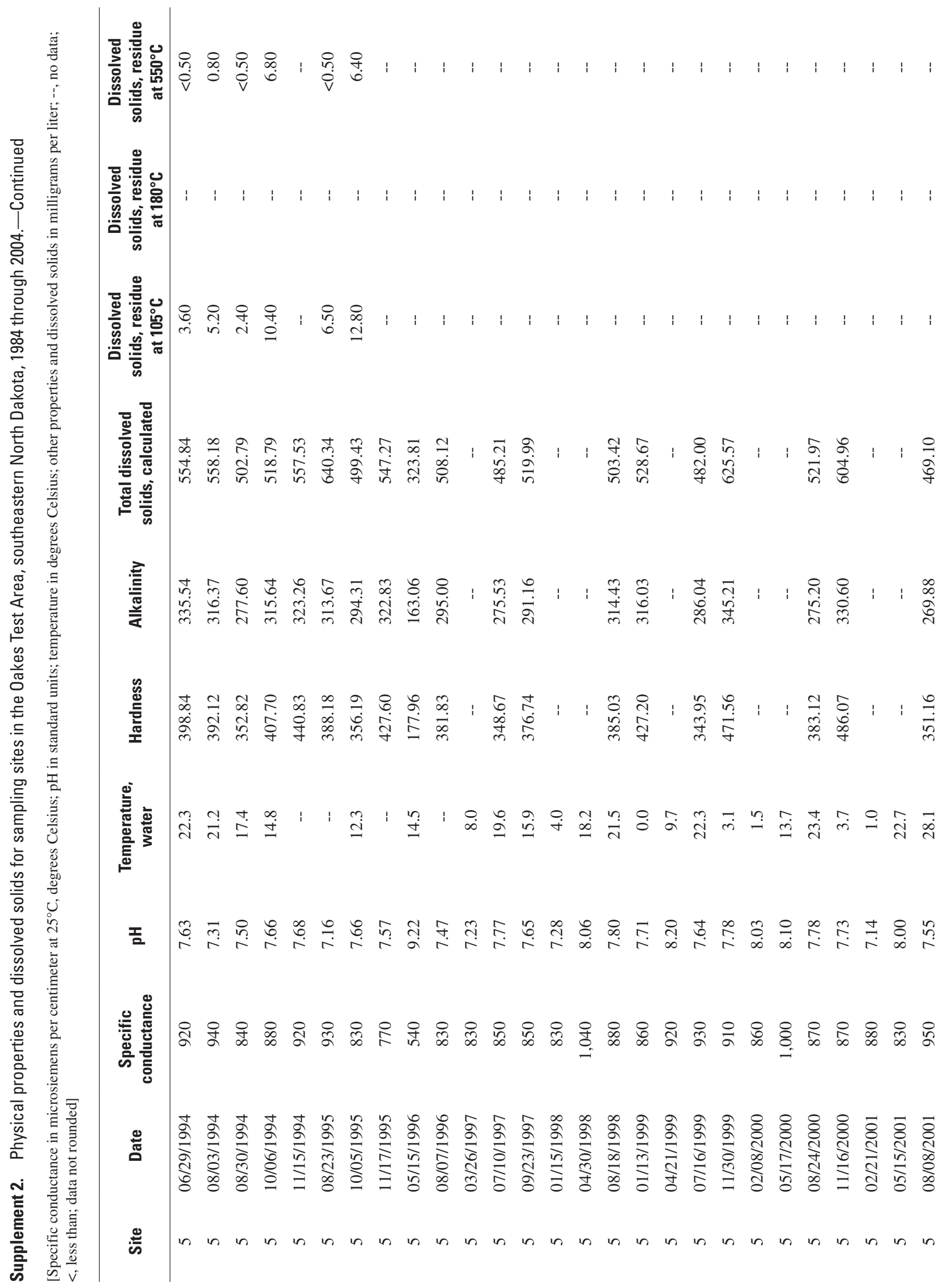




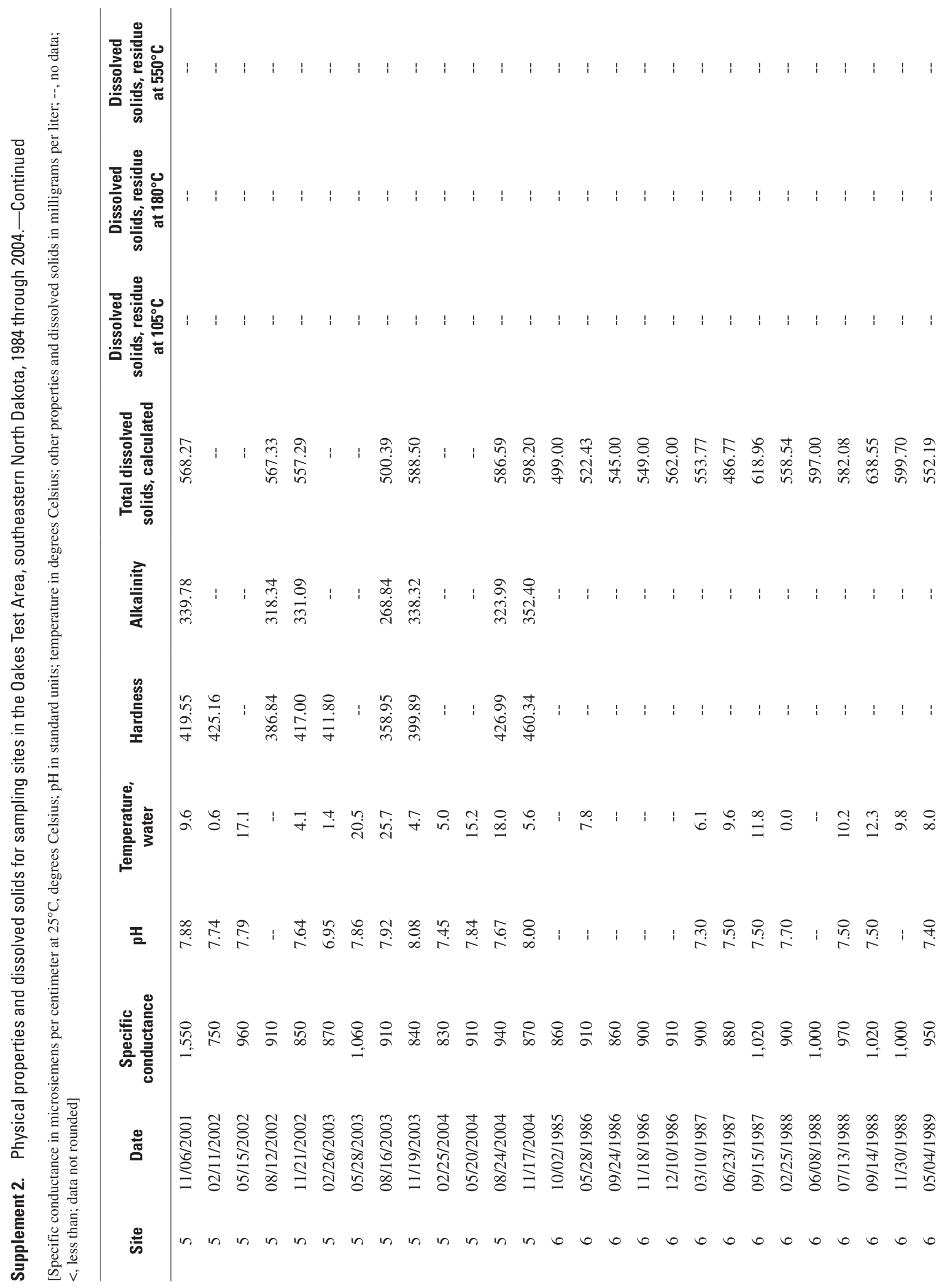




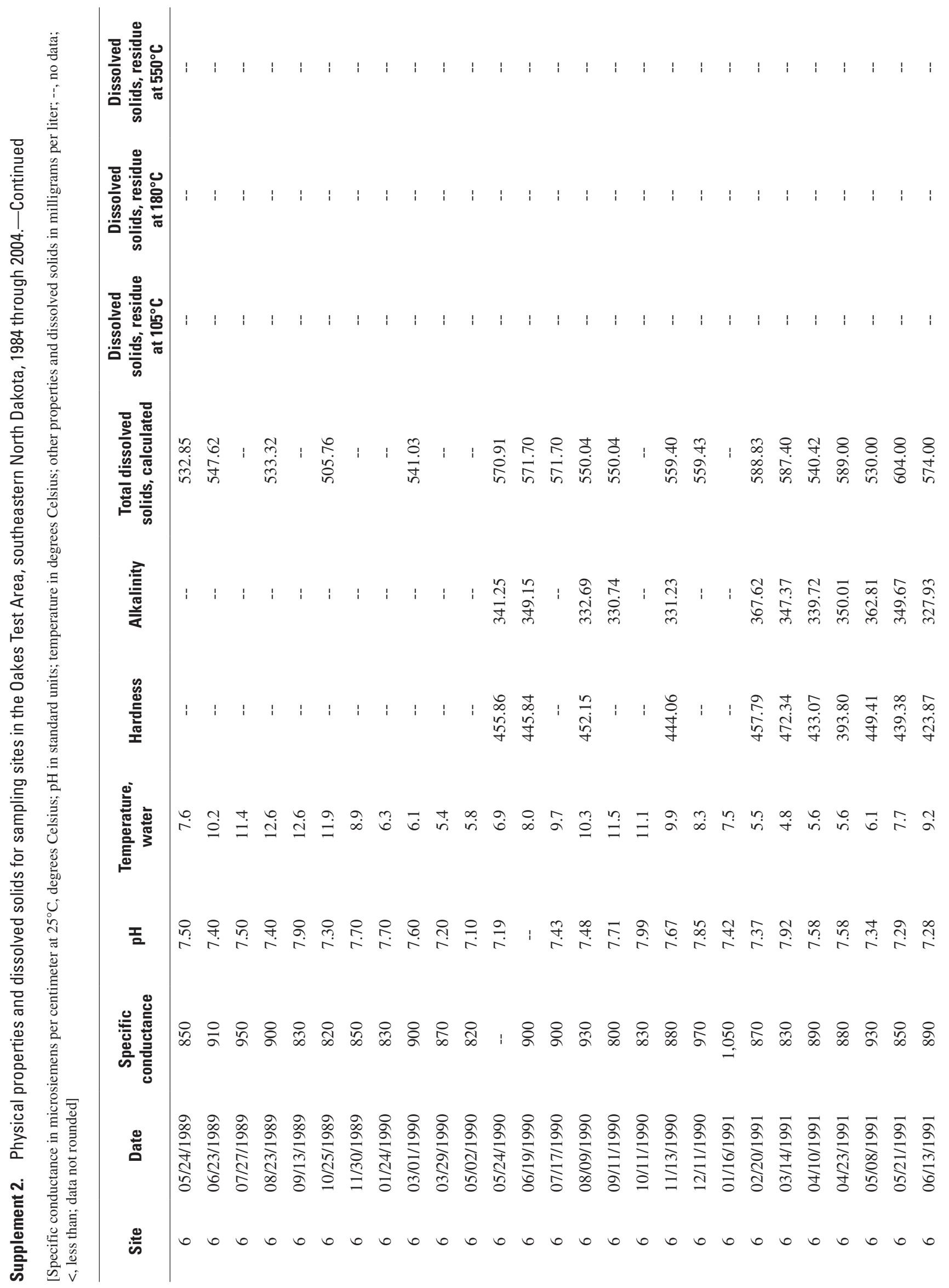




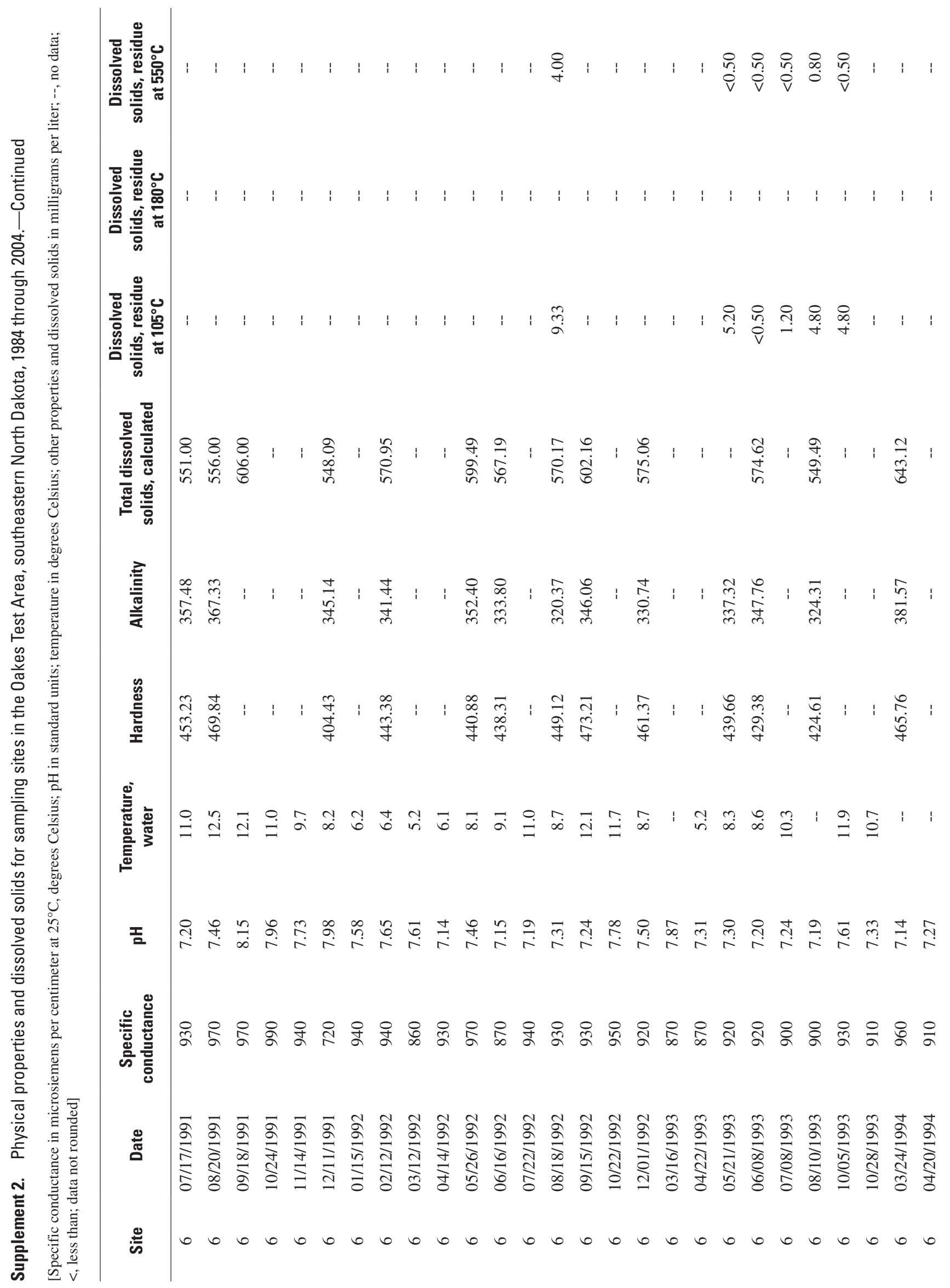




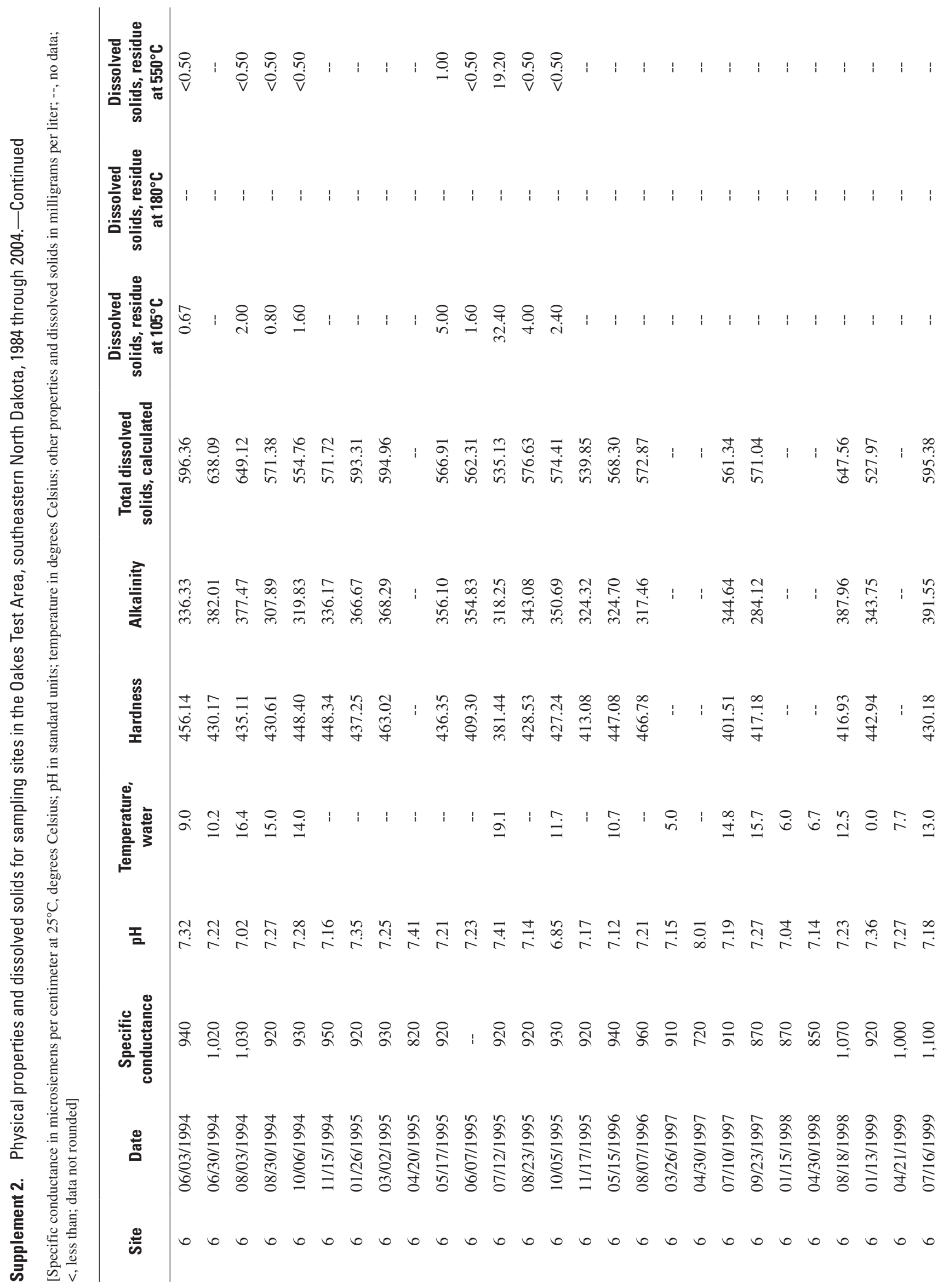




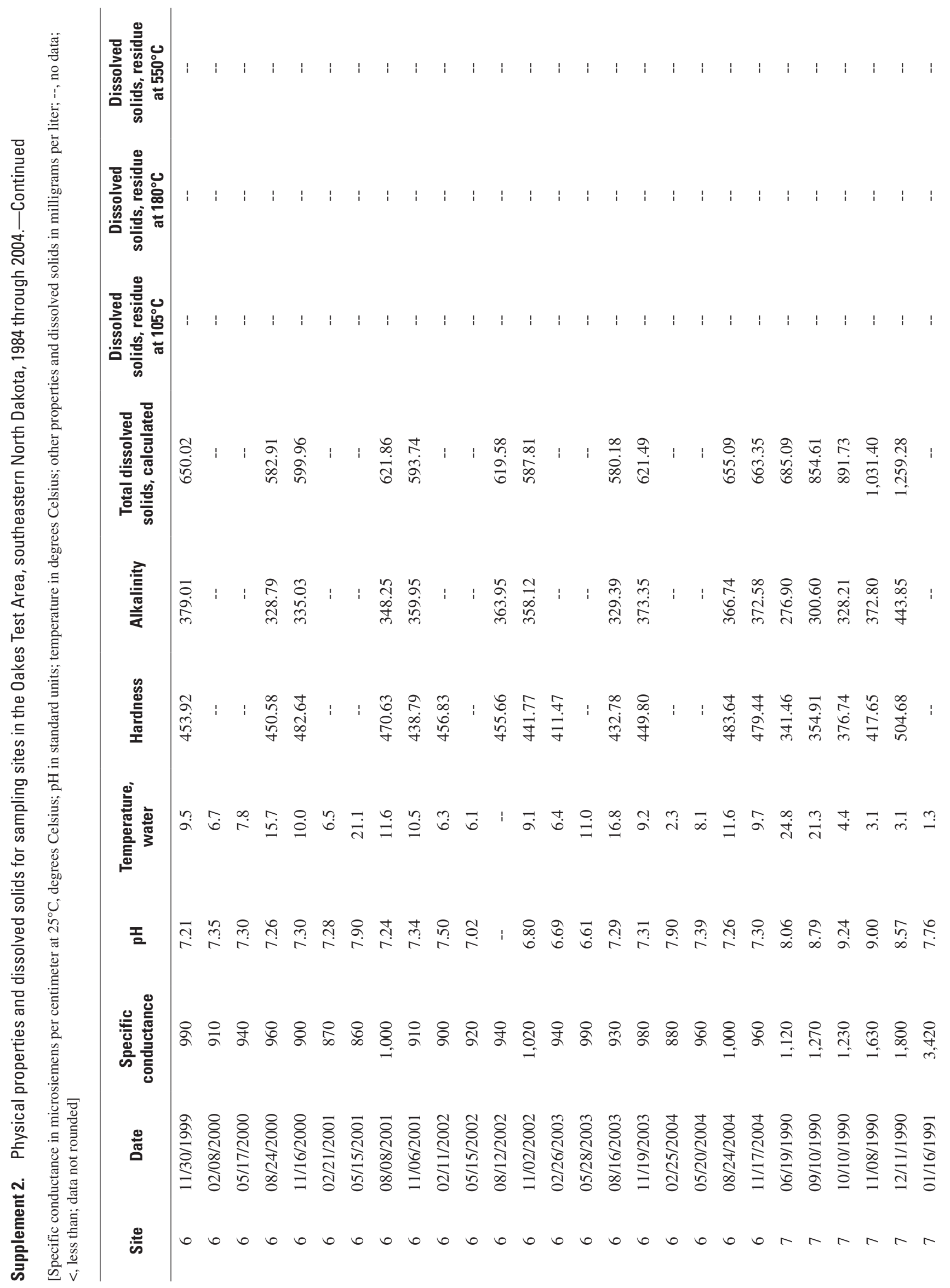




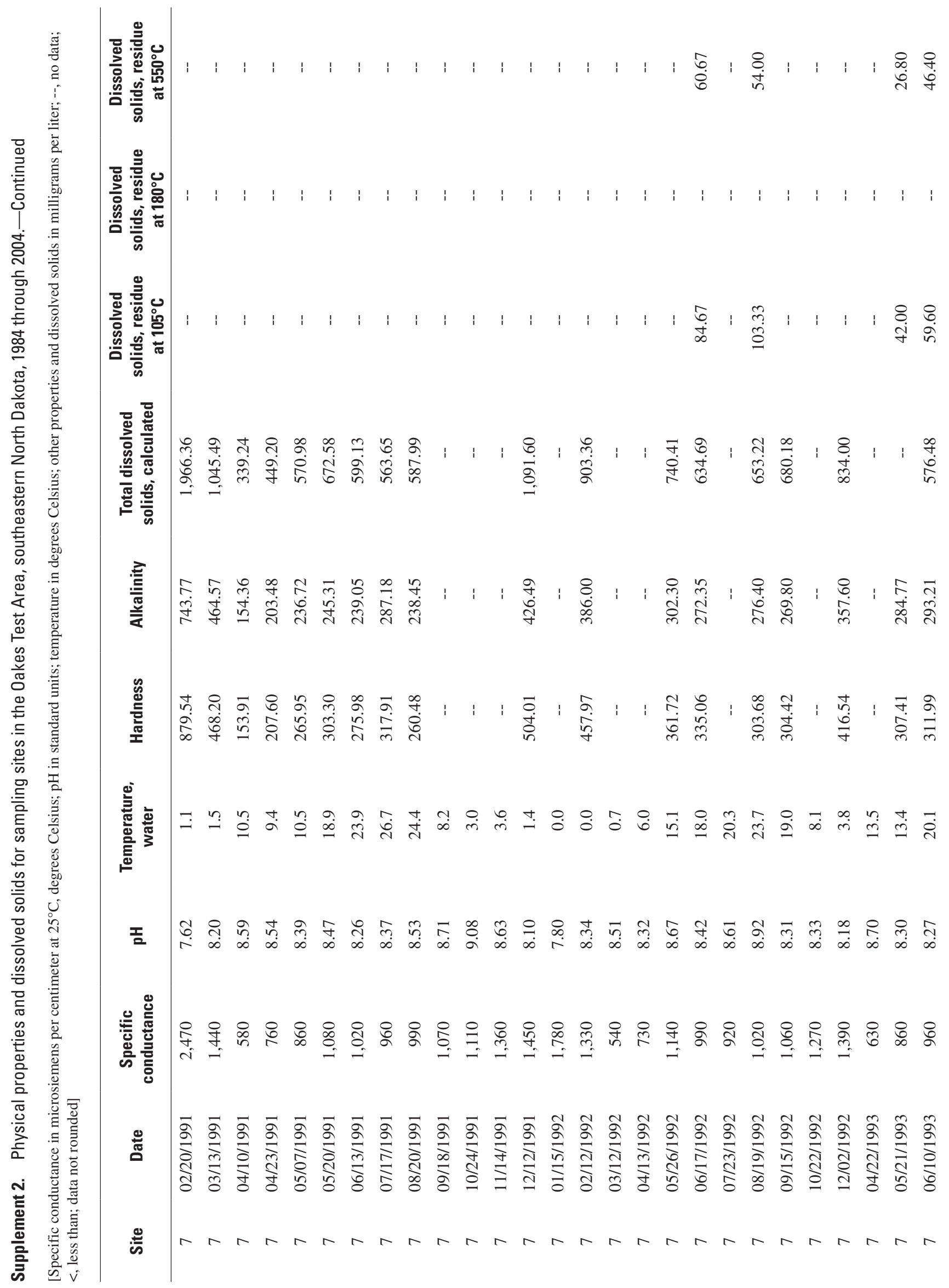




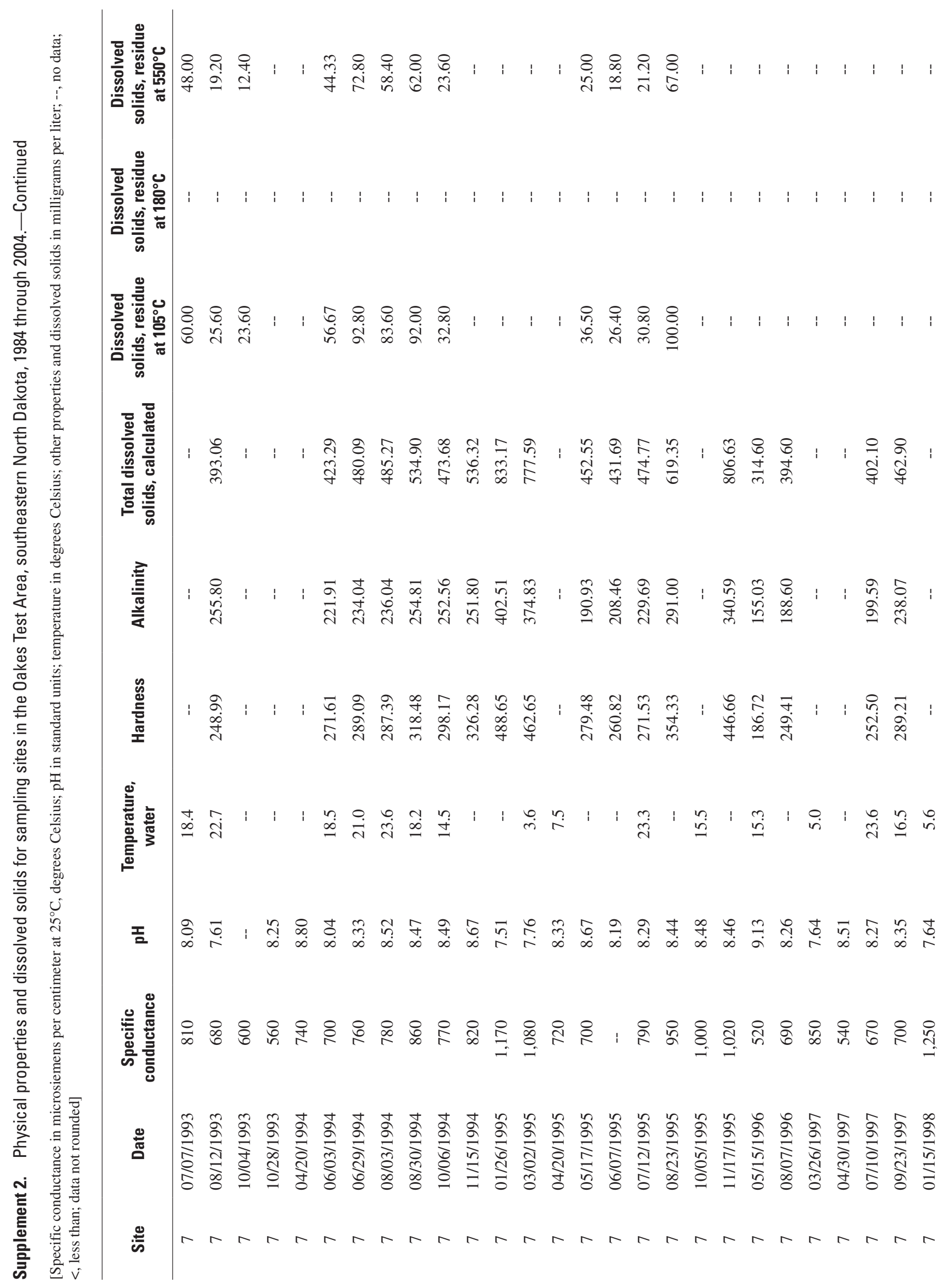




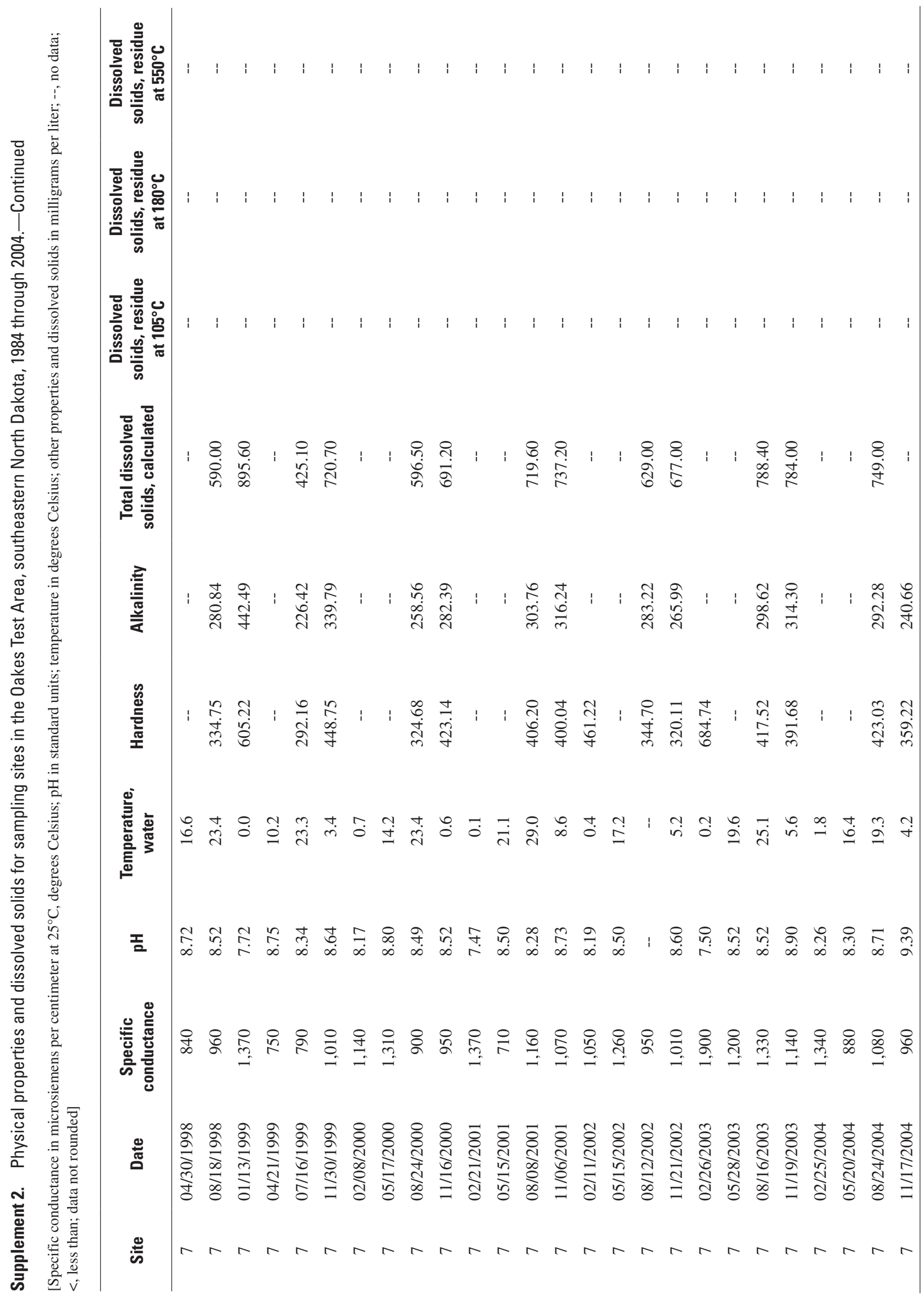




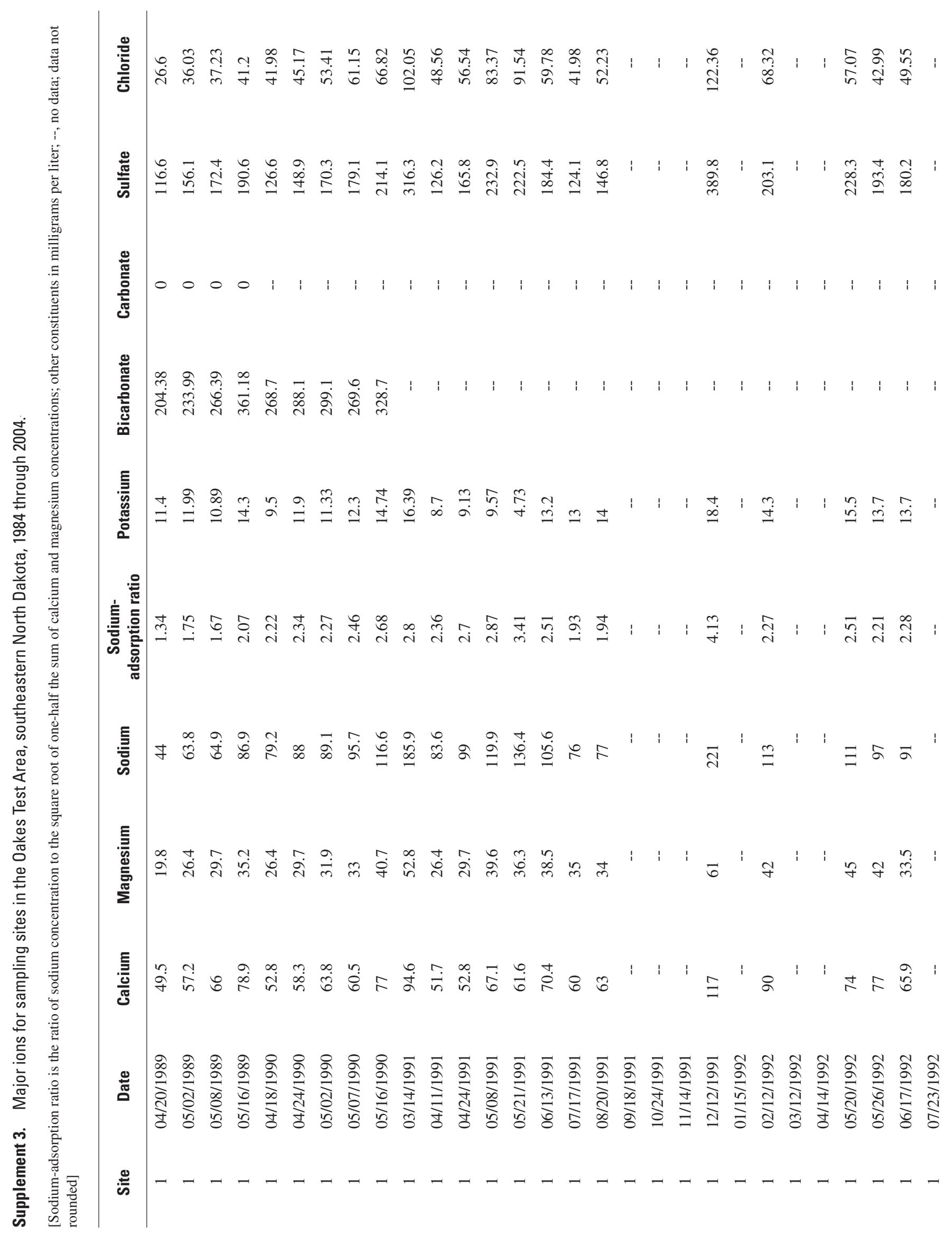




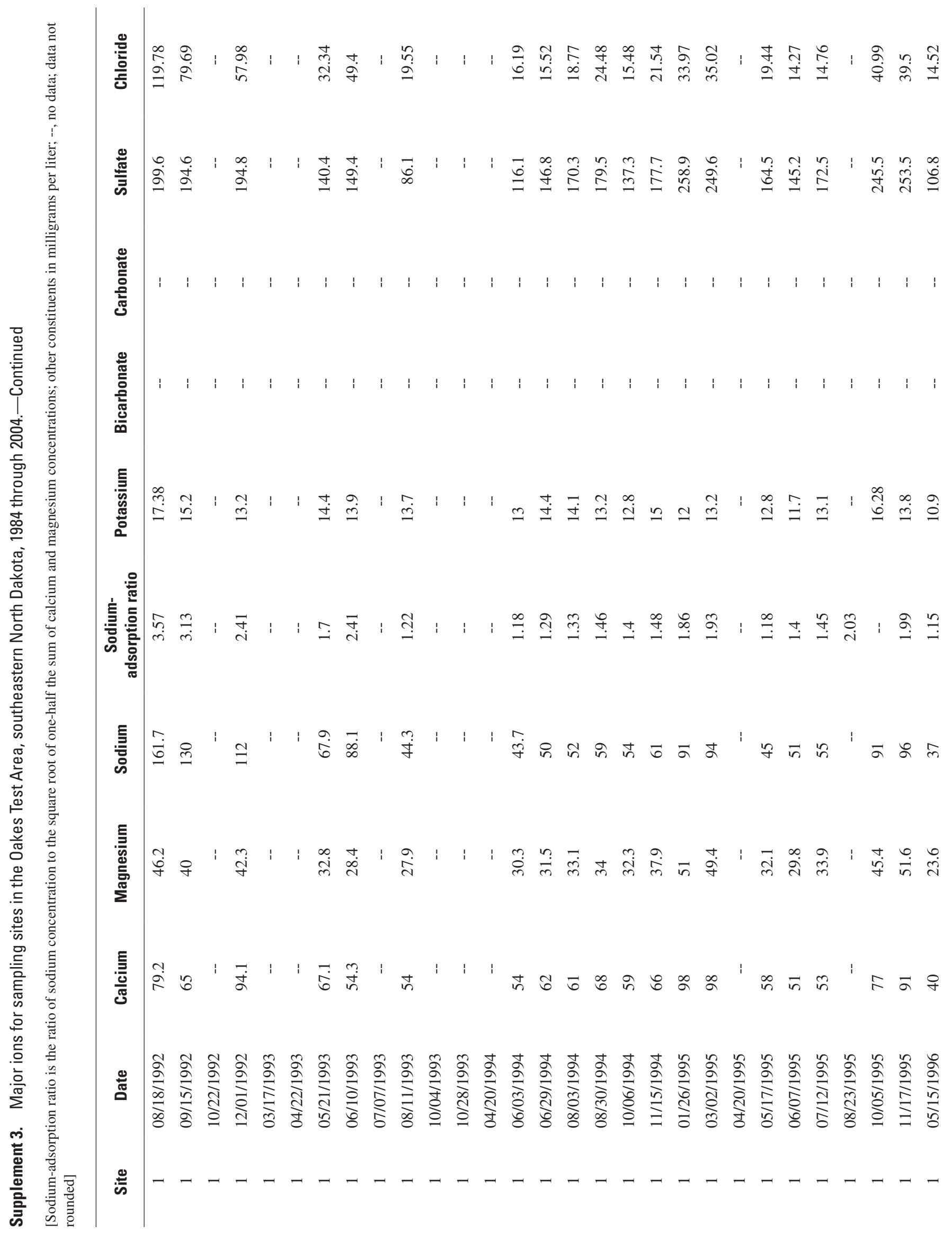




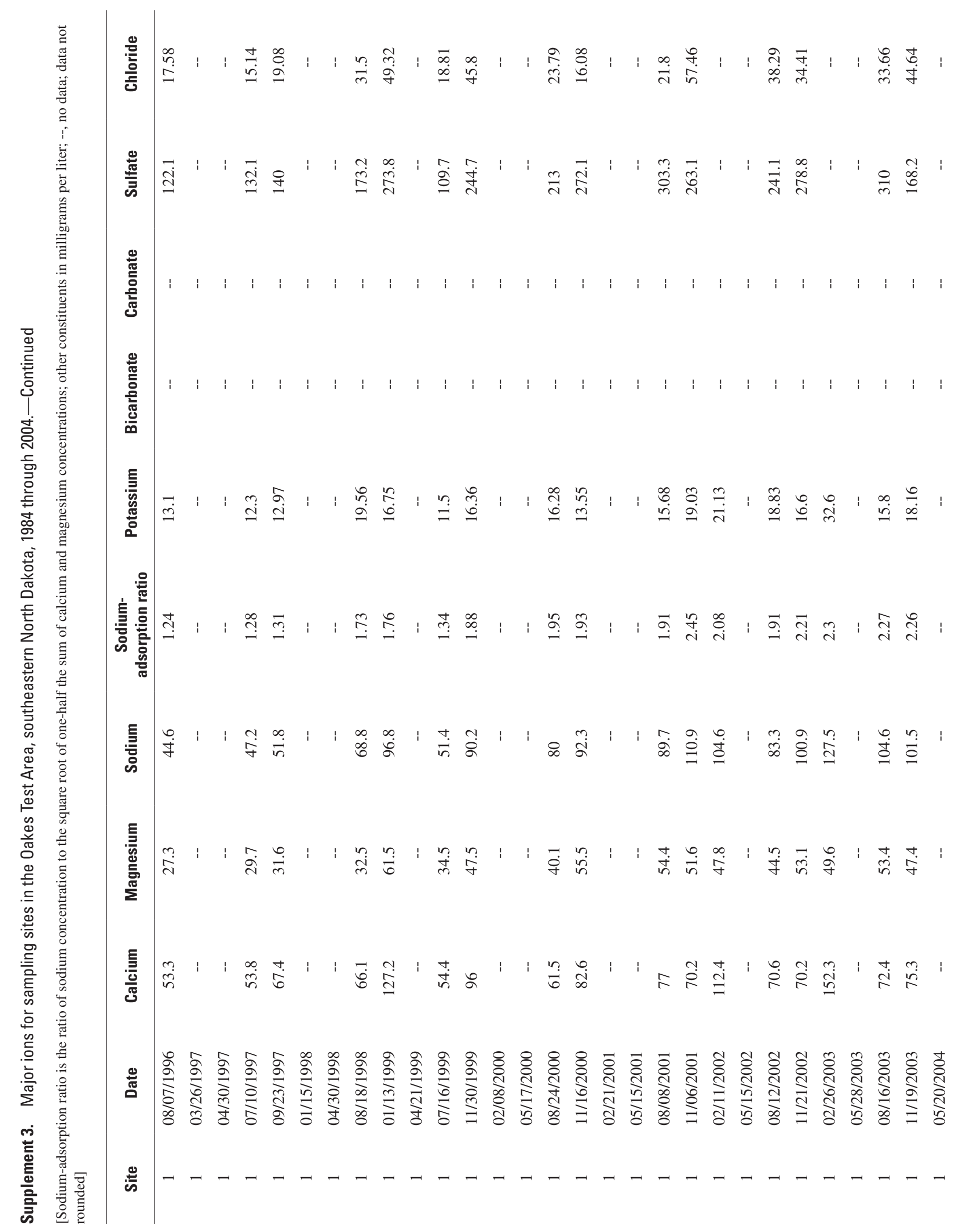




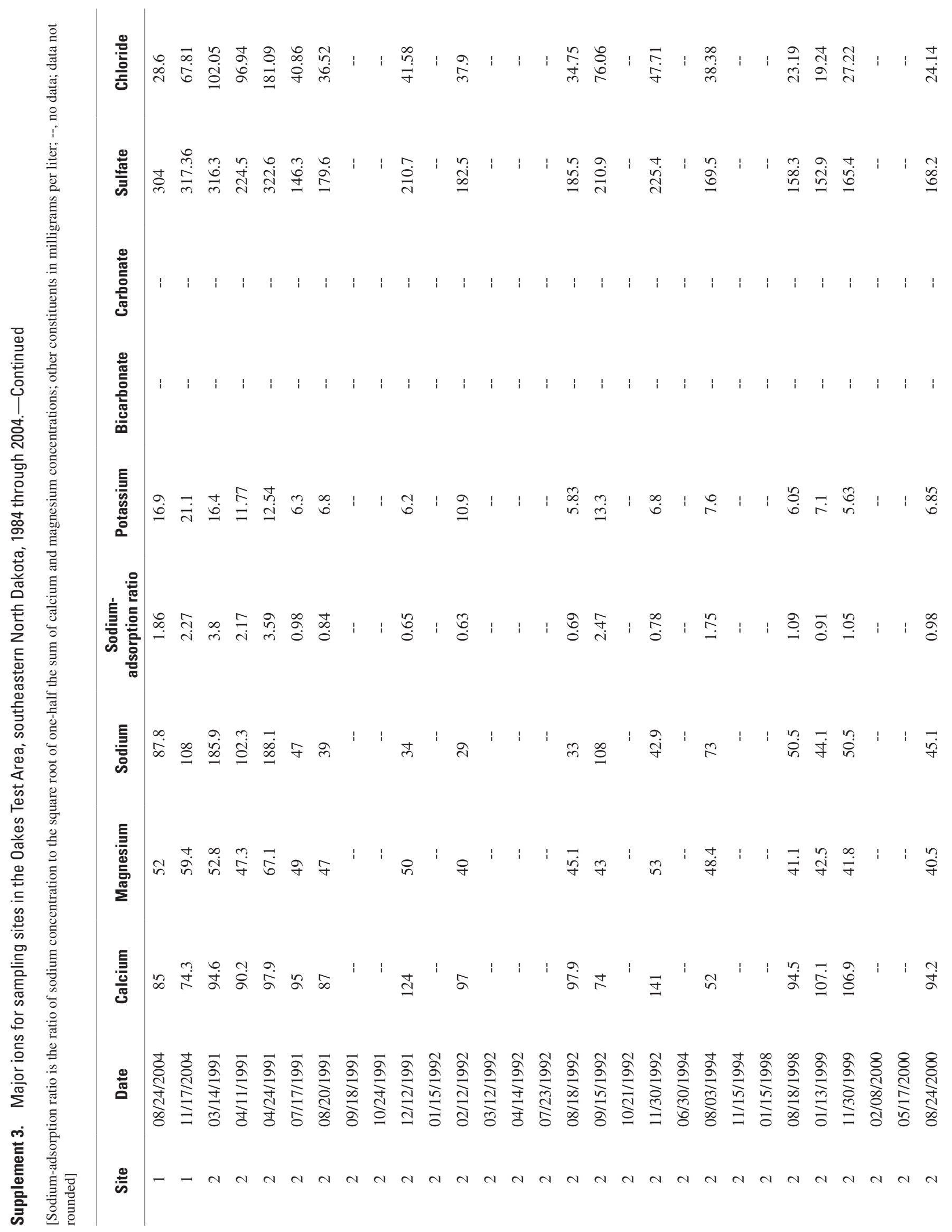




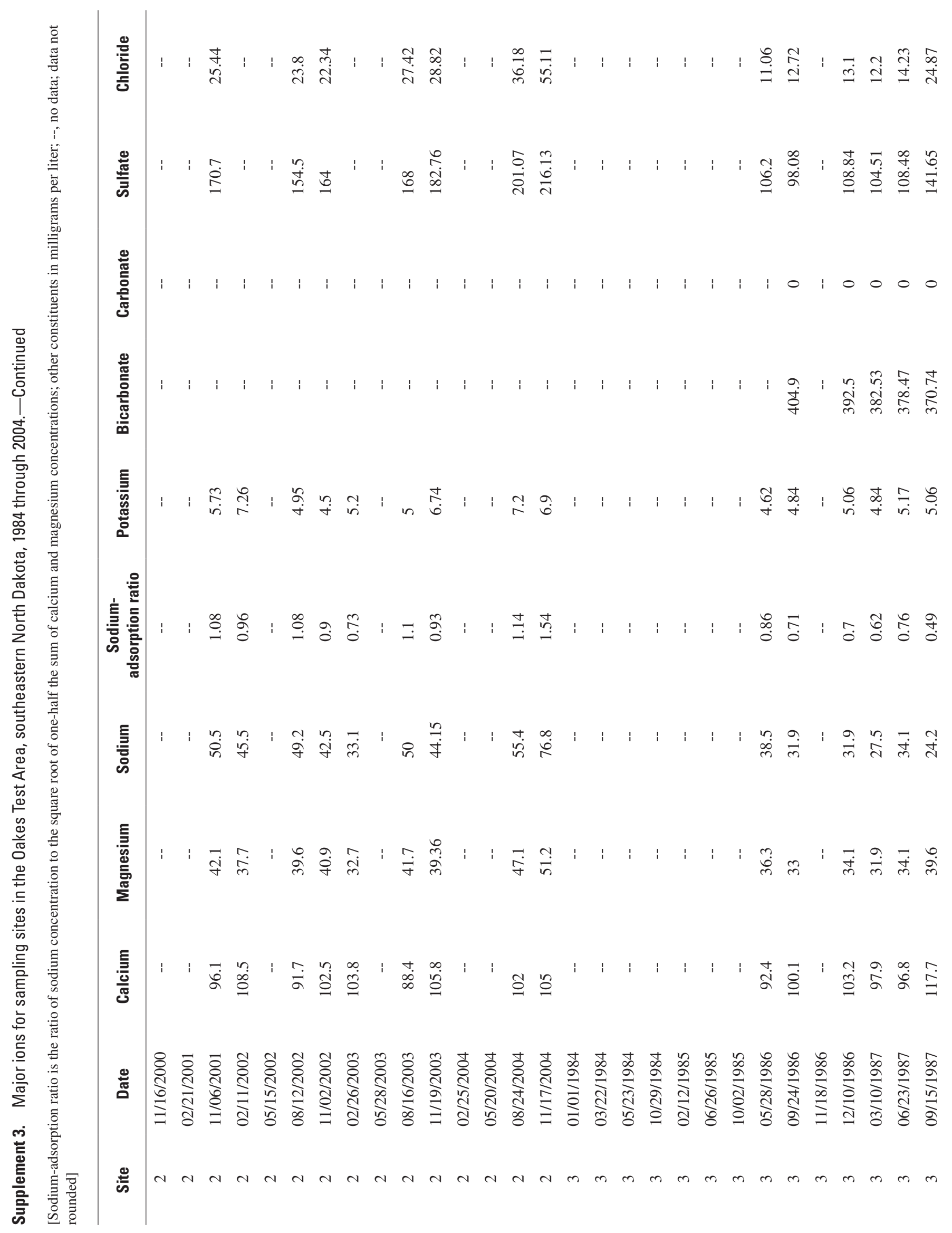




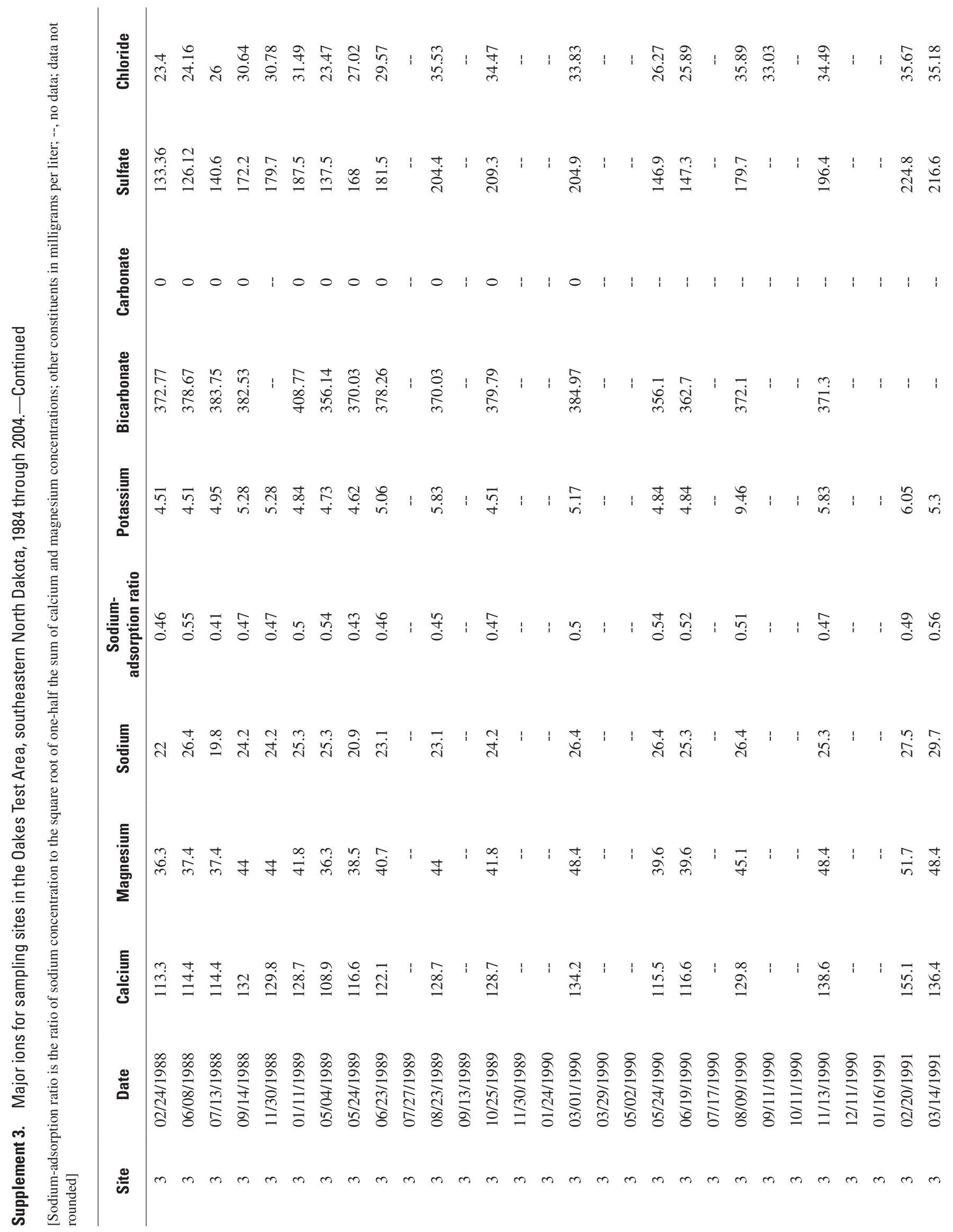




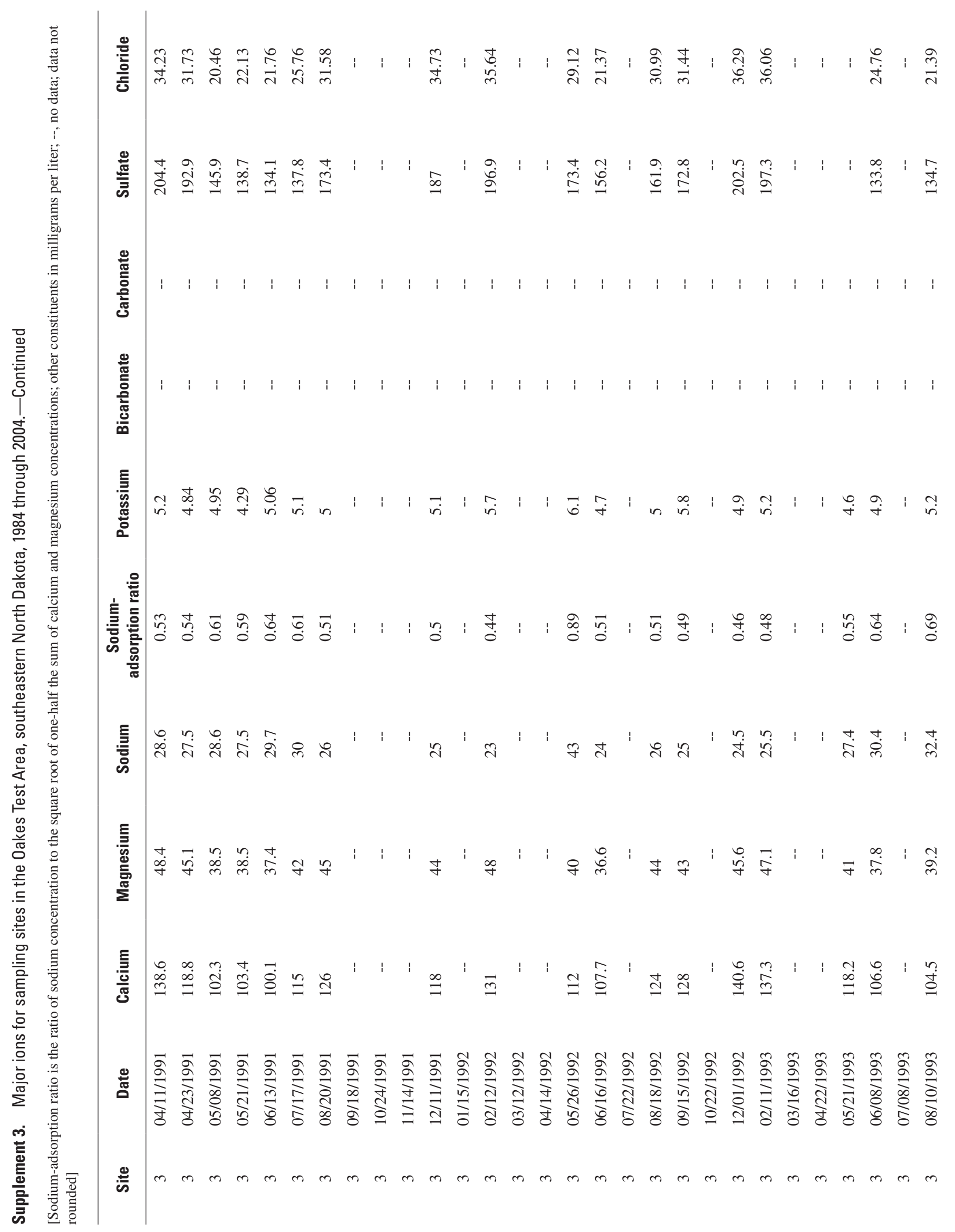




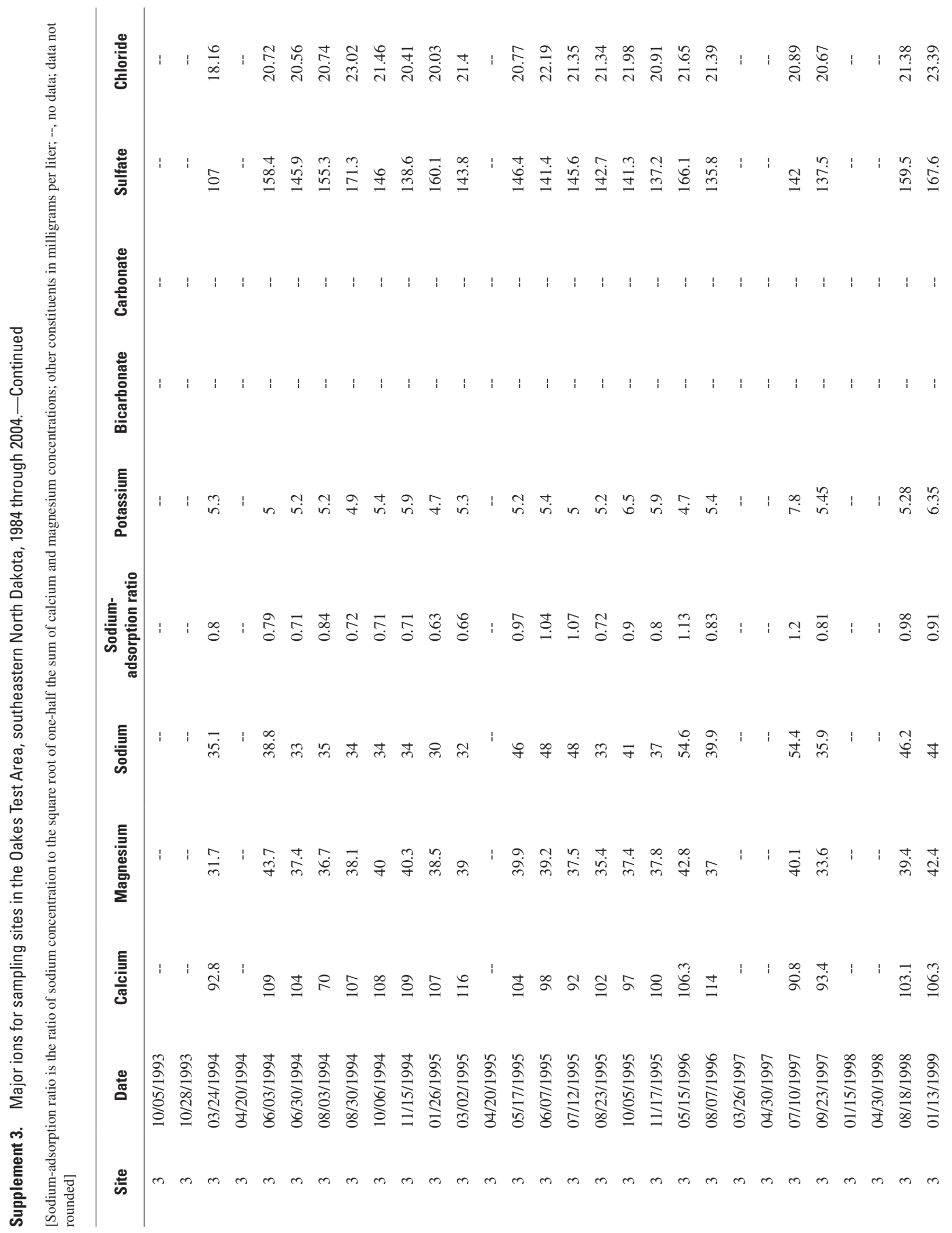




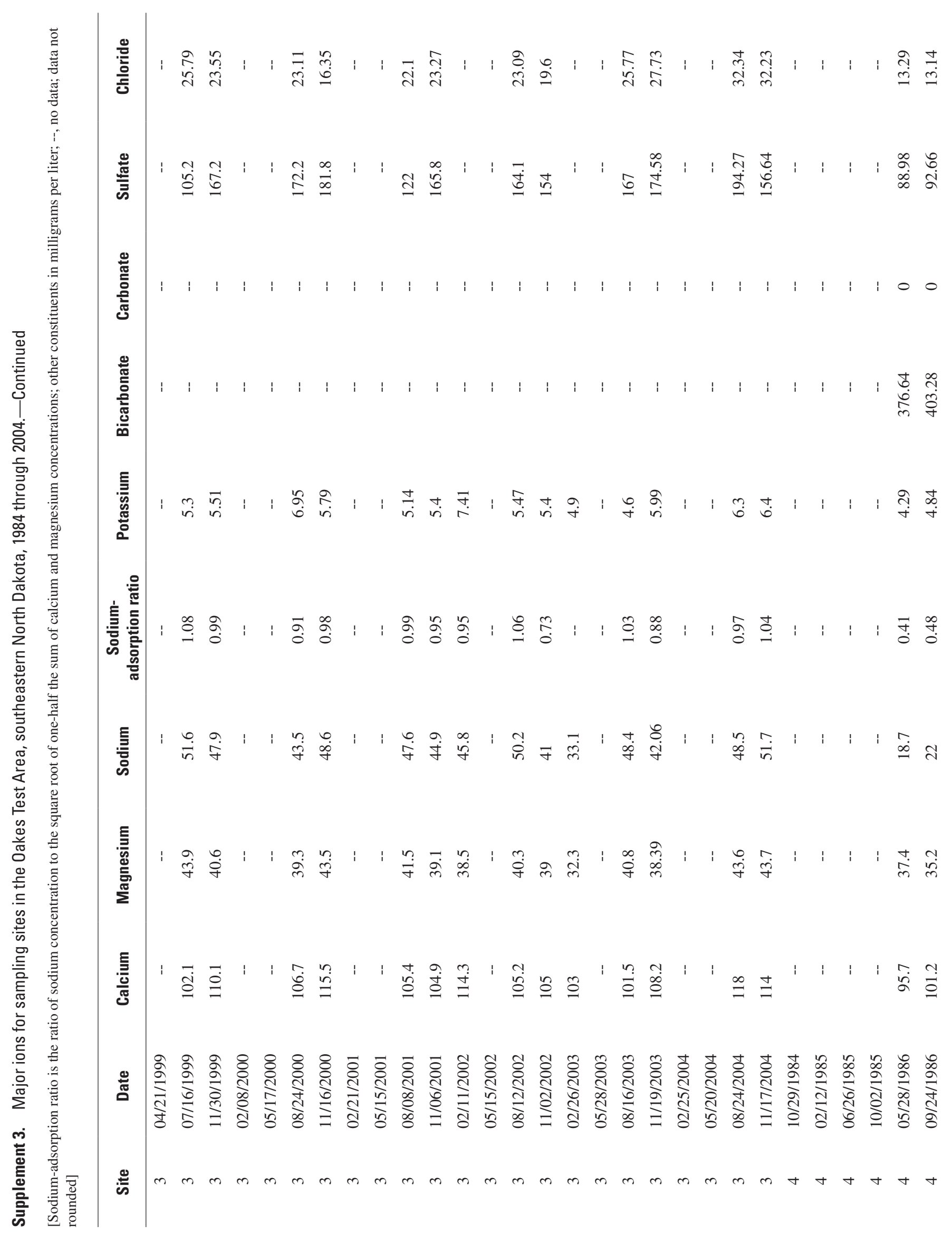




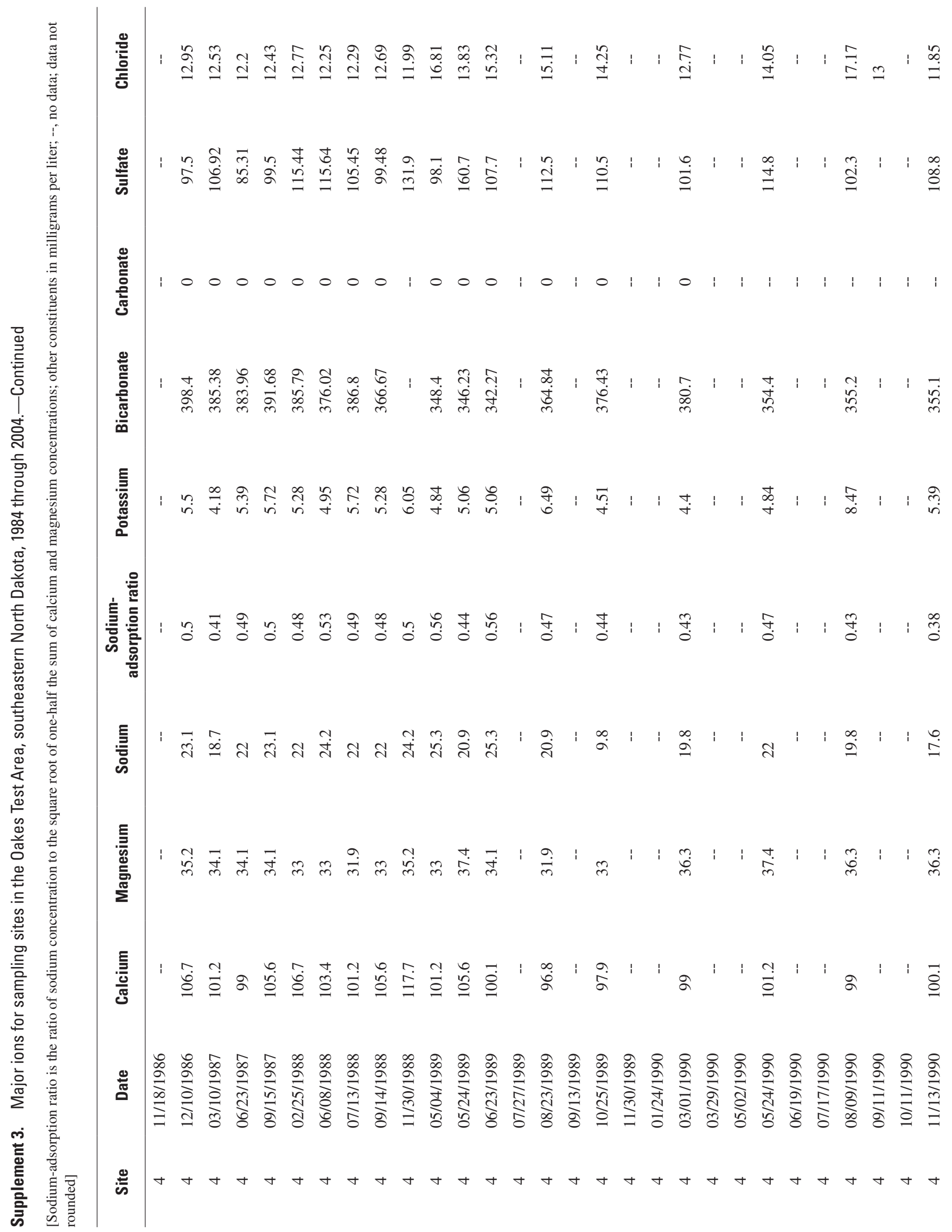




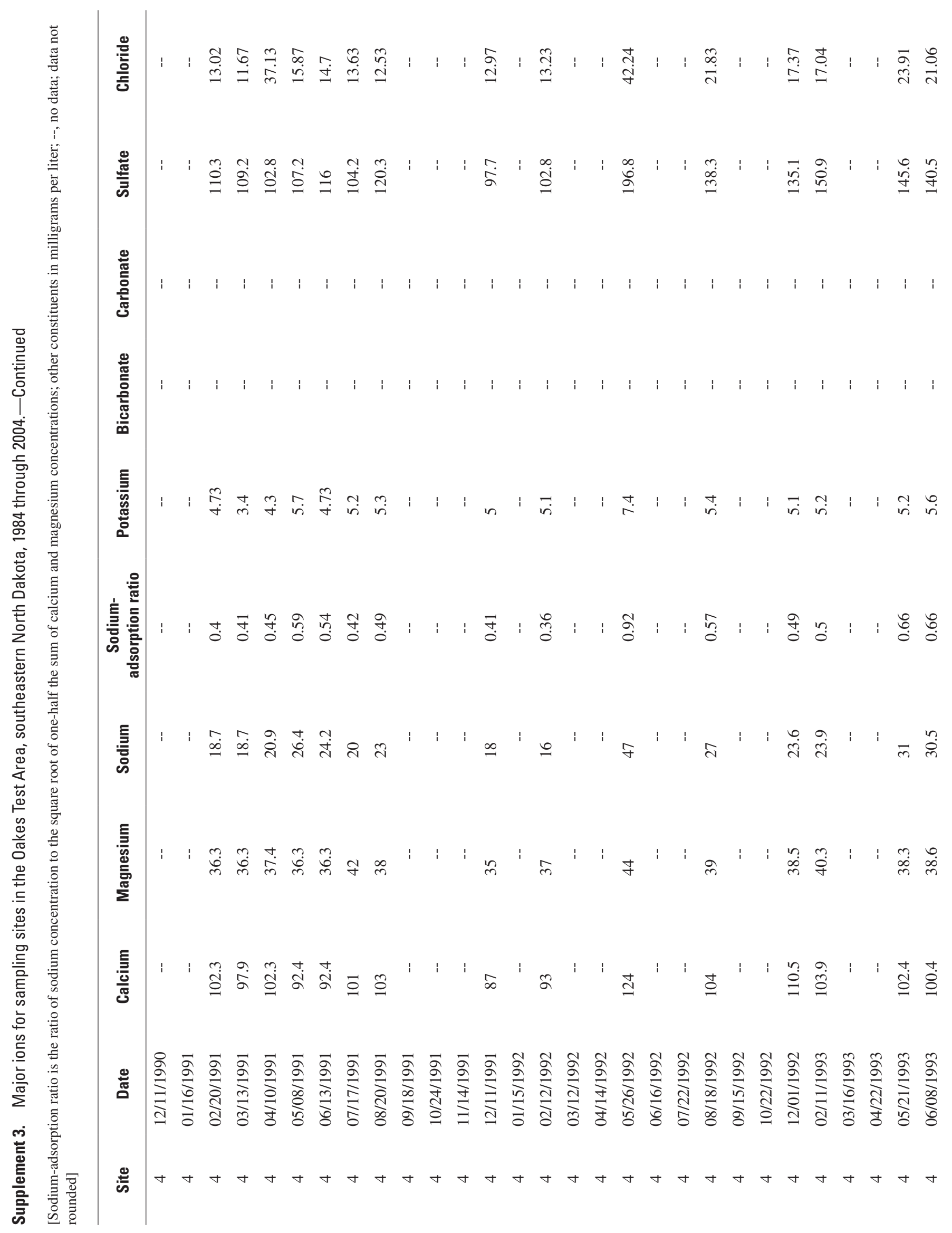




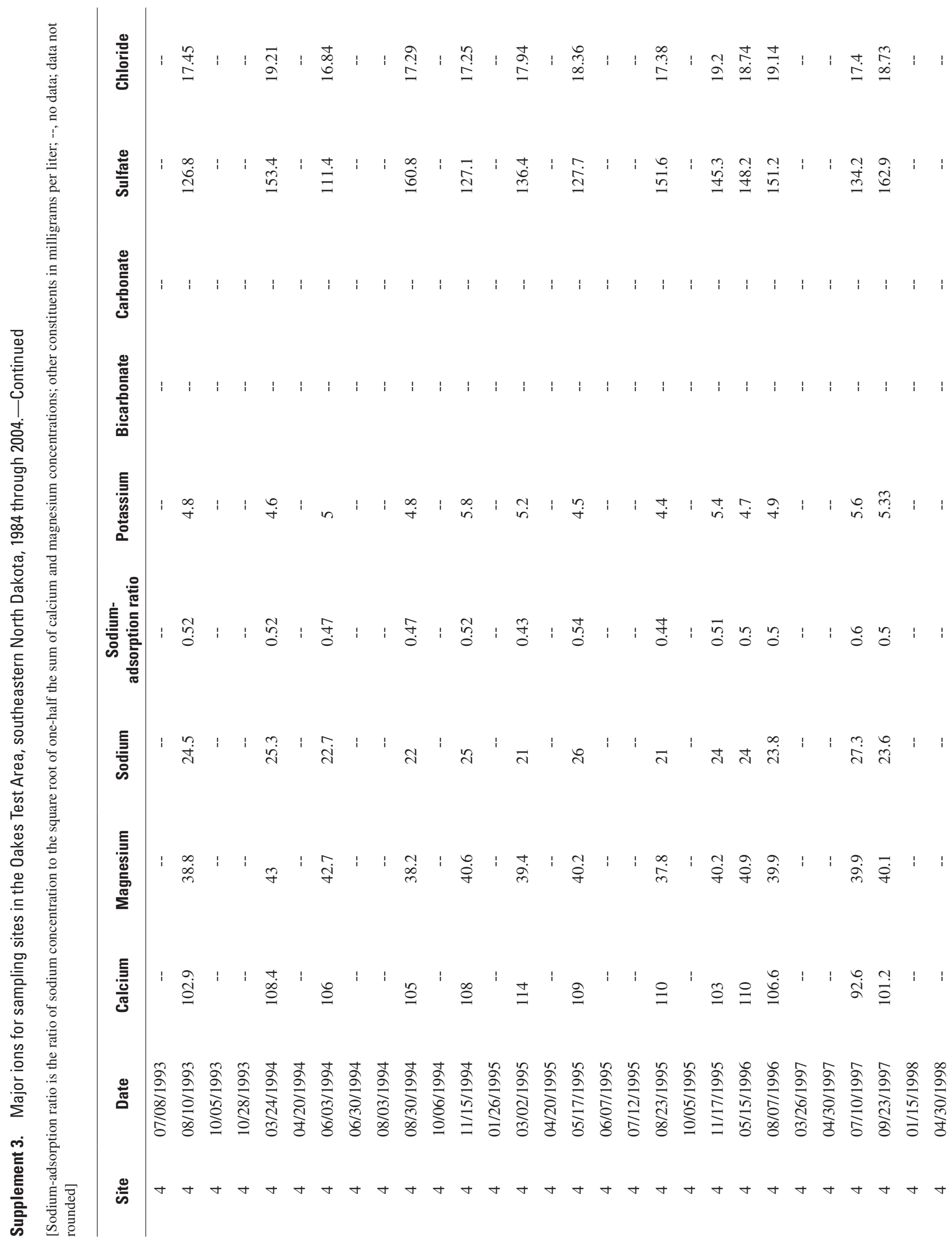




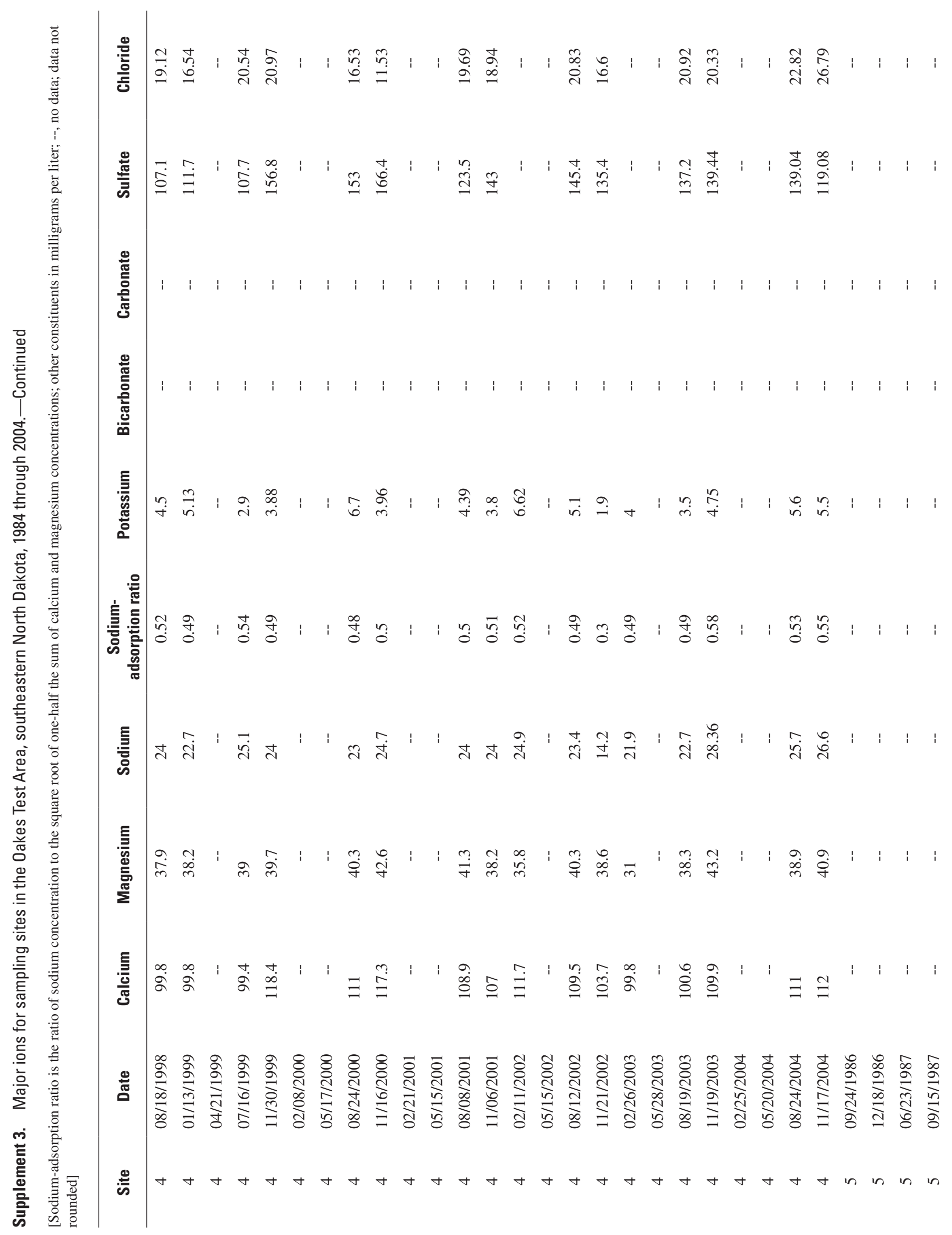




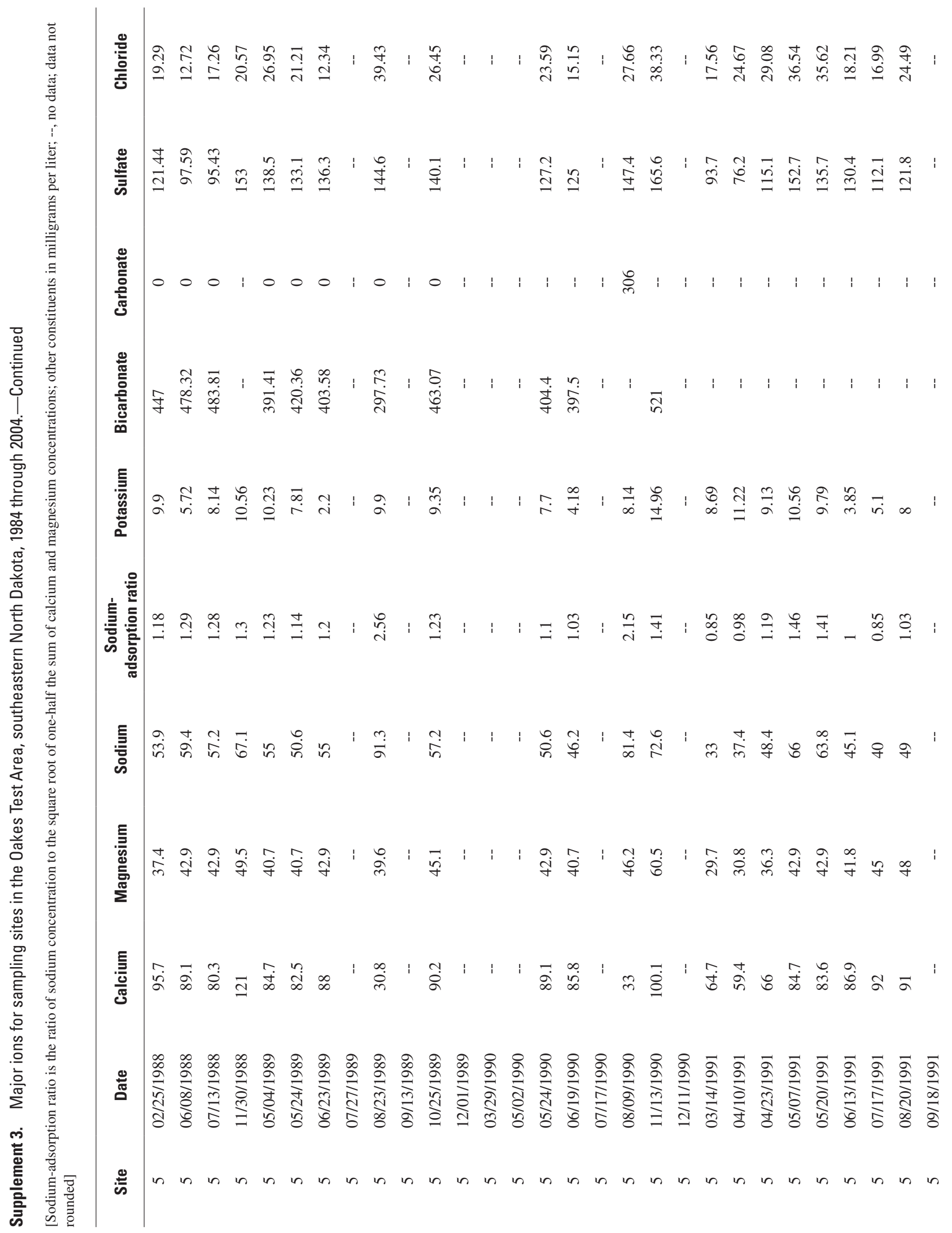




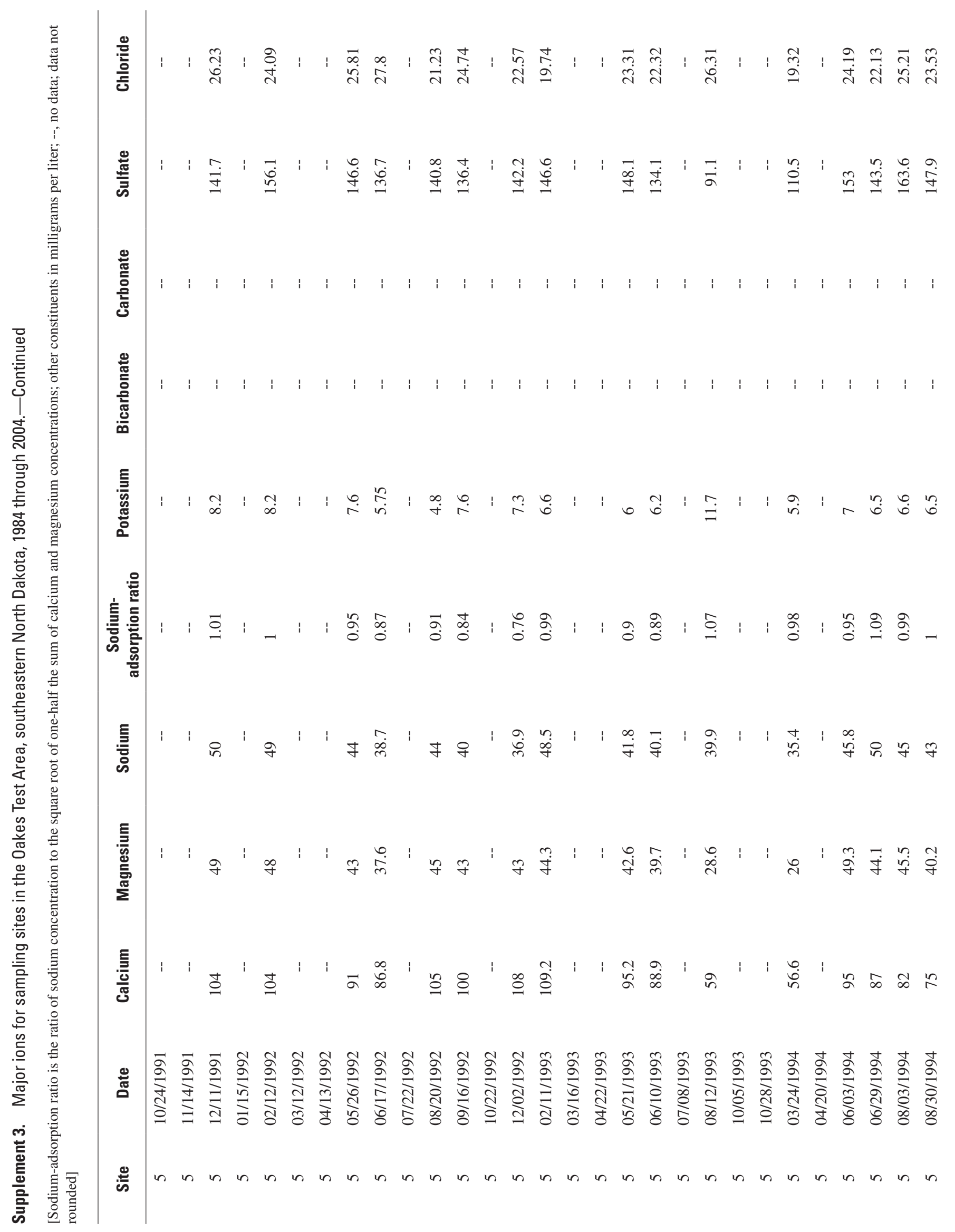




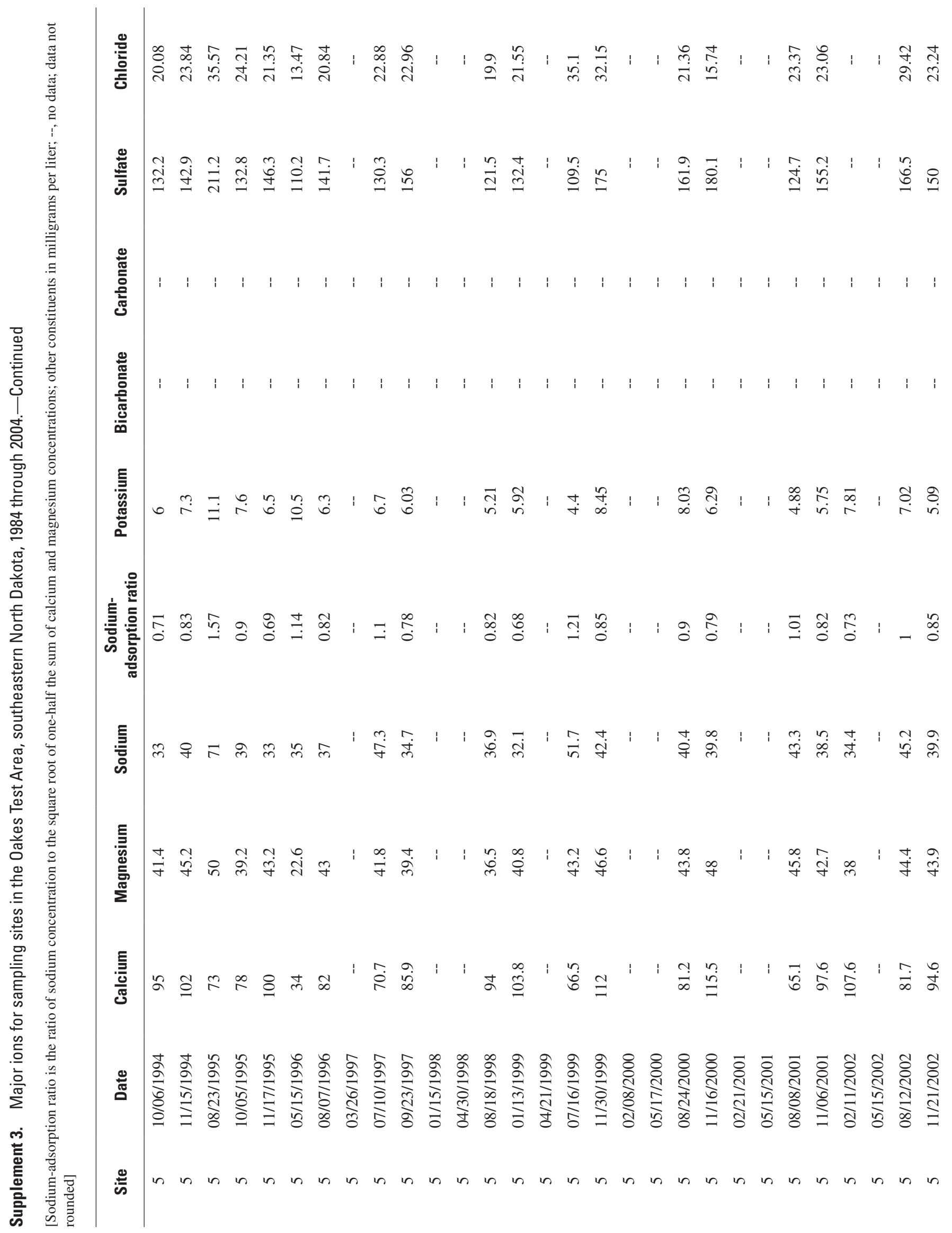




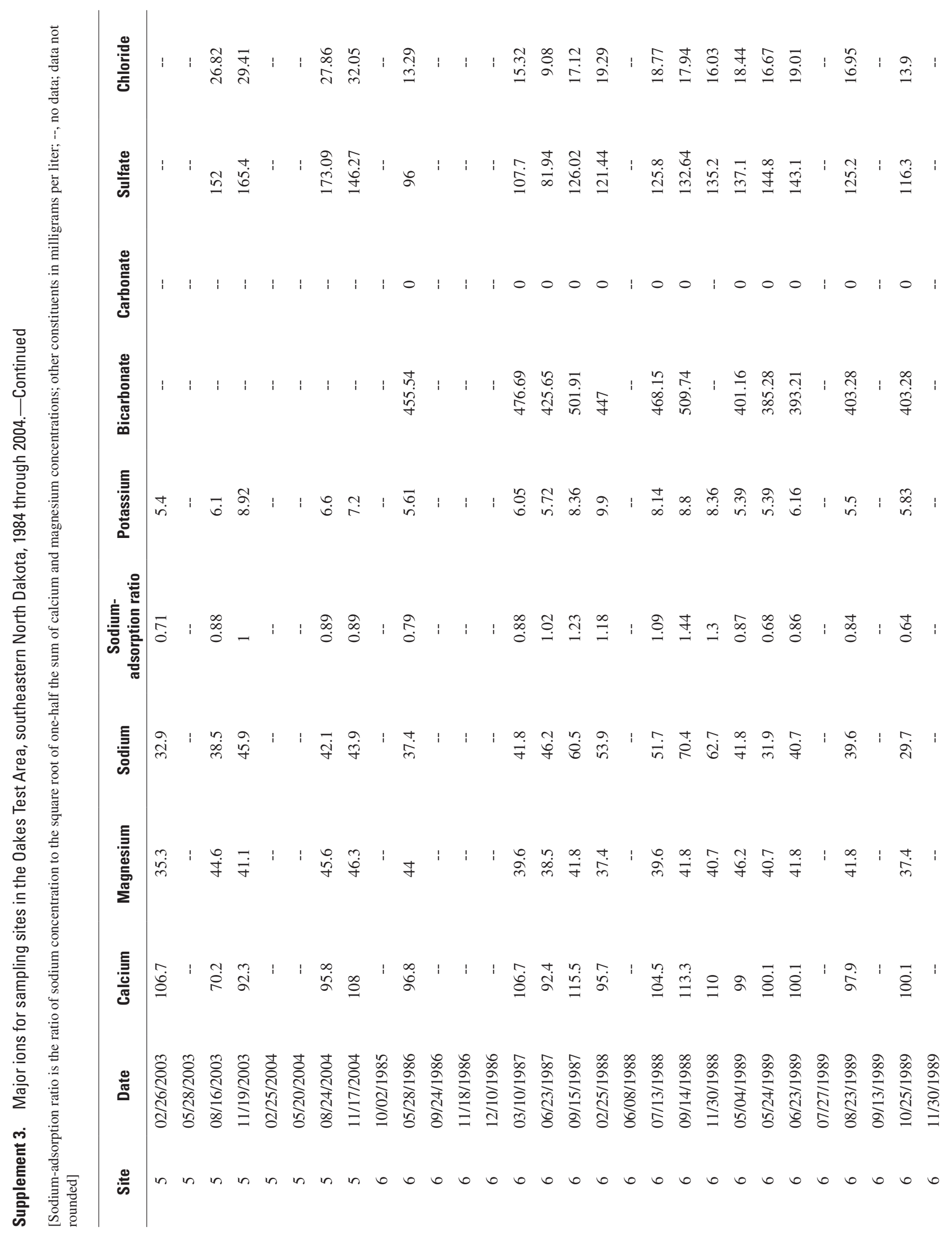




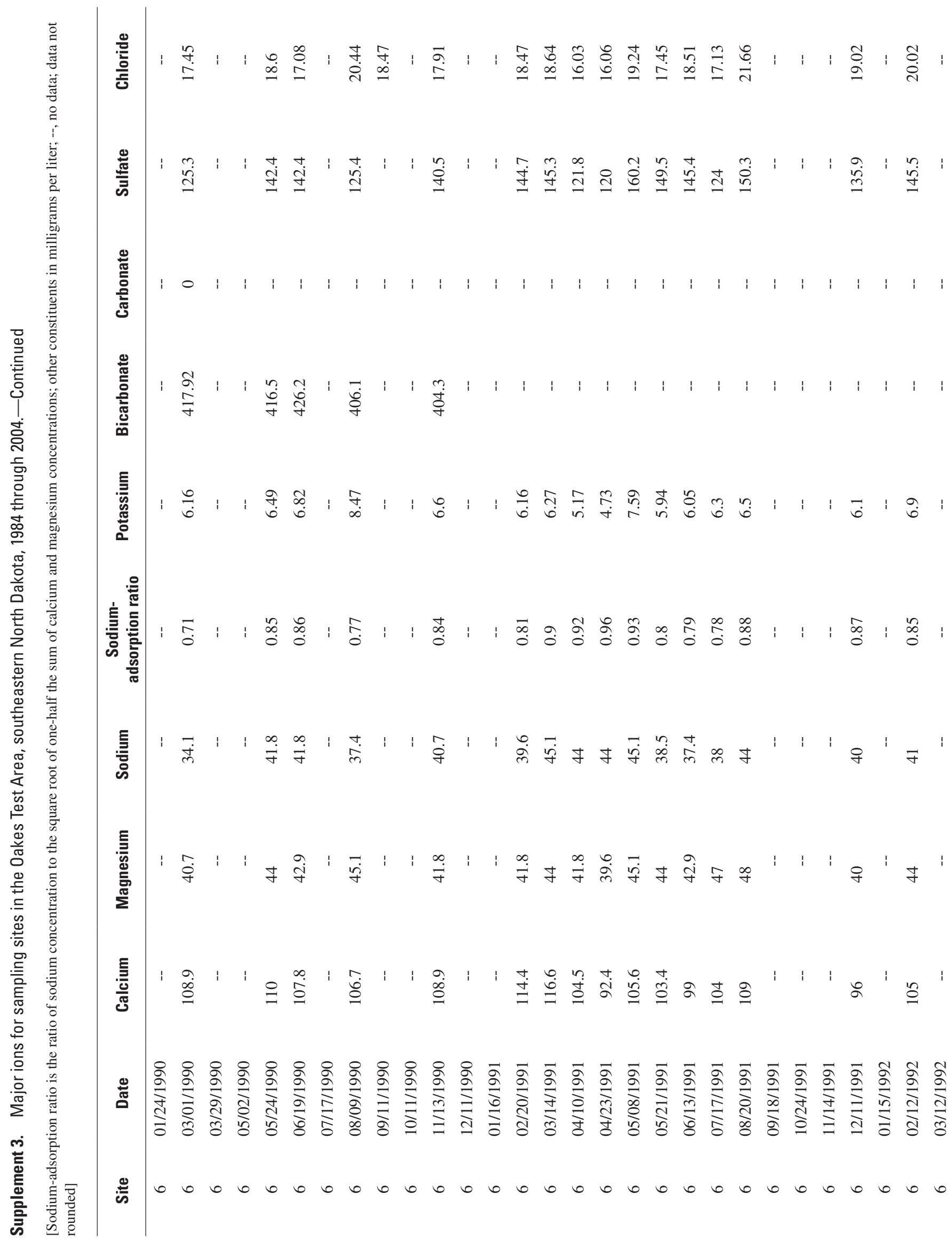




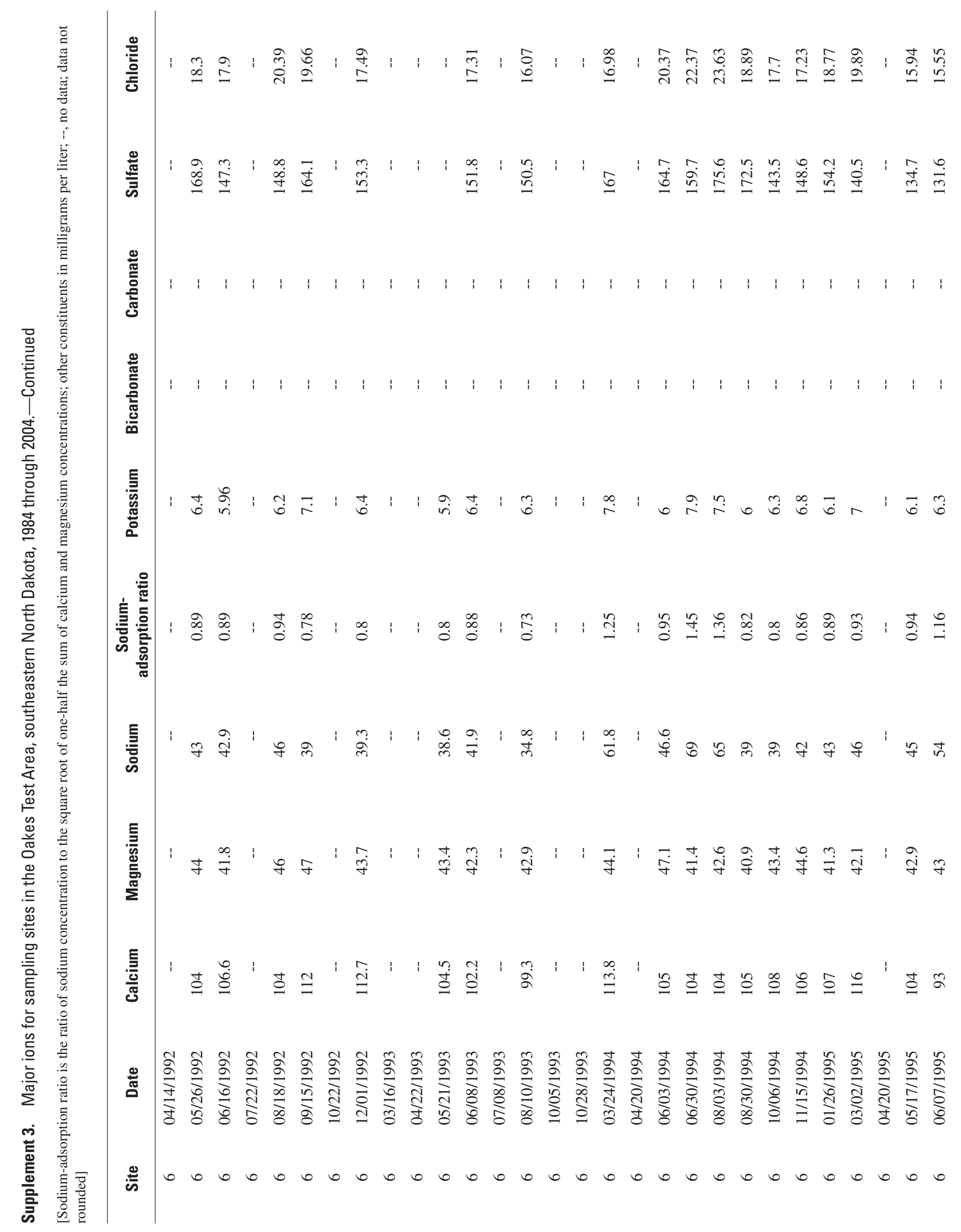




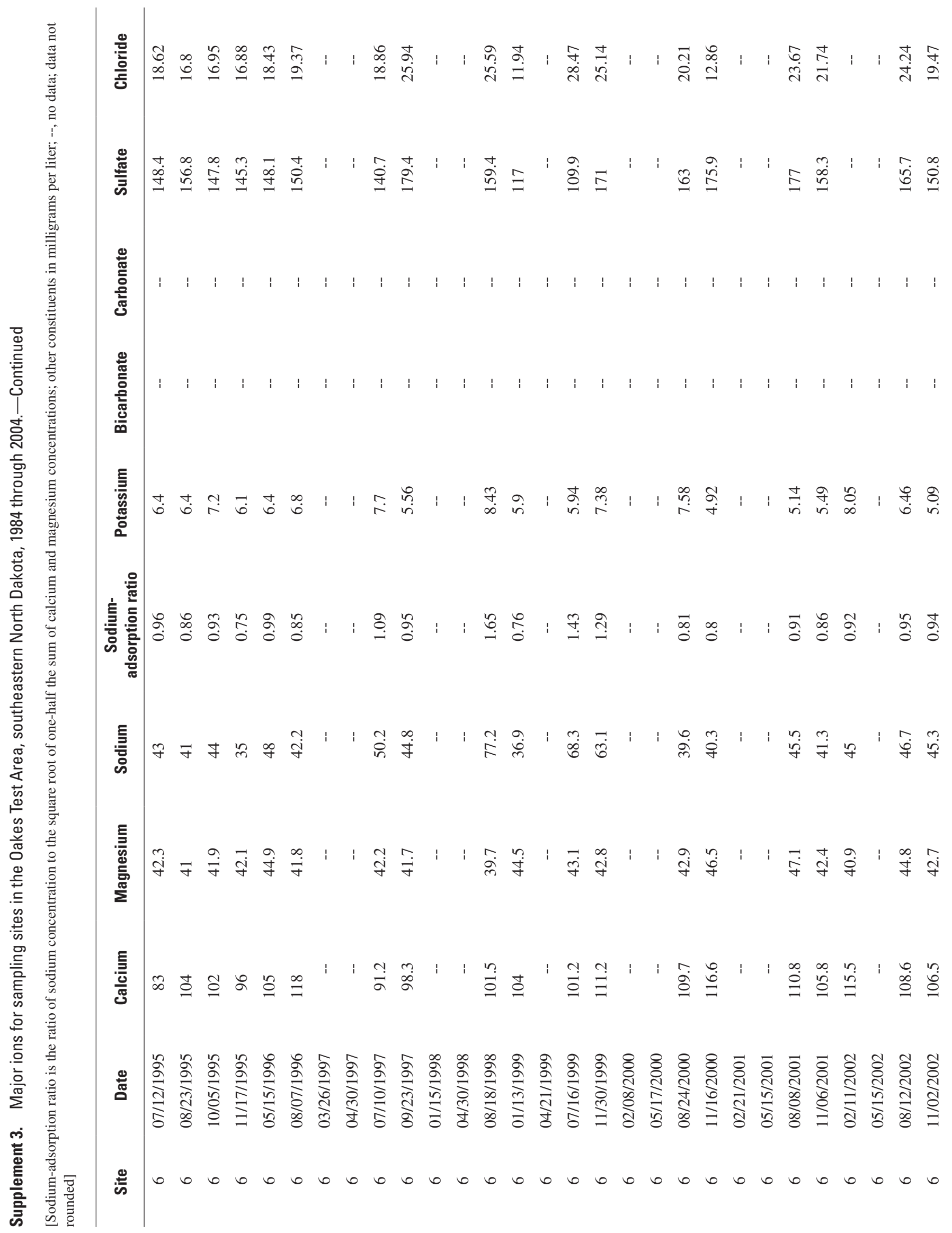




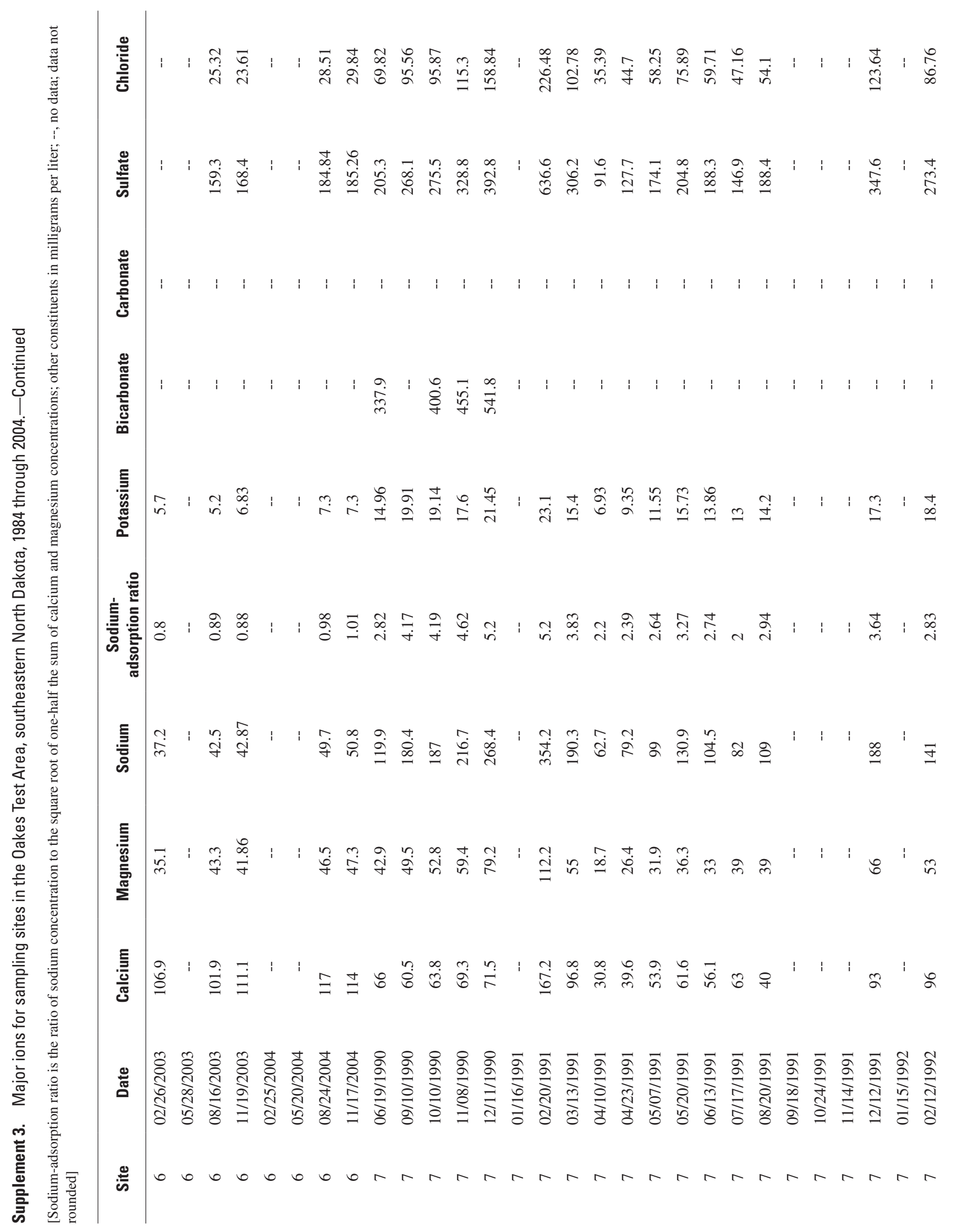




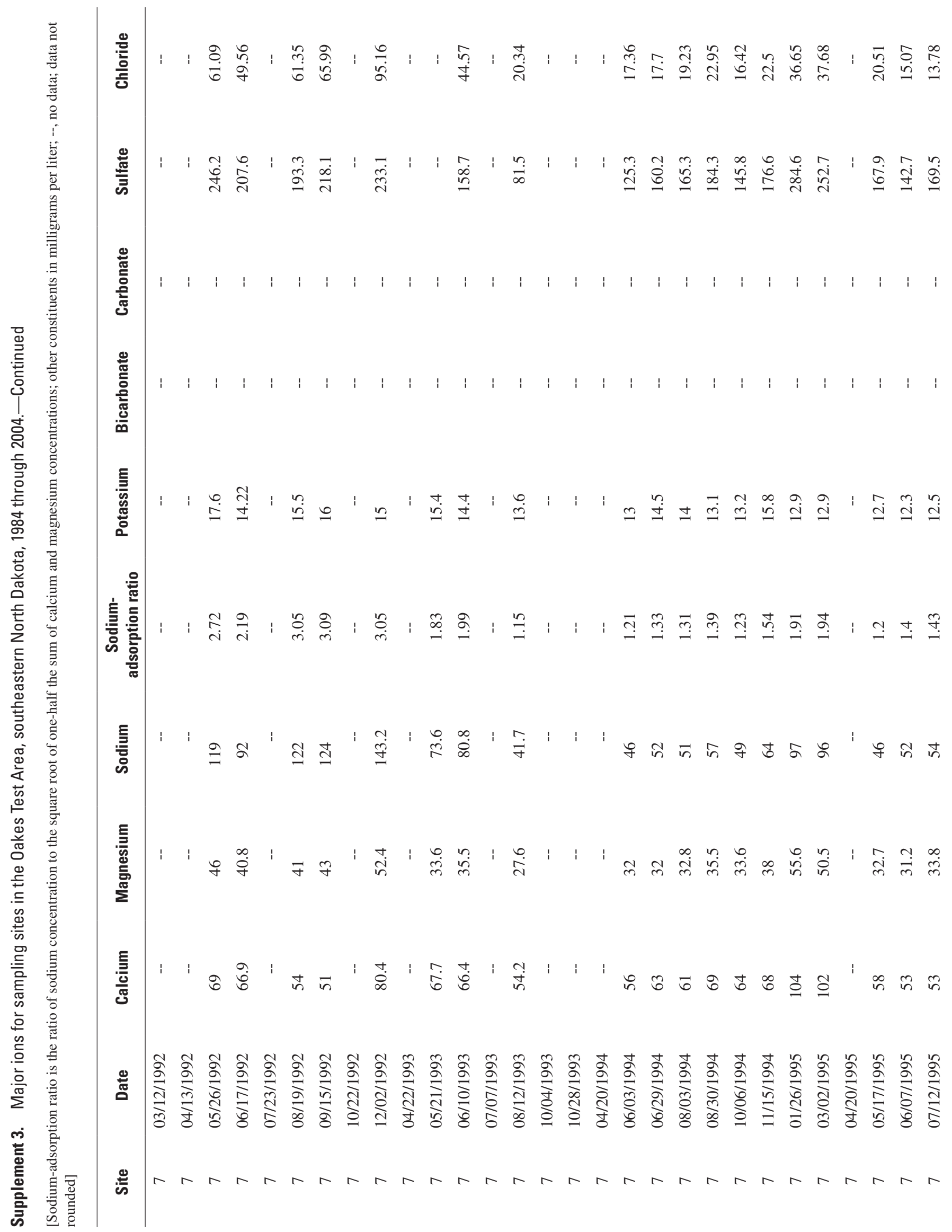




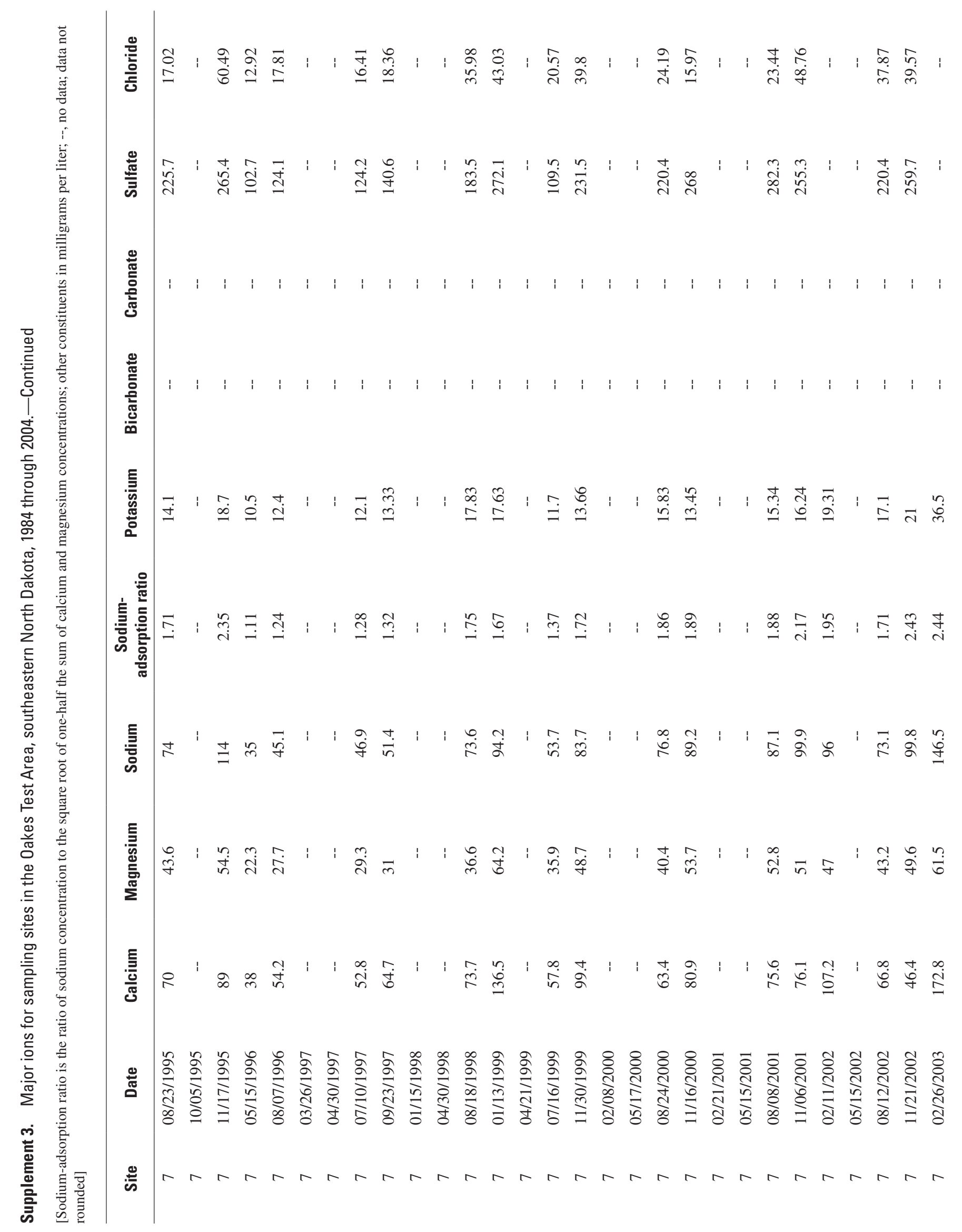




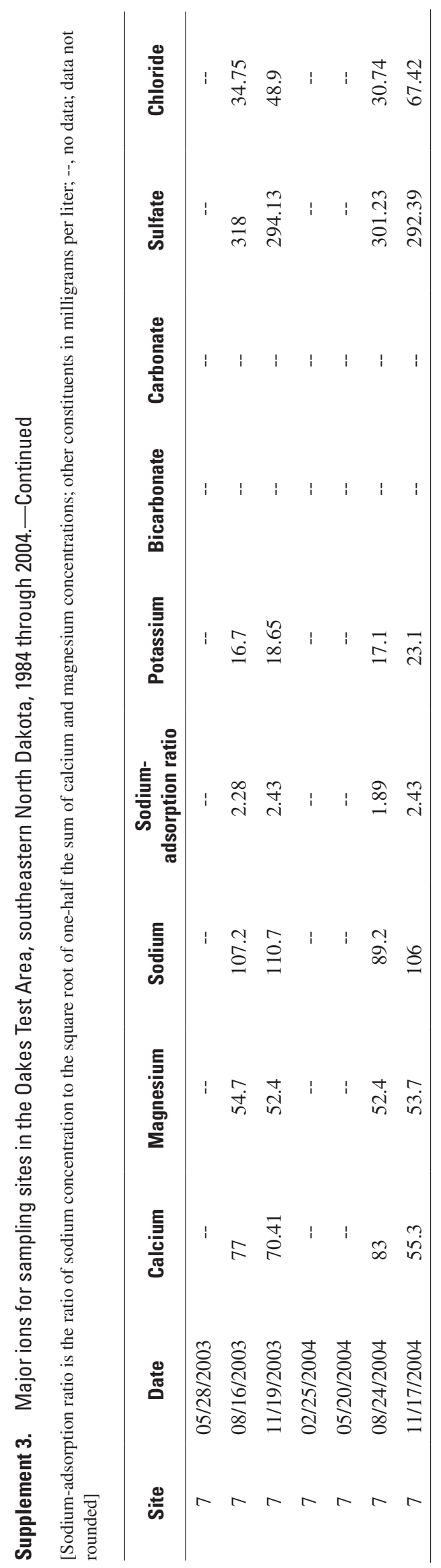




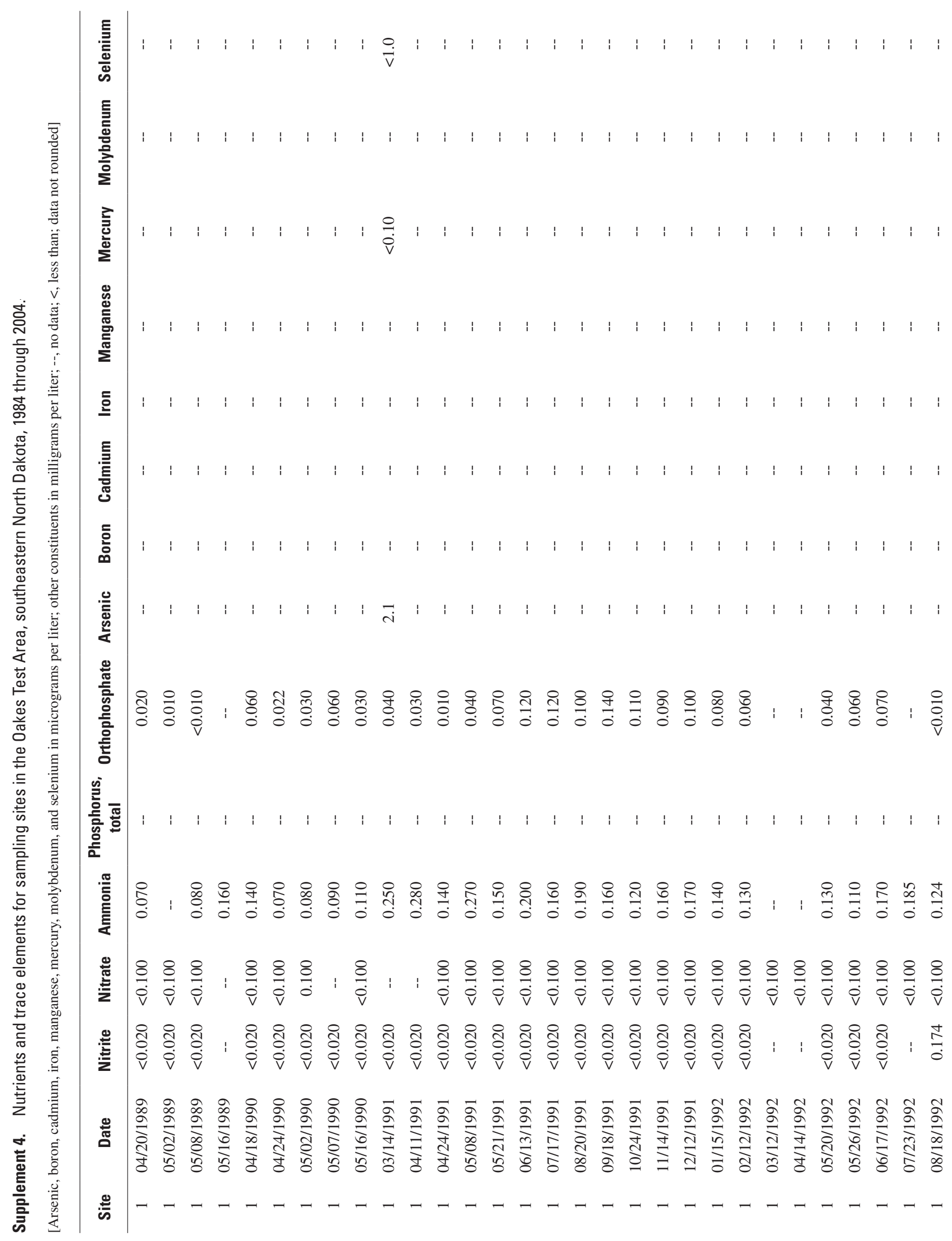




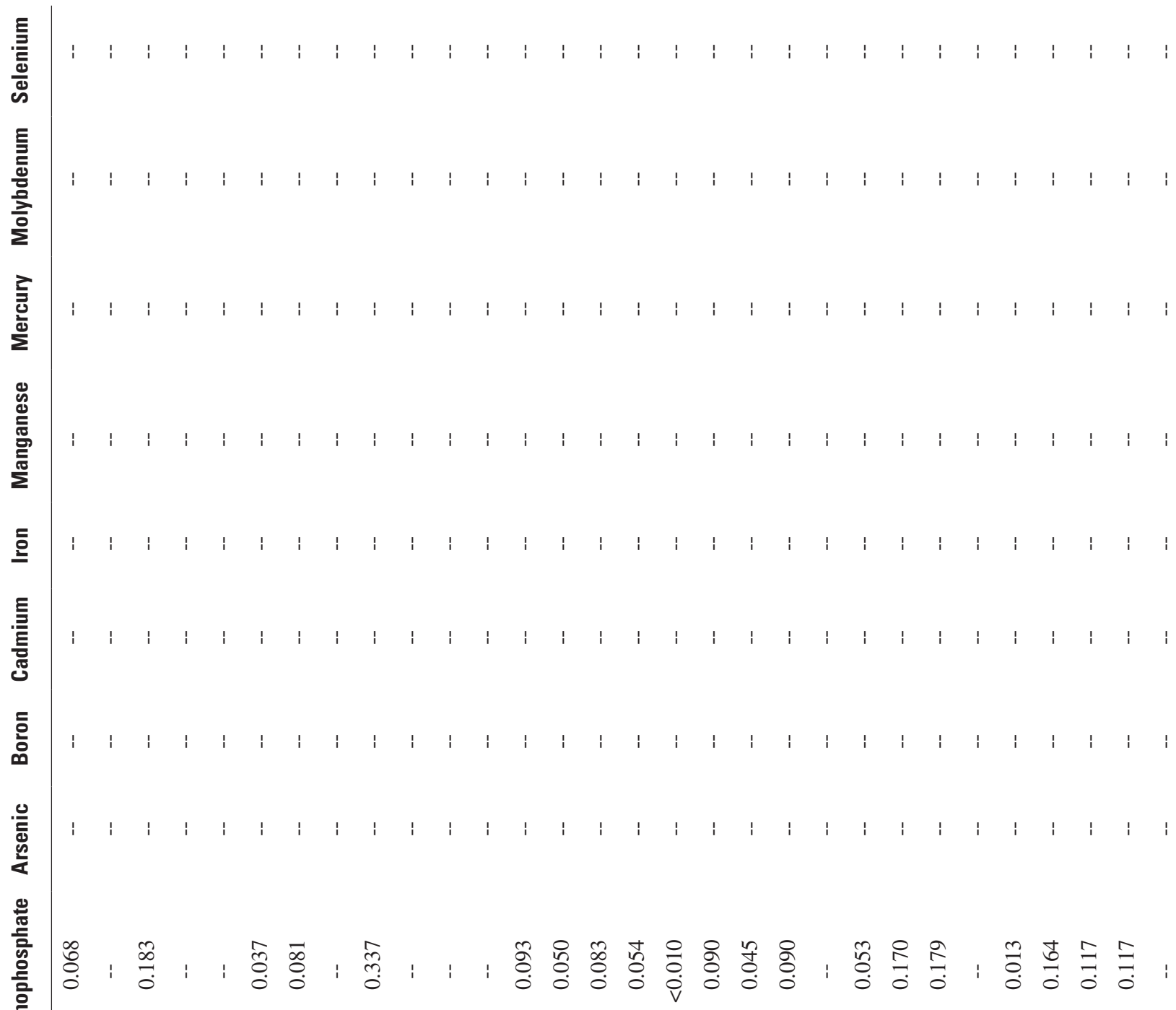

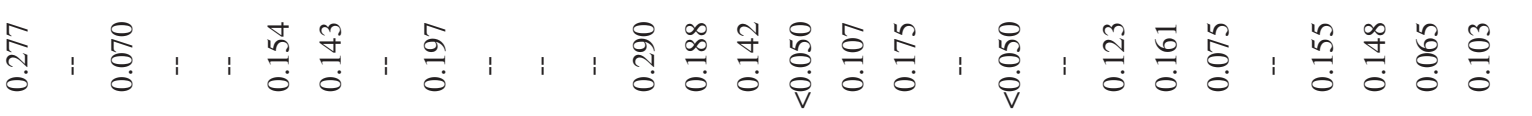

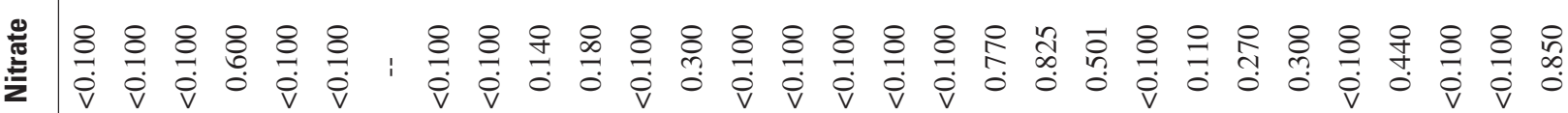

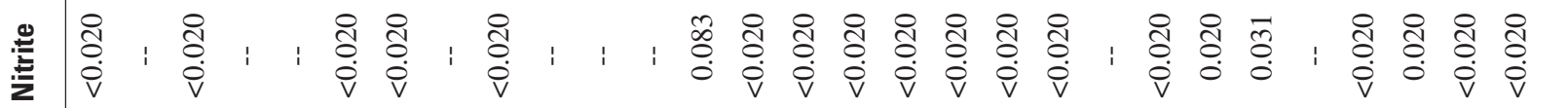

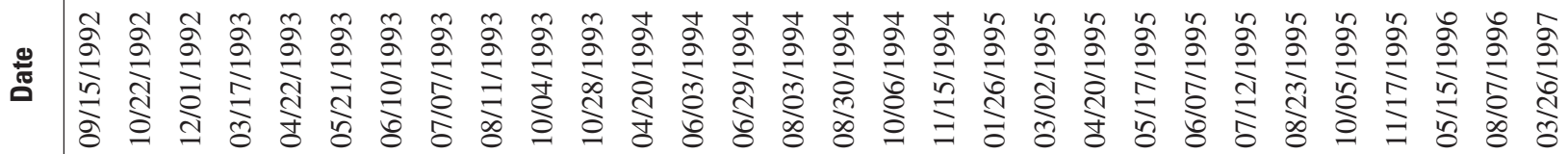


Supplement $\quad 97$

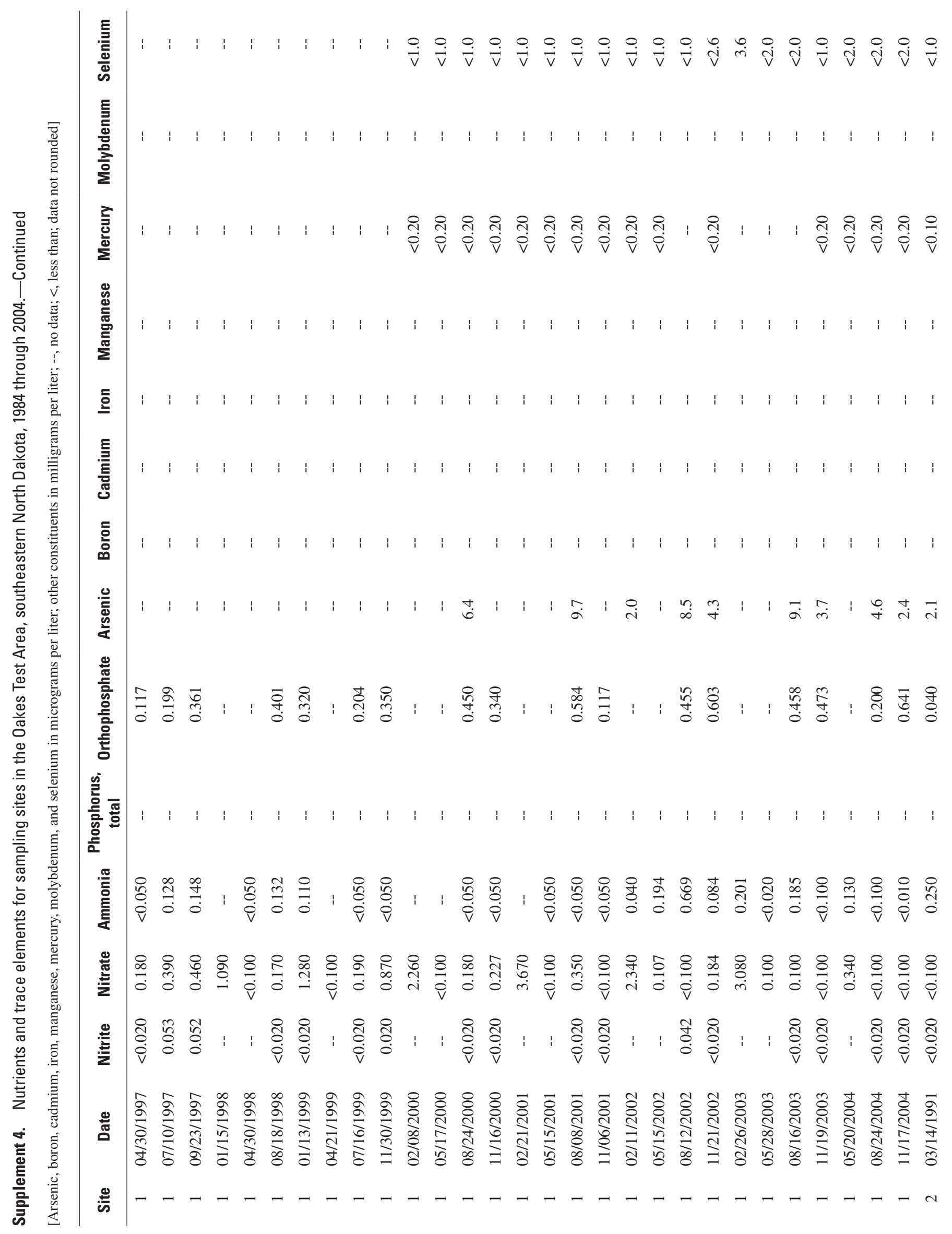




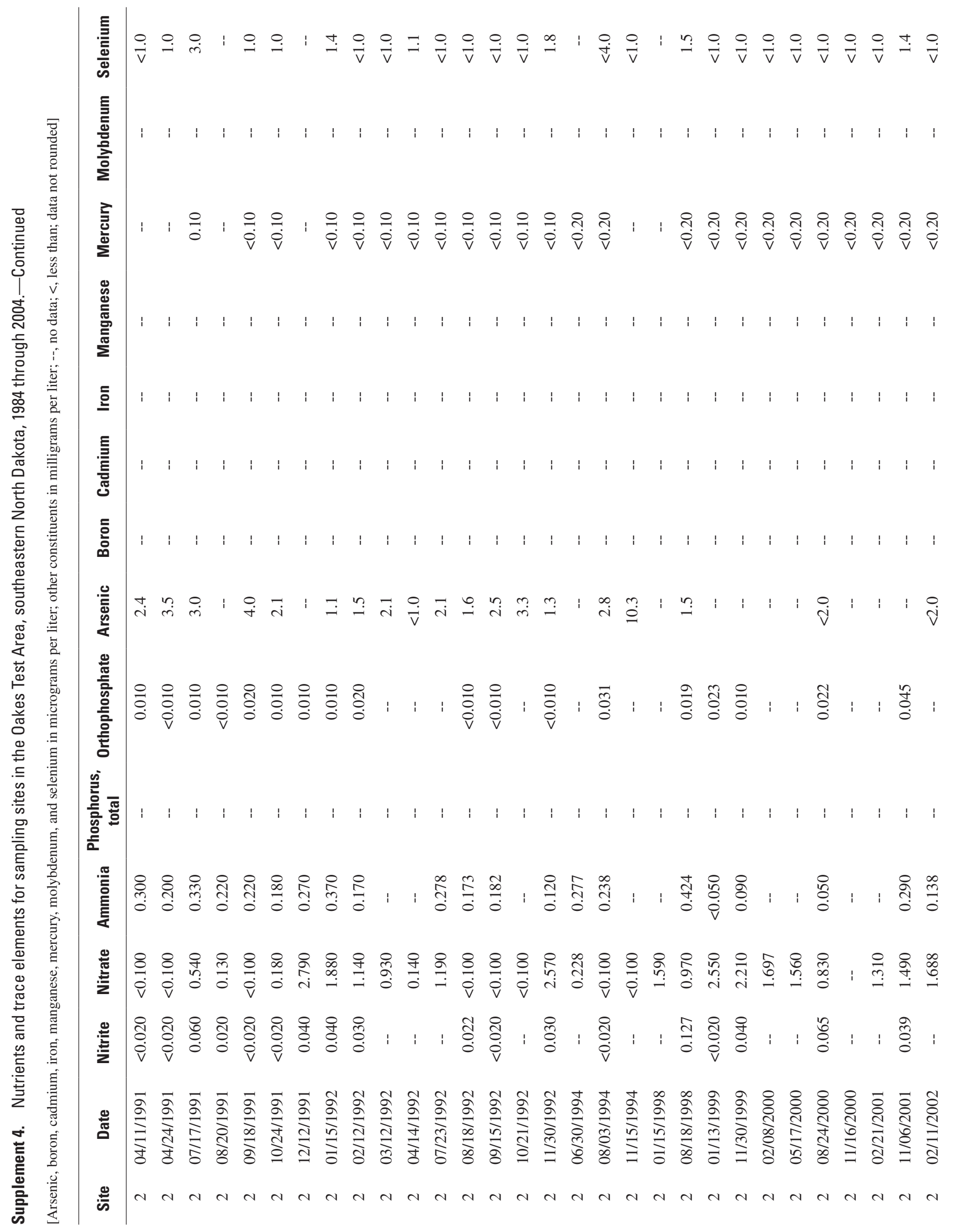




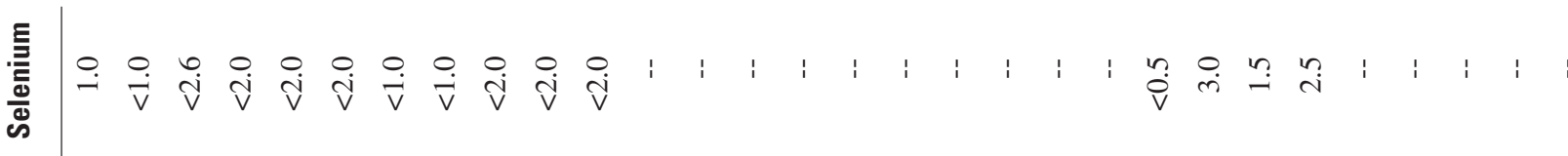




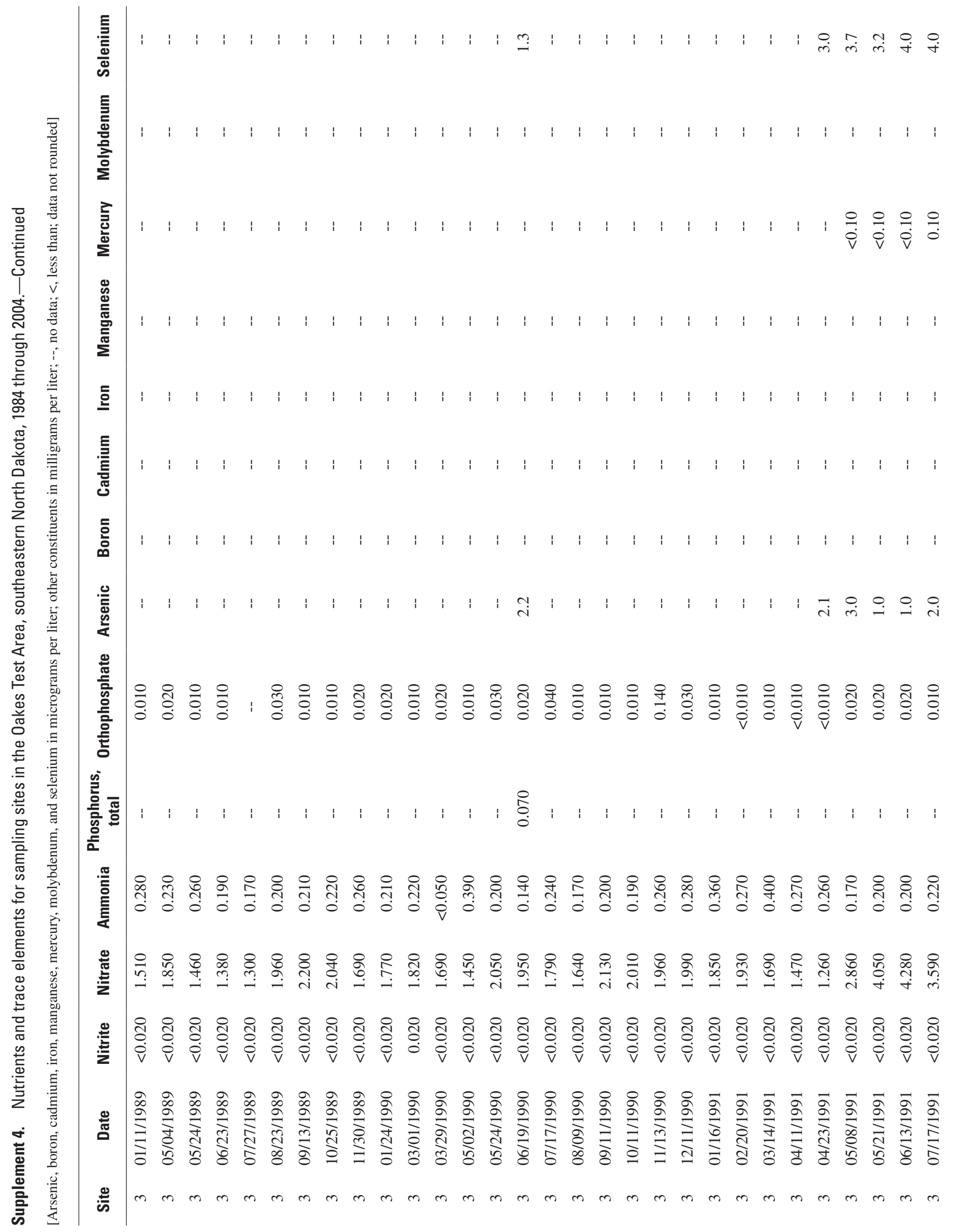




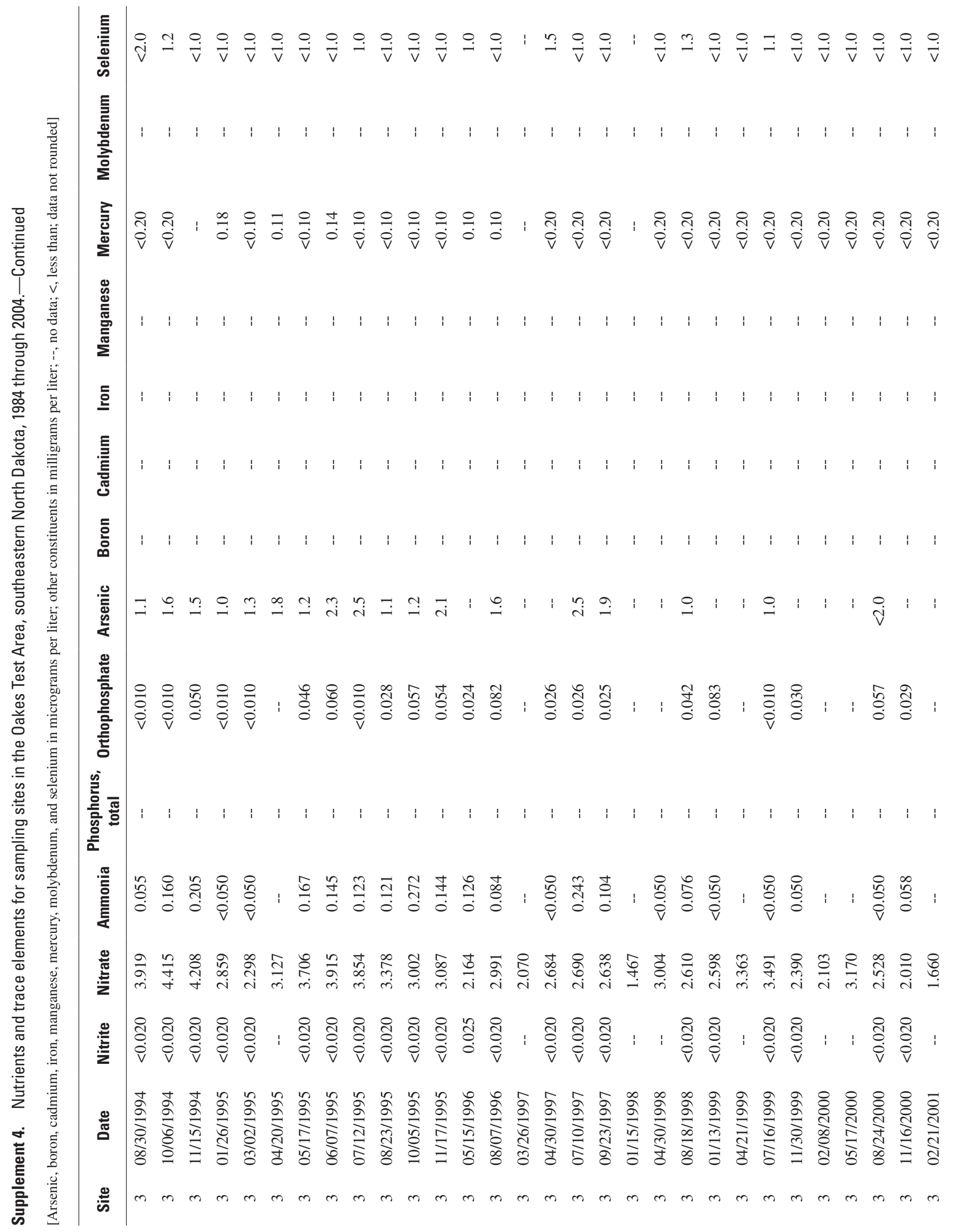




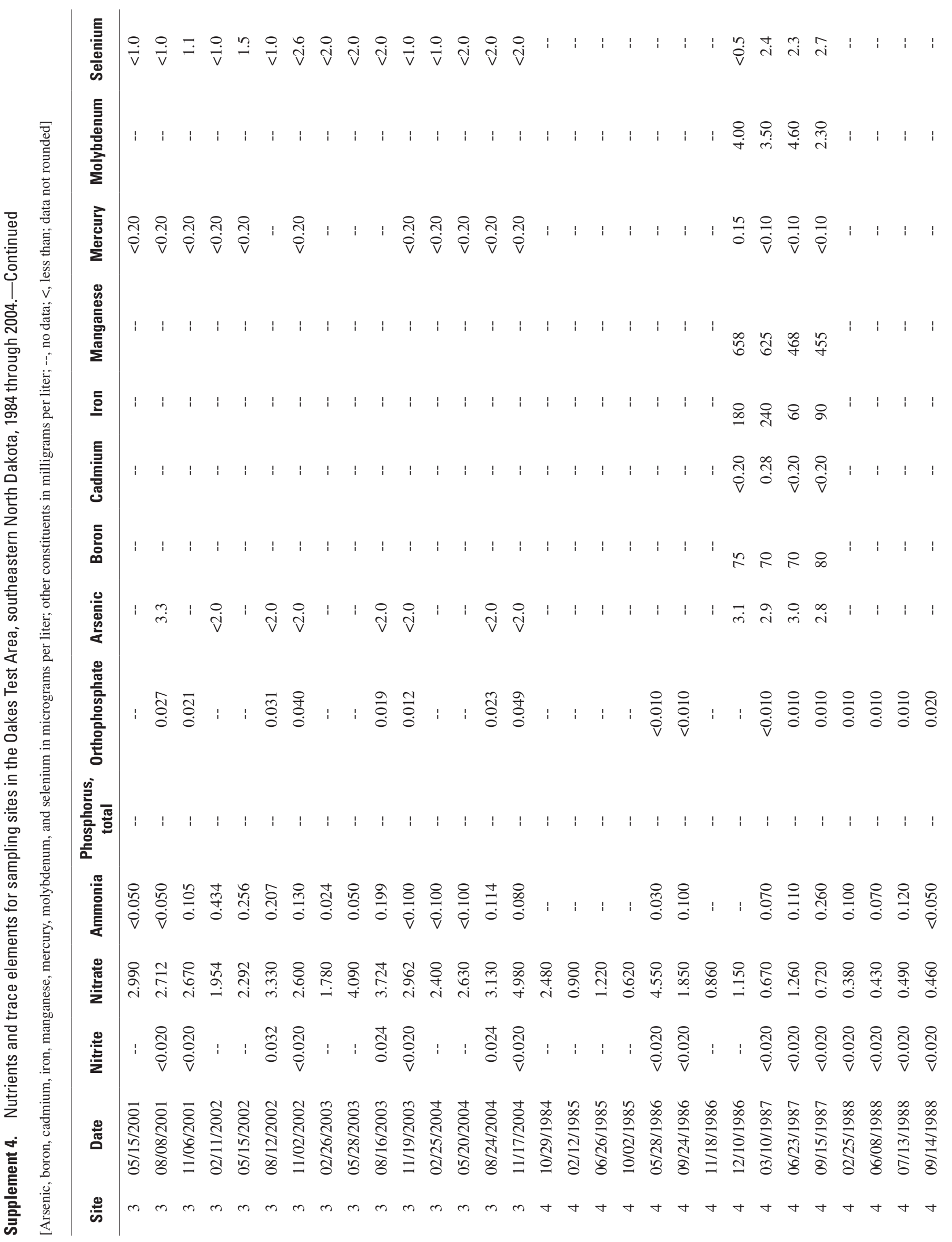




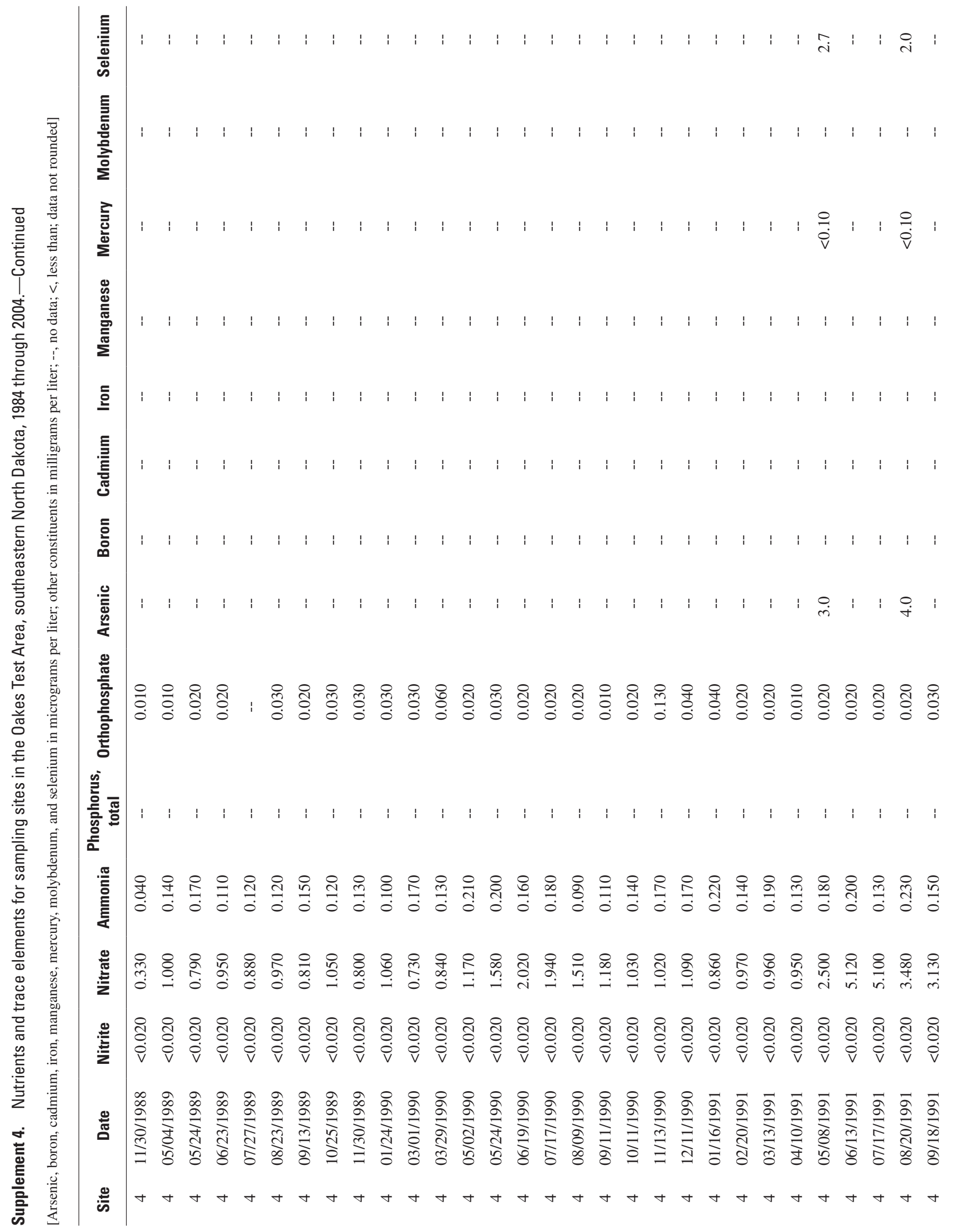




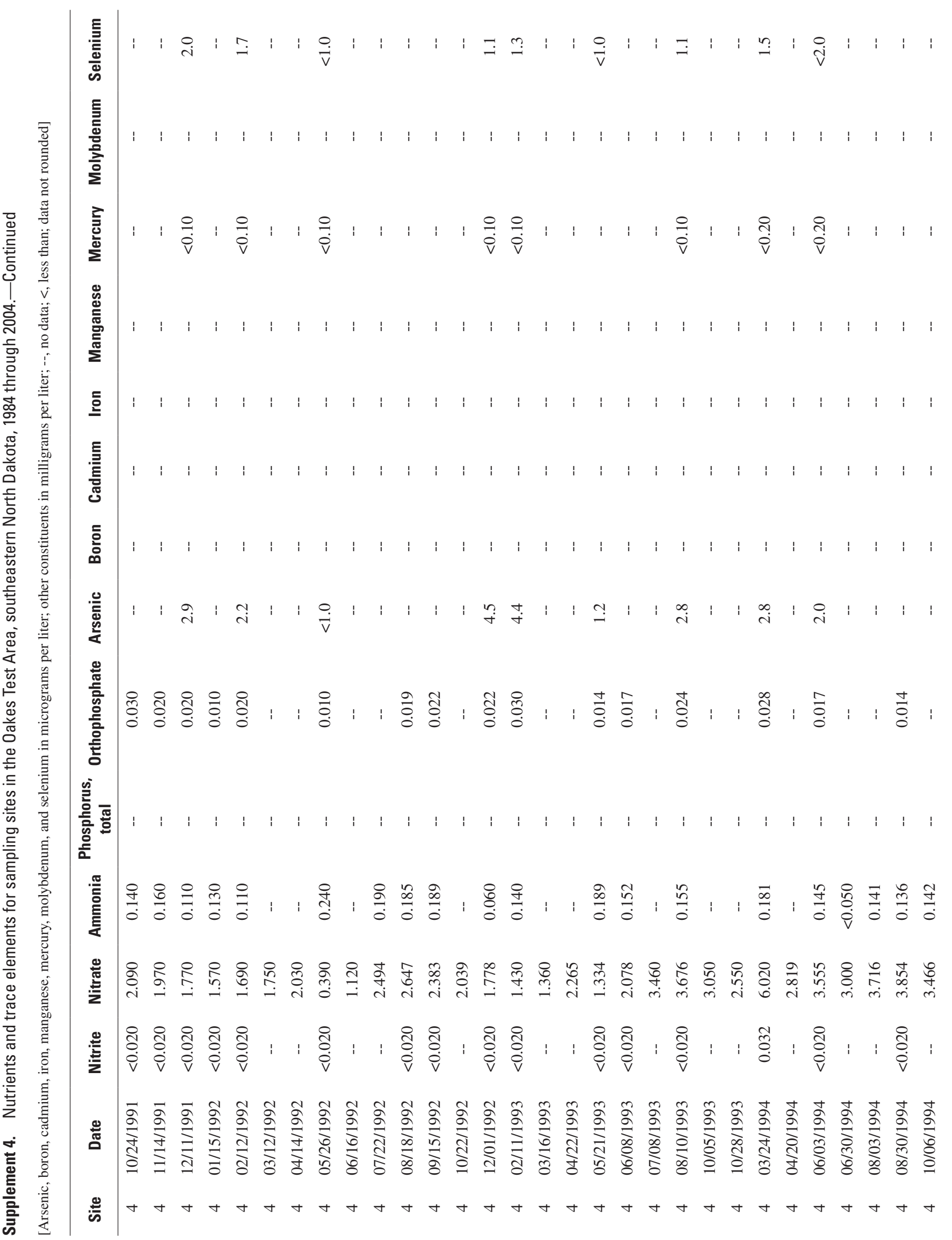




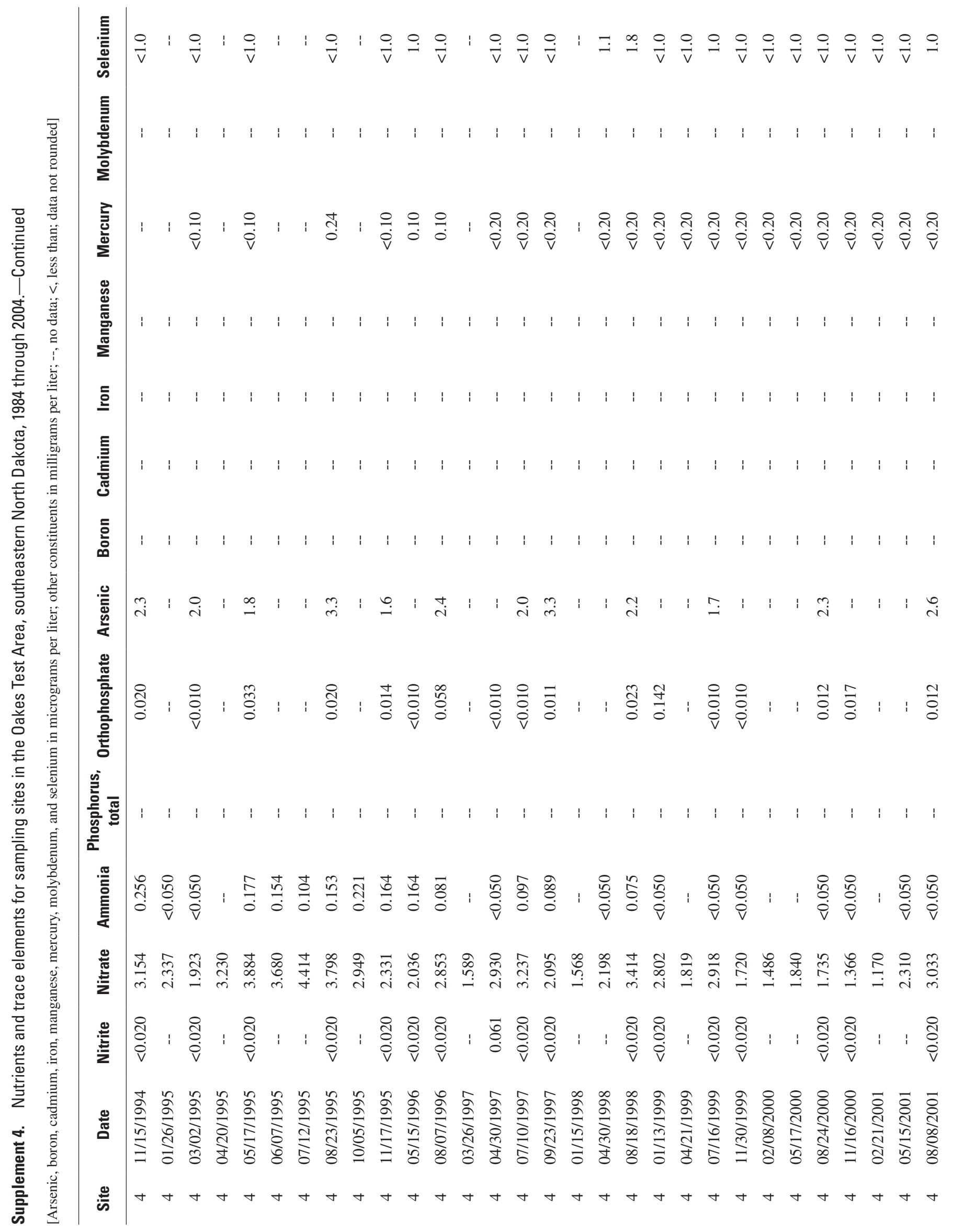




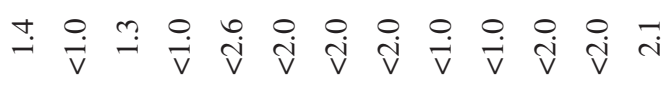

च

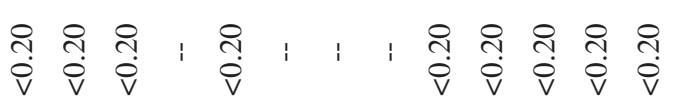




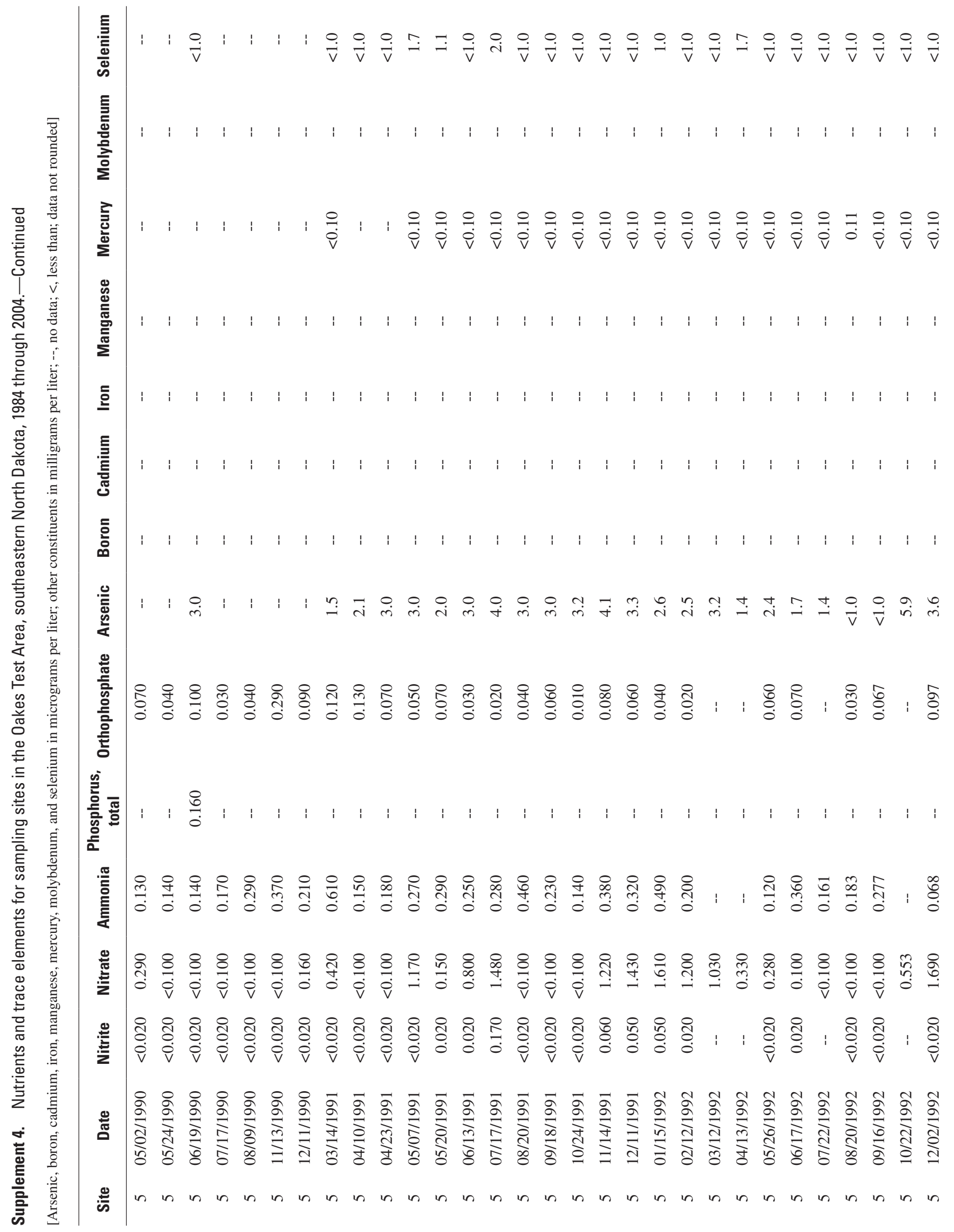




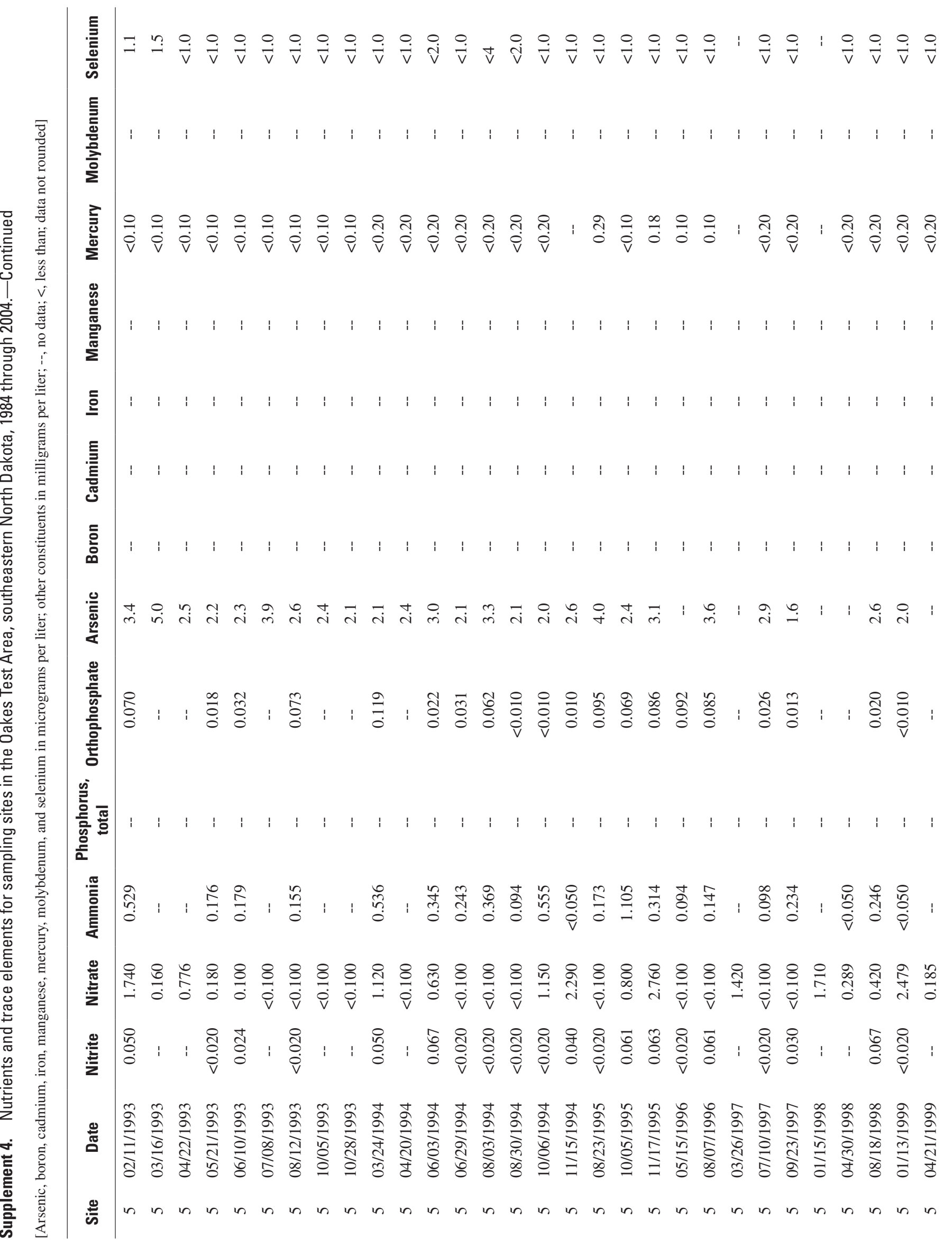




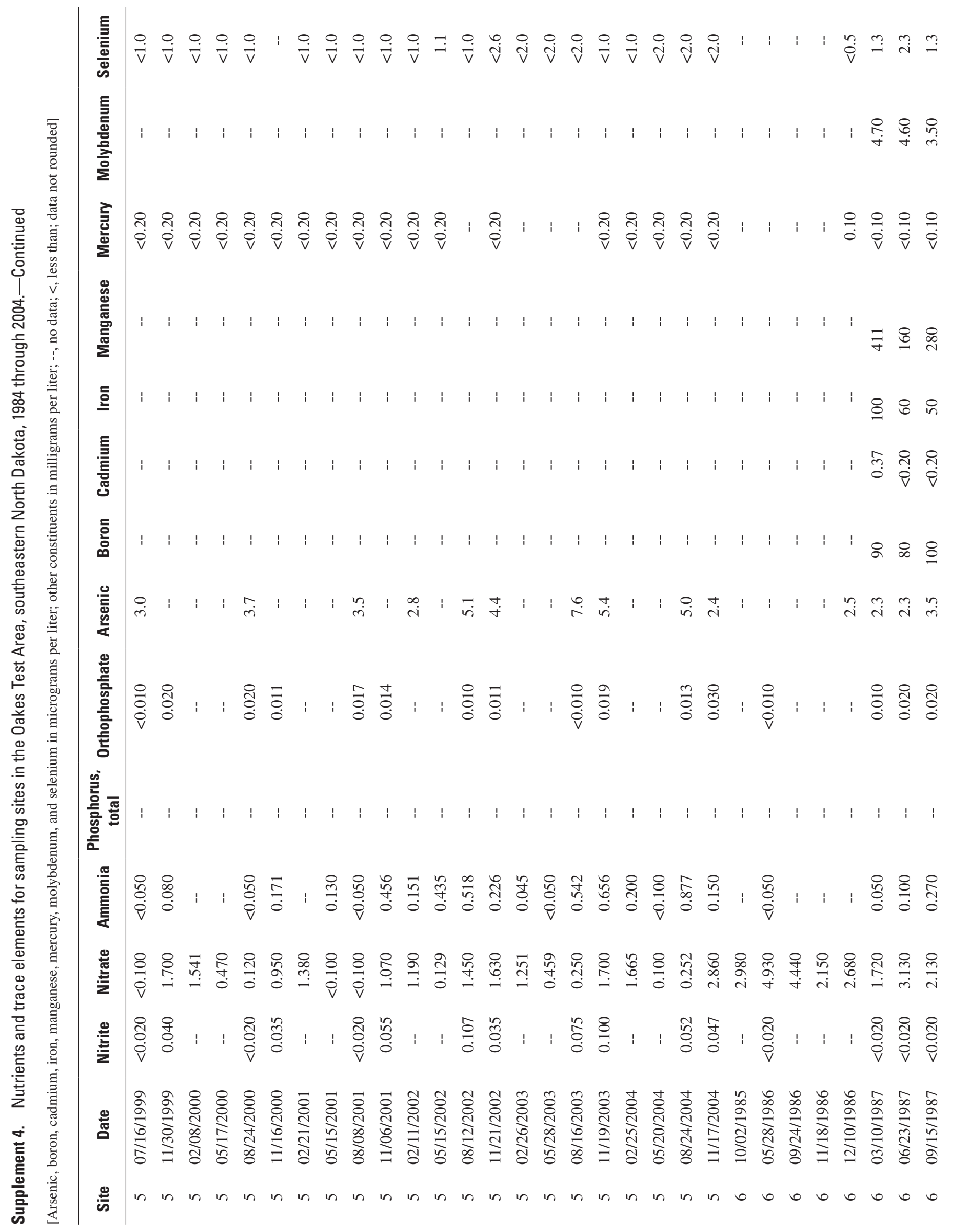




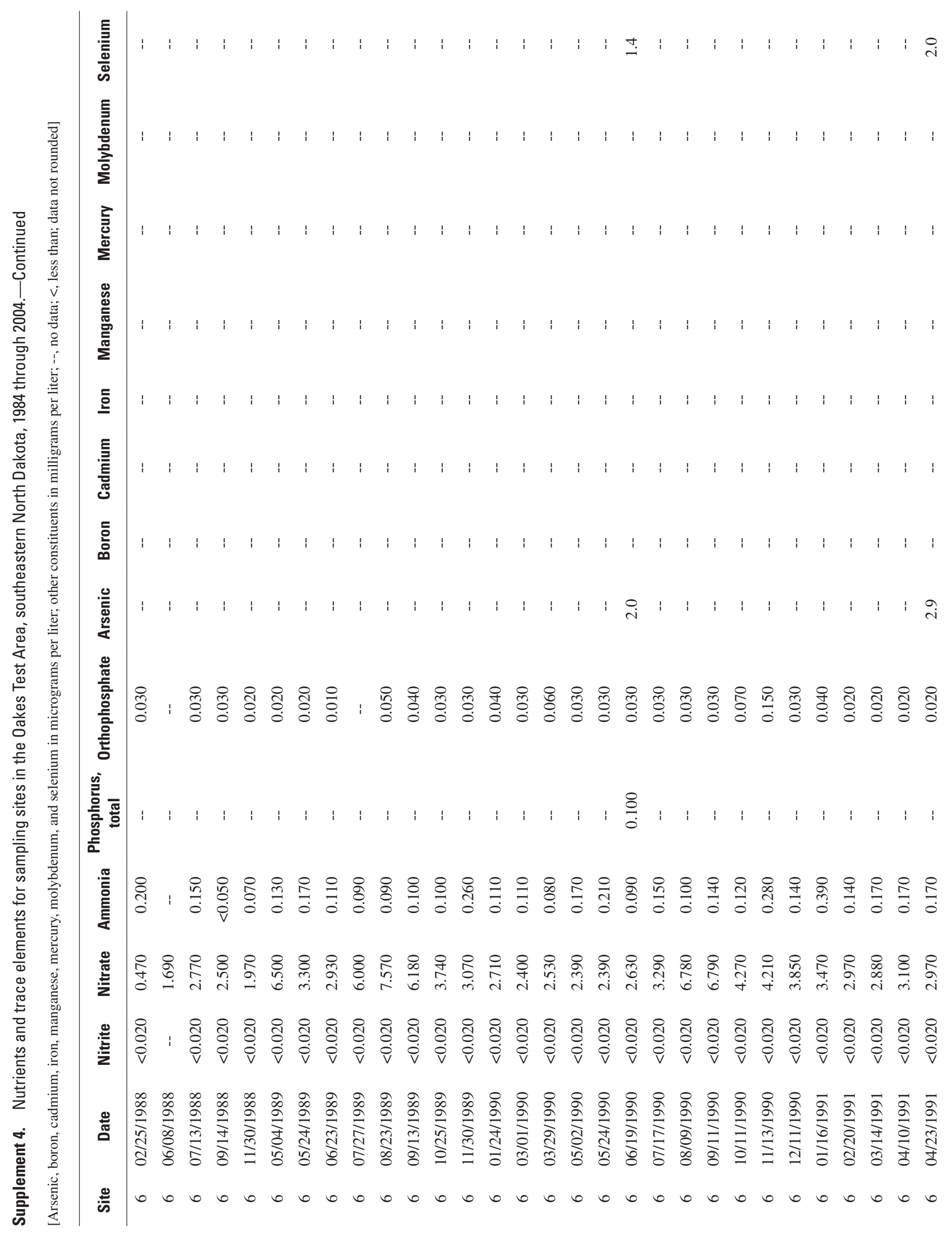


产

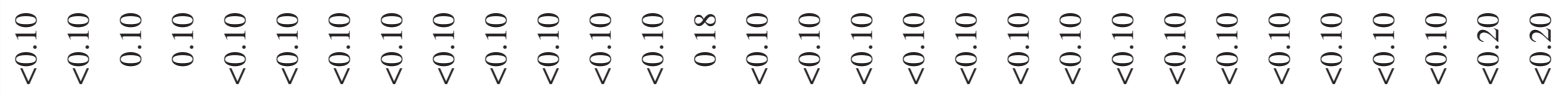

要

호ํ

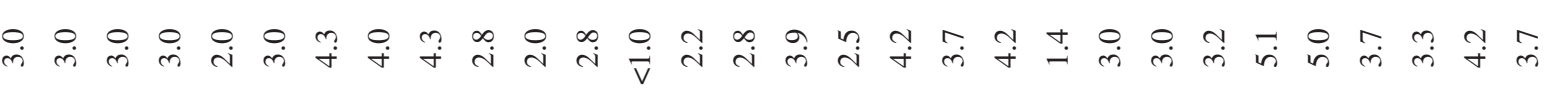

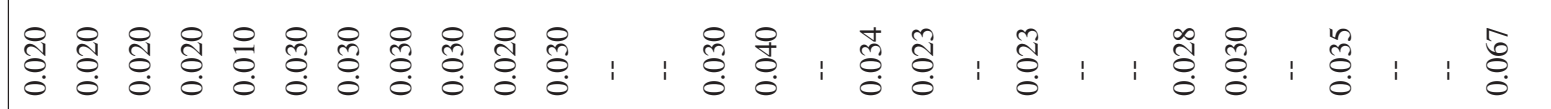




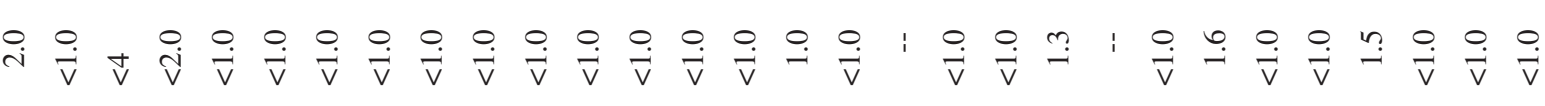

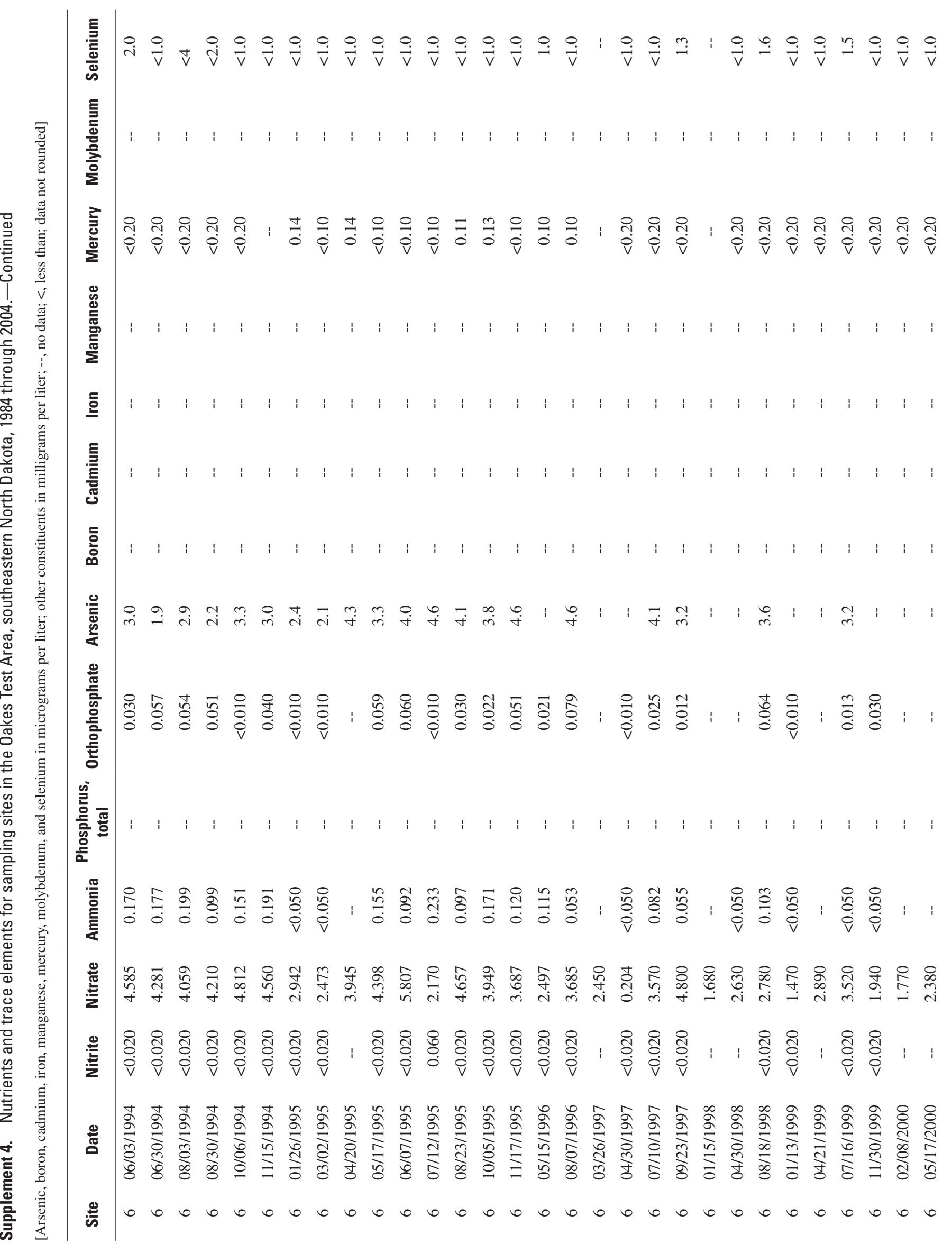




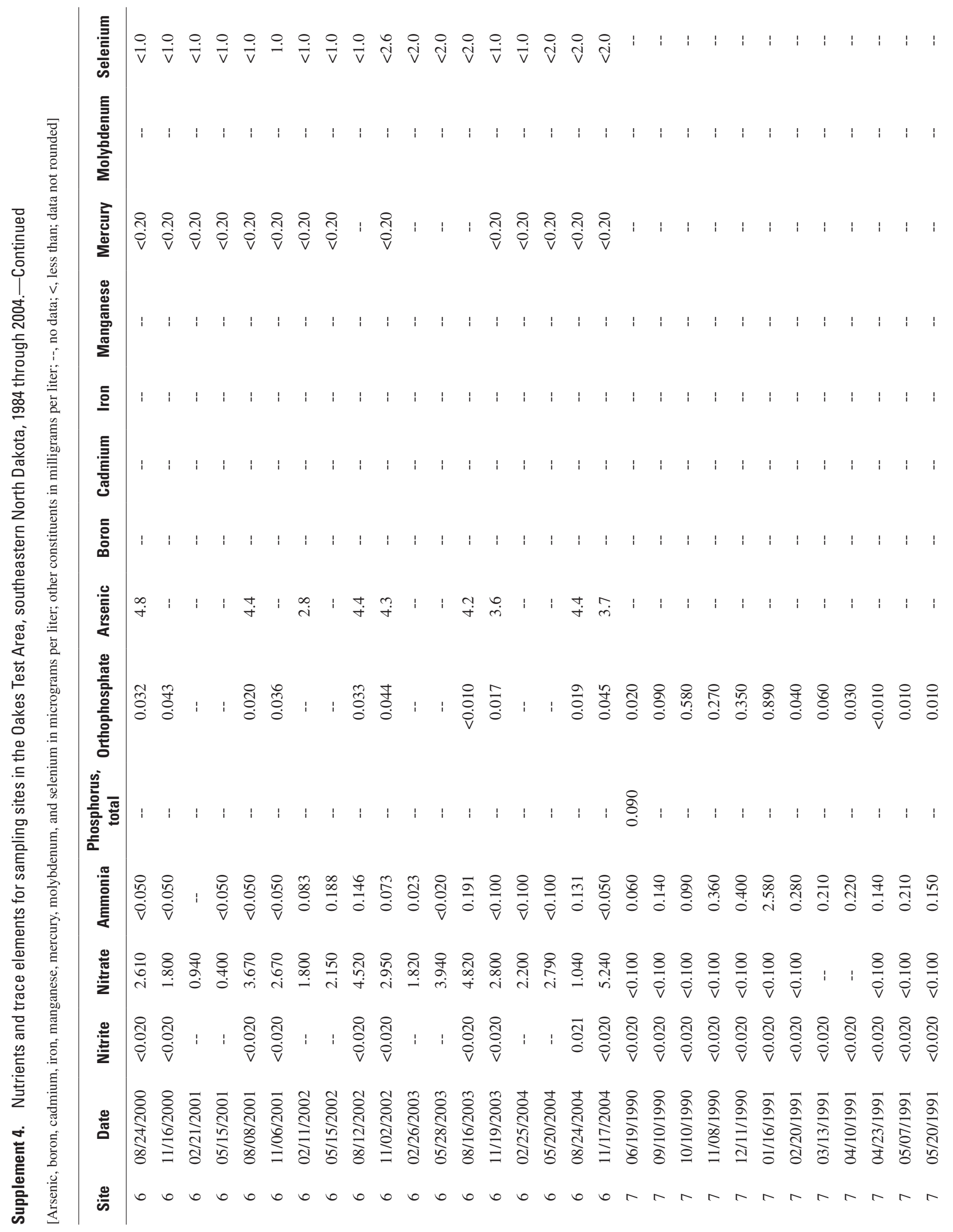




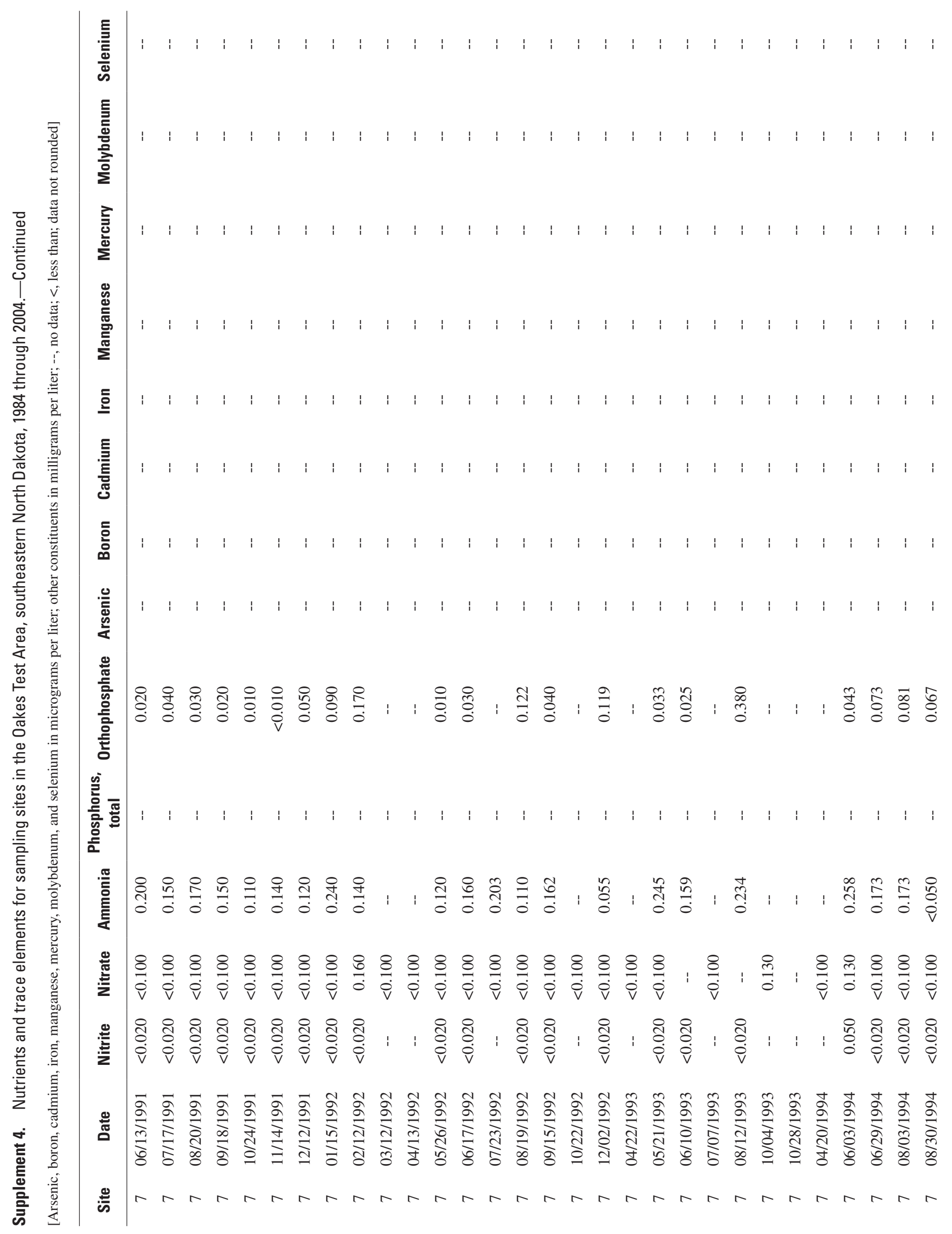




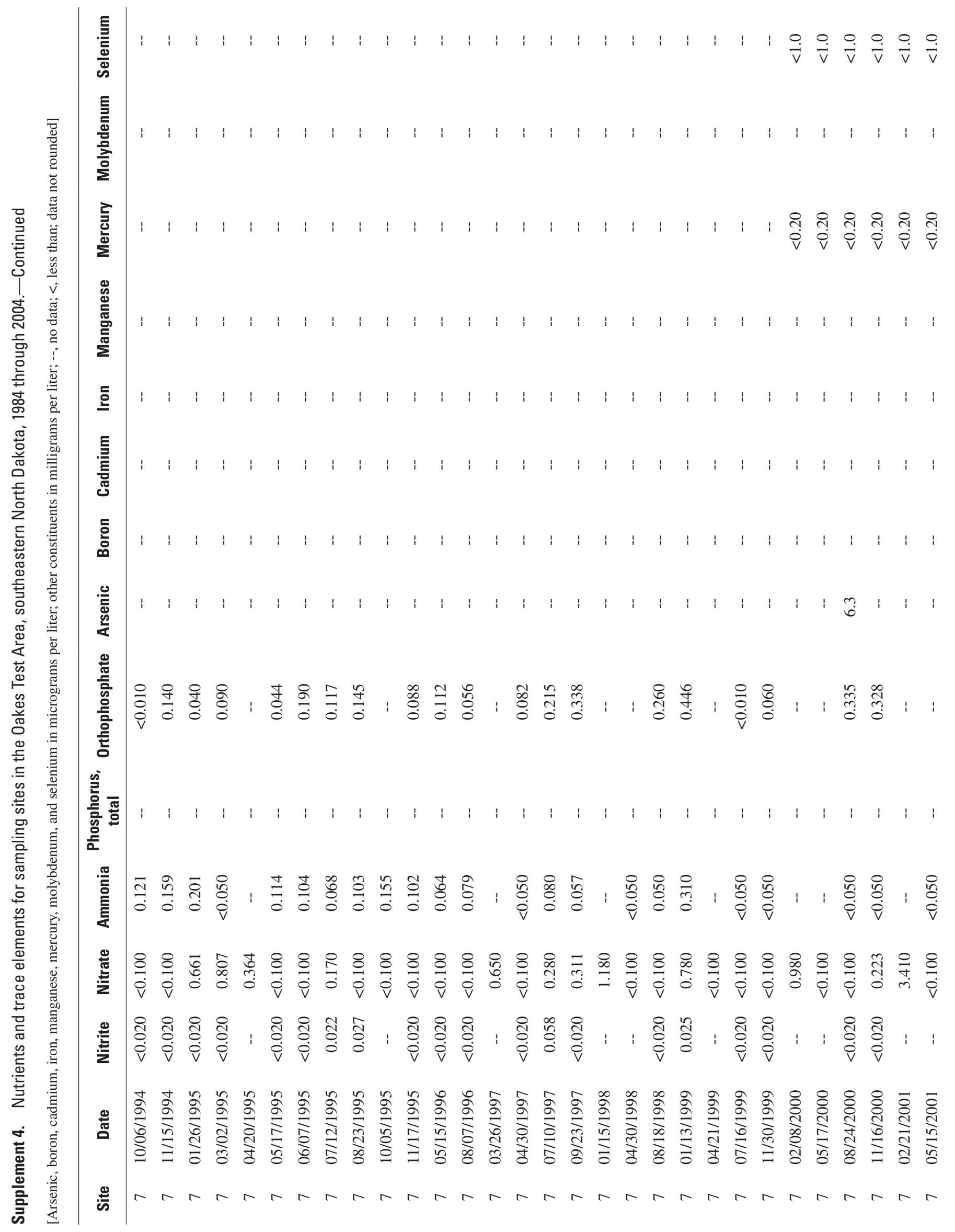


Manuscript approved for publication, April 3, 2007.

Prepared by the Helena Publishing Service Center.

For more information concerning the research in this report, contact: U.S. Geological Survey

Director, North Dakota Water Science Center

821 E. Intersate Avenue

Bismarck, ND 58503-1199

http://nd.water.usgs.gov/ 


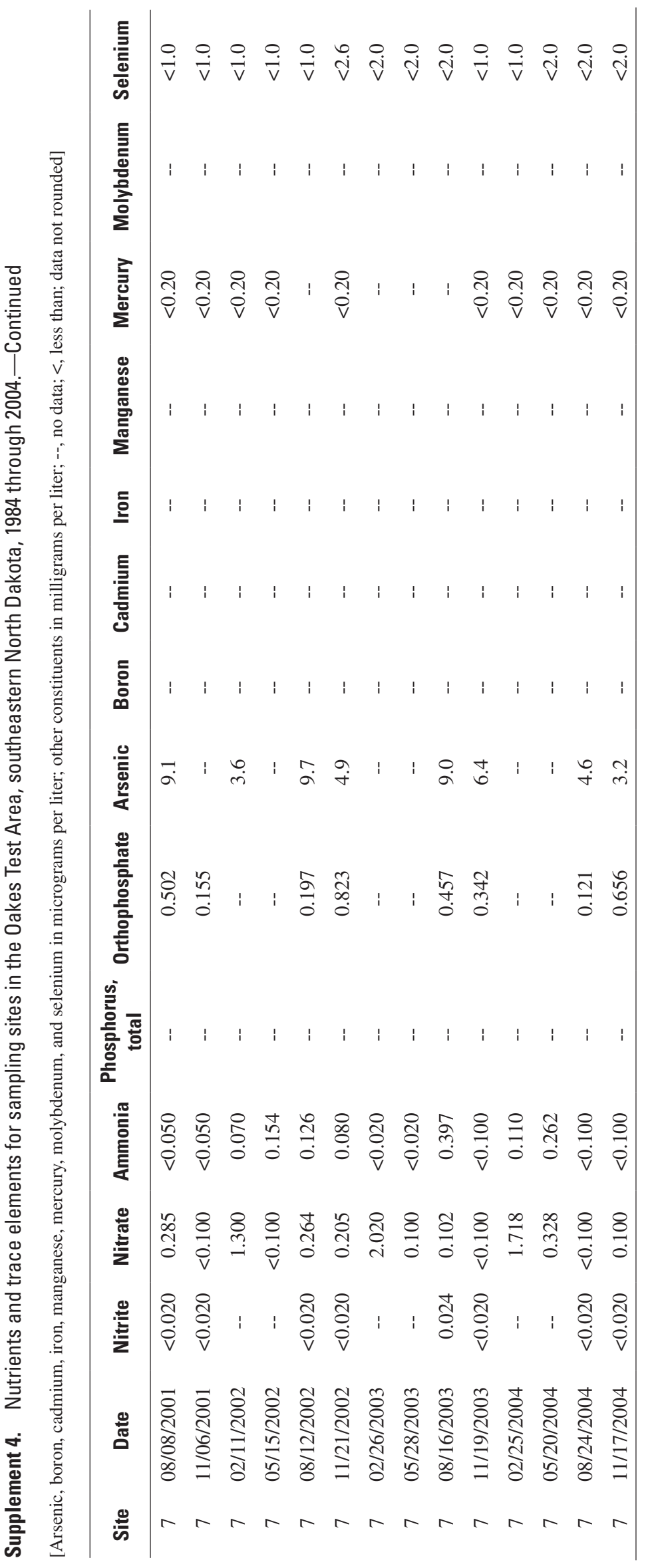

